PNL-3121

UC-97a

\title{
Proceedings of the Workshop on Electrical and Biological Effects Related to HVDC Transmission
}

Richland, Washington/The Dalles, Oregon October 19-20, 1978

August 1979

Coordinated by

Pacific Northwest Laboratory for

Bonneville Power Administration and Electrical Energy Systems Division, U.S. Department of Energy under

Contract EY-76-C-06-1830

Pacific Northwest Laboratory Operated for the U.S. Department of Energy by Battelle Memorial Institute 
NOTICE

This report was prepared as an account of work sponsored by the United States Government. Neither the United States nor the Department of Energy, nor any of their employees, nor any of their contractors, subcontractors, or their employees, makes any warranty, express or implied, or assumes any legal liability or responsibility for the accuracy, completeness or usefulness of any information, apparatus, product or process disclosed, or represents that its use would not infringe privately owned rights.

The views, opinions and conclusions contained in this report are those of the contractor and do not necessarily represent those of the United States Government or the United States Department of Energy.

\author{
PACIFIC NORTHWEST LABORATORY \\ operated by \\ BATTELLE \\ for the \\ UNITED STATES DEPARTMENT OF ENERGY \\ Under Contract EY-76-C-06-1830
}
Printed in the United States of America
Available from
National Technical Information Service
United States Department of Commerce
S285 Port Royal Road
Springfield, Virginia 22151

Price: Printed Copy 5

$\because$ Microfiche $\$ 3.00$

NTIS

- Pages Selling Price

$\begin{array}{ll}001-0.25 & \$ 4.00 \\ 026-050 & \$ 4.50 \\ 051-075 & \$ 5.25 \\ 076-100 & \$ 6.00 \\ 101-125 & 56.50 \\ 126-150 & 57.25 \\ 151-175 & 58.00 \\ 176-200 & \$ 9.00 \\ 201-225 & \$ 9.25 \\ 226-250 & 59.50 \\ 251-275 & \$ 10.75 \\ 276-300 & 511.00\end{array}$


PNL-3121

UC-97a

\section{9}

\section{PROCEEDINGS OF THE WORKSHOP \\ ON ELECTRICAL AND BIOLOGICAL EFFECTS \\ RELATED TO HVDC TRANSMISSION}

Richland, Washington/The Dalles, Oregon

October 19-20, 1978

Editor: T. Dan Bracken

Bonneville Power Administration

Branch of Laboratories

Vancouver, WA 98660

August 1979

Coordinated by

PNL for Bonneville Power Administration and Electrical Energy Systems Division, U.S. Department of Energy under

Contract EY-76-C-06-1830

Pacific Northwest Laboratory

Richland, Washington 99352 


\section{PREFACE}

Up to the present, much emphasis has been placed on the electrical and biological effects from ac transmission lines. This is understandable since almost all the transmission lines in the world operate at 50 or $60 \mathrm{~Hz}$. The number of operating high voltage direct current (HVDC) transmission lines in the world is less than twenty and until 1977, there was only one HVDC transmission line in the United States. However, as HVDC becomes an economically viable alternative for long distance transmission, the number of $D C$ lines will multiply and interest in the possible effects of these lines will increase. In anticipation of the need for additional information on electrical and biological effects of HVDC transmission, the Bonneville Power Administration and the Electrical Energy Systems Division of the Department of Energy sponsored this workshop on October 19-20, 1978 in Richland, Washington and the Dalles, Oregon.

The objectives of the interdisciplinary workshop were:

1. To stimulate communication among scientists and engineers working in the area of $B C$ electrical and biological effects.

2. To present a state-of-the-art review of various aspects of HVDC research as they relate to bioeffects.

3. To identify specific areas for future research.

To accomplish the first objective, the participants included engineers, biological, medical, and environmental scientists, researchers who are or have worked in this area, instrument manufacturers, and representatives of funding and regulatory agencies. In a11, 43 persons attended. The informal atmosphere and amount of discussion is reflected in the edited transcripts which make up a large portion of these proceedings.

Specific topics identified for review were the HVDC electrical environment, instrumentation and measurement techniques, possible biological effects, methodology for biological/environmental studies, and DC exposure systems. 
F. Ralph Kotter of the National Bureau of Standards, Asher R. Sheppard of the J. L. Pettis Veterans' Hospital, Jack M. Lee, Jr. of the Bonneville Power Administration, and John R. Decker of Pacific Northwest Laboratory accepted invitations to prepare state-of-the-art reviews in their respective areas of expertise. The first day of the workshop was devoted to their contributions and the subsequent discussions. In addition, all participants were asked to briefly describe their present research in areas related to HVDC effects. To provide an opportunity to experience the HVDC environment and view HVDC technology, tours of the BPA The Dalles HVDC Test Site and Celilo Converter Station were conducted on the second day.

Emphasis during both the formal and informal portions of the program was placed on unanswered questions, specific problems, and needed information. Hopefully, these proceedings can serve as a guide for additional efforts and provide future researchers with a list of pitfalls to avoid.

The unfamiliar and controversial aspects of DC bioeffects stimulated much lively and welcome dialogue. To enhance continuity and clarity and minimize redundancy, the verbatim transcript was edited with the help of the other authors. However, responsibility for any omissions or misinterpretations rests with me and I apologize to the willing participants for any errors that may have occurred.

The workshop required efforts by a large number of persons. No meeting of this size can be successful without planning, organization, and patience. Mrs. Judith A. Rising of the Pacific Northwest Laboratory provided all these in welcome abundance. My thanks go to her, Glenn Horstman and many others from Battelle, whose efforts made the workshop possible. In addition, the contributions of the many BPA staff members who conducted the tours at The Dalles Test Site and the Celilo Converter Station is much appreciated. Ralph S. Gens of BPA provided initial impetus and support for the workshop. Valuable administrative support and technical suggestions were provided by Richard Phillips of Pacific Northwest Laboratory during the entire workshop 
effort. William Feero of the Electrical Energy Systems Division, as in absentia cochairman of the workshop, supplied technical, managerial and moral support through the whole endeavor. Finally, I express my gratitude to the authors and other participants for their willing contributions, openness, and candor. This is the ultimate evidence of a successful workshop.

T. Dan Bracken

Bonneville Power Administration

Vancouver, WA 


\section{CONTENTS}

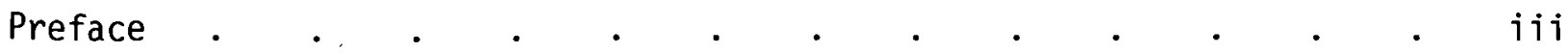

1. The HVDC Transmission Line Environment, T. Dan Bracken . . . 1.1 Discussion $. \quad . \quad . \quad . \quad . \quad . \quad . \quad . \quad . \quad . \quad . \quad 1.35$

2. Characterization of the Electric Environment Under HVDC Transmission Lines: Instrumentation and Measurement Techniquies, F. Ralph Kotter Discussion

3. Biological Effects of Static Electric Fields and Air Ions in Relation to DC Power Transmission, Asher R. Sheppard . . . 3.1

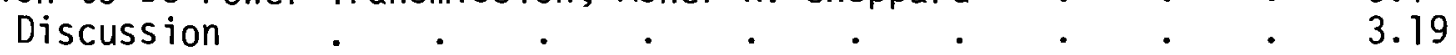

4. Needs of Utilities for Information on Biological Effects of HVDC Transmission and the Role of Environmental Studies, Jack M. Lee, Jr. Discussion

5. Animal Housing Design Considerations in DC Electric Field Bioeffects Research, J. R. Decker, W. T. Kaune and M. F. Gillis . . . 5.1

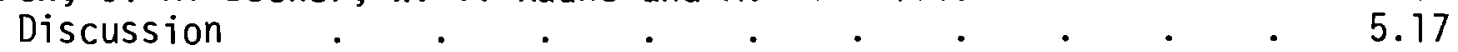

6. Ongoing Research Related to HVDC Transmission Lines and Effects • 6.1

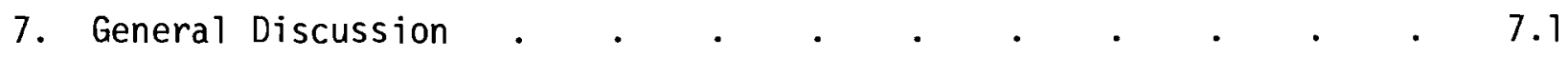

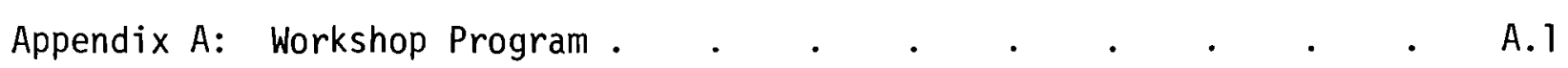

Appendix B: Workshop Participants and Institutional Affiliations . B.l 

1. THE HVDC TRANSMISSION LINE ENVIRONMENT

T. Dan Bracken

Bonneville Power Administration

Vancouver, Washington 98660 


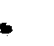


THF HVDC TRANSMISSION IINE ENVIROMMENT

T. Dan Bracken

Bonneville Power Administration

Vancouver, Washington

\begin{abstract}
The environment near HVDC transmission lines is discussed with emphasis on the electrical parameters of interest for biological effects research. The complex and dynanic nature of the electrical environment is demonstrated by measurements made under the BPA The Dalles $\pm 600 \mathrm{kV} \mathrm{D}-\mathrm{C}$ Test Line. Prediction methods for the primary electrical paraneters are discussed conceptually. Electrical and other effects which are of less significance biologically are also identified. Topics for future investigation are suggested.
\end{abstract}

\title{
I. INTRODUCTION
}

Prior to embarking on research to assess effects of the electric fields and currents near high voltage direct current (HVDC) transmission lines, it is necessary to understand the uniqueness of the HVDC electrical environment. The purpose of this paper is to qualitatively and quantitatively describe the HVDC transmission line environnent and to identify significant design parameters for $d-c$ exposure systems which simulate this environment. To accomplish this both measurements and models of the important parameters are discussed. Electrical and other effects which are of less concern biologically are also identified. Because the HVDC electrical environment has not received the attention that the a-c field environment has, there are many questions which remain to be answered. Therefore, areas for possible research activity are identified. 


\section{PRINCIPAL ELEECTRICAI PARAMETTRS}

A high voltage direct current (HVDC) transmission line has two poles maintained at constant voltage, $\pm v$, with respect to ground. This is in contrast to the three phases of an a-c transmission line which each have a $60-\mathrm{Hz}$ voltage with respect to ground. In considering the electric field from the d-c line, we might think we could just superpose the fields from the two poles in a simple electrostatic calculation. Unfortunately, this is not the case. The conductors of high voltage transmission lines are in corona because of surface protrusions caused by insects, dust, and burrs. The corona generates ions in the vicinity of the conductors. Instead of the conductors representing a simple line charge, they actually become a line charge plus a line source of current as shown conceptually in Figure 1.

Each pole of the HVDC line is in corona. Near the positive conductor, the negative ions generated in corona are attracted to the conductor while the positive ions are repelled. The opposite thing happens at the negative pole. Consequently, the inter-electrode region of an HVDC transmission line is filled with space charge. Positive space charge is concentrated around the positive pole and negative space charge is concentrated around the negative pole. The presence of the space charge leads to three parameters which describe the HVDC electrical environment in contrast to the electric field alone which is sufficient to describe the HVAC electrical environment.

The space charge is a source of electric field. Thus, the total field, $\overrightarrow{\mathrm{E}}$, under an HVDC transmission line is the superposition of two fields: the nominal field, $\overrightarrow{\mathrm{E}}_{\mathrm{n}}$, which is due to the charge on the conductors, 
and the field due to the space charge, $\overrightarrow{\mathrm{E}}_{\text {ion }}$ The ions, which make up the space charge can provide a significant contribution $(>50 \%)$ to the field. They are free to move along the field lines due to coulomb forces. In addition, the ions can be transported by air movenent. ConsequentIy, the portion of the field due to space charge can vary greatly depending on wind.

The ions themselves constitute a second electrical parameter which can be expressed either by the ion concentration, $\mathrm{n}$, in ions/ $\mathrm{cm}^{3}$ or by the space charge density, $\rho$, in $\mathrm{C} / \mathrm{m}^{3}$. If we assume singly-charged unipolar ions, then the number density is given directly by the space charge density divided by $e$, the electronic charge.

A third principal electric parameter is the ion current density in $\mathrm{A} / \mathrm{m}^{2}$. The total current density, $\vec{j}$, is the sur of the conductive current due to charge motion in an electric field and the convective current due to wind. It is given by:

$$
\vec{j}=\rho \vec{k}+\rho \vec{u}
$$

where $\rho$ is the space charge density, $k$ is the mobility of the ions, is the total eloctric field and $\vec{u}$ is the wind velocity. At ground level we assume that the current is conductive, i.e., the wind perpendicular to the earth is zero. However, in space where there is air movement, the relative importance of the two components will depend on proximity to the transmission line and the wind speed. At a great distance away from a line, where fields are small, the convective term will dominate. Similarly, underneath a line the conductive term will predorainate provided the wind is not too strong. 
Representative values for the principal electrical parameters are given in Table I for ambient conditions and for the HVDC electrical environment. Atmospheric scientists have been studying the electrical properties of the atmosphere for a long time so there is a great body of literature on ambient levels and instrumentation (Chalmers, 1967). Ambient levels of the electric field are about $130 \mathrm{~V} / \mathrm{m}$ during fair weather with higher levels during thunderstorms. This compares with a mean value of about $20 \mathrm{kV} / \mathrm{m}$ under a $\pm 500 \mathrm{kV}$ HVDC transmission line.

Natural current densities at ground level are typically 1 to $2 \times 10^{-12}$ $\mathrm{A} / \mathrm{m}^{2}$. Conduction current during thunder storms may reach $5 \times 10^{-10}$ $\mathrm{A} / \mathrm{m}^{2}$ due to corona on the ground (Kasemir, 1978). The mean current density under a $\pm 500 \mathrm{kV}$ line is on the order of $4 \times 10^{-8} \mathrm{~A} / \mathrm{m}^{2}$. However, peak levels can be many times this value.

Ambient charge densities are typically $10^{-11} \mathrm{c} / \mathrm{m}^{3}$. Under the same $\pm 500 \mathrm{kV}$ transmission line, ion levels are typically $10^{-8} \mathrm{c} / \mathrm{m}^{3}$ or $6 \times 10^{4}$ ions $/ \mathrm{cm}^{3}$. Thus levels of all three parameters under an HVDC transmission line can exceed ambient levels by several orders of magnitude.

For comparison, the electric field and displacement current density for an a-c, 500-kV transmission line are also shown in Table I. The 450-kV peak line-to-ground voltage for the a-c line is comparable with the $500 \mathrm{kV}$ d.c. line-to-ground voltage. The peak a-c electric field is about $12 \mathrm{kV} / \mathrm{m}$ and the peak displacement current density at $60-\mathrm{Hz}$ is about $38 \times 10^{-6} \mathrm{~A} / \mathrm{m}^{2}$. This latter value is several orders of magnitude larger than the comparable $d-c$ current density. 
TABIE I

FUECTRICAI PARAMETERS AT GROUND IEVEU

\begin{tabular}{|c|c|c|c|c|c|}
\hline Parameter & \multirow{2}{*}{$\begin{array}{c}\text { Arnbient }^{1} \\
.13 \\
3\end{array}$} & \multicolumn{2}{|c|}{$\begin{array}{l} \pm 500 \mathrm{kV} \text { HVBC } \\
\text { Test Iine } \\
\text { positive negative }\end{array}$} & \multicolumn{2}{|c|}{$\begin{array}{c}500 \mathrm{kV} \\
60-\mathrm{Hz} A-C \text { Line } \\
\text { rms peak } \\
\end{array}$} \\
\hline Flectric Field: $\mathrm{E}, \mathrm{kV} / \mathrm{m}$ & & 21 & -16 & 8 & 11.3 \\
\hline Current Density: $j, \mu \mathrm{A} / \mathrm{m}^{2}$ & $\begin{array}{r}+2 \times 10^{-6} \\
5 \times 10^{-4}\end{array}$ & .042 & -.035 & 27 & 38 \\
\hline Charge Density: $\rho, \mathrm{nc} / \mathrm{m}^{3}$ & +.01 & 12 & -10 & & \\
\hline Magnetic Field: $\mathrm{B}, \times 10^{-4} \mathrm{~T}$ & .53 & .22 & & .14 & \\
\hline
\end{tabular}

1 Chalmers (1967). Value of $\mathrm{E}=3 \mathrm{kV} / \mathrm{m}$ was regorted under thunder clouds without lightning. Value of $j=5 \times 10^{-4} \mu \mathrm{A} / \mathrm{m}^{2}$ represents corona current from the ground during thunder storms (Kasemir, 1978).

2 Mean of maxirum values measured under low wind conditions for the Dalles HVDC Test Line. Magnetic field measured under the $\pm 400 \mathrm{kV} \mathrm{d}-\mathrm{c}$ Intertie.

3 Calculated marimum values. 
The relative magnitudes of the total electric field calculated using an ideal no-wind model for several different lines are shown in Figure 2. The relative nature of these profiles should be emphasized because of the uncertainty in application of the calculation to practical situations. Work at The Dalles indicates that this model may approximate the field which is exceeded by only $10 \%$ of fair weather measurements. (Bracken et al, 1978c). However, more all-seasonal data is necessary to confirm this hypothesis. The calculations are based on a corona onset gradient of $14 \mathrm{kV} / \mathrm{cm}$ and indicate maximum fields of $20 \mathrm{kV} / \mathrm{m}$ and $30 \mathrm{kV} / \mathrm{m}$

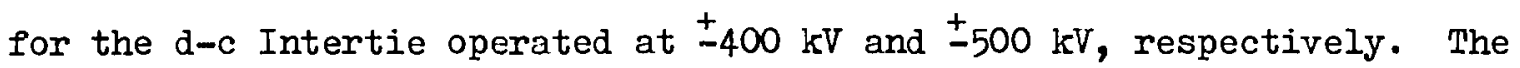
Soviet lines which have been included for comparison show higher fields because of lower conductors and smaller conductors. Thus, for an existing Soviet $\pm 400 \mathrm{kV}$ line the estimated field value is $35 \mathrm{kV} / \mathrm{m}$ while for a proposed $\pm 750 \mathrm{kV}$ line in that country the estimated field is in excess of $50 \mathrm{kV} / \mathrm{m}$.

\section{ION CHARACTERISTICS}

In addition to describing the macroscopic electrical properties of the ions such as current and net charge, it is also necessary to consider the microscopic properties of the ions. The nature of the ions migrating away from the HVDC conductors to form space charge in the interelectrode region depends on the atmosphere in the area of the transmission line. In general, ions, charged particles, and particles in the atmosphere can be classified by their size and mobility as shown in Figure 3. Mobility, $\mathrm{k}$, is defined as the ratio of mean drift velocity, $\mathrm{v}$, to applied electric field, E :

$$
\mathrm{k}=\mathrm{v} / \mathrm{E}
$$


For transmission line fields away from the conductors the mobility is independent of the electric field. The ions of interest biologically are the small ions with mobilities from about 1 to $2 \times 10^{-4} \mathrm{~m}^{2} / \mathrm{V}-\mathrm{s}$ which are comprised of several molecules. The excess electrical charge provides the binding for these ions. Consequently, when they are neutralized the constituents separate. Iarge ions, on the other hand, represent charges which have become attached to particles or aerosols in the atmosphere, and renain in tact after neutralization. Under fair weather conditions, the small ions are the ones of interest in proximity to HVDC transmission lines. During mist or fog, or in heavily polluted areas when sigmificant numbers of aerosols are present, the larger, less mobile ions become important. Changes in gas density cause changes in collision frequency between ions and gas molecules. The actual mobility is thus proportional to pressure and inversely proportional to absolute temperature.

Antually there is a spectrum of mobilities corresponding to the complex chemical nature of the atmosphere in question. Mobilities of small ions roughly range from $0.2 \times 10^{-4}$ to $2.5 \times 10^{-4} \mathrm{~m}^{2} / \mathrm{V}-\mathrm{s}$. The nost frequent mobility is reported as the average nobility. The average mobilities reported for small ions in dry air at room temperature and atmospheric pressure are (Mohnen, 1974):

$$
\begin{aligned}
& k_{+}=1.37 \times 10^{-4} \mathrm{~m}^{2} / \mathrm{v}-\mathrm{s} \\
& k_{-}=1.89 \times 10^{-4} \mathrm{~m}^{2} / \mathrm{v}-\mathrm{s}
\end{aligned}
$$

These values are independent of the source of ionization: $x$-rays, a radiation, $\gamma$ radiation, or corona. Average values in the atmosphere are less than those measured in the laboratory because of the longer 
time between generation and neasurement. For the atmosphere, Mohnen (1974) reports STP corrected mobilities of

$$
\begin{aligned}
& k_{+}=1.14 \times 10^{-4} \mathrm{~m}^{2} / \mathrm{v}-\mathrm{s} \\
& k_{-}=1.24 \times 10^{-4} \mathrm{~m}^{2} / \mathrm{v}-\mathrm{s}
\end{aligned}
$$

Whether the 3- to 5-second transit time from HVDC conductor to ground is sufficient to reach this natural level is a question which needs further investigation.

In addition to the slight difference in magnitudes of positive and negative mobilities, there is also a difference in the nature of the small ion mobility spectra for the different polarities as shown representatively in Figure 4 (Hoppel, 1968). The negative mobility distribution is bronder than the positive distribution. The different ions species with different mobilities which make up the spectrum are the result of the composition of the atmosphere. In a simple atmosphere comprised of only $\mathrm{N}_{2}, \mathrm{O}_{2}, \mathrm{CO}_{2}, \mathrm{H}_{2} \mathrm{O}$, the only positive ions which exist in equilibrium are oxonium and its hydrates: $\mathrm{H}_{3} \mathrm{O}^{+} \cdot\left(\mathrm{H}_{2} \mathrm{O}\right)_{\mathrm{n}}$ (Mohnen, 1974). For negative ions in a simple gas, the stable ions are $\mathrm{CO}_{4}^{-} \cdot\left(\mathrm{H}_{2} \mathrm{O}\right)_{\mathrm{n}}$ and $\mathrm{O}_{2}^{-} \cdot\left(\mathrm{H}_{2} \mathrm{O}\right)_{\mathrm{n}}$. However, these ions should only be considered as possible precursors of the actual ions in the atmosphere. Trace gases such as $\mathrm{NH}_{3}, \mathrm{NO}, \mathrm{NO}_{2}$, $\mathrm{N}_{2} \mathrm{O}, \mathrm{HNO}_{3}, \mathrm{CO}, \mathrm{CH}_{4}$ and unsaturated hydrocarbons are presont as well as $\mathrm{H}_{2} \mathrm{~S}, \mathrm{SO}_{2}, \mathrm{H}_{2} \mathrm{SO}_{4}, \mathrm{O}_{3}, \mathrm{I}_{2}, \mathrm{C}, \mathrm{HCL}, \mathrm{OH}, \mathrm{O}$, and others. A collision with one of these molecules can change an ion's constitution. Since the lifetimes of ions are quite long, collisions with all impurities are probable and the composition of ions is under going constant change. For a typical reaction rate constant of $10^{-16} \mathrm{~m}^{3} / \mathrm{s}$, Mohnen (1974) reports reaction times of ions with trace molecules are $4 \times 10^{-4}$ and $4 \times 10^{-1} \mathrm{~s}$ for concentrations 
of $1 \mathrm{ppm}$ and $1 \mathrm{ppb}$, respectively. This would imply that cluster growth is through chemical reactions, molecular rearrangements, etc., as opposed to addition of water vapor. However, the amount of hydration will depend on the partial pressure of $\mathrm{H}_{2} \mathrm{O}$. Thus as the partial pressure of $\mathrm{H}_{2} \mathrm{O}$ increases the mobility will decrease. Since the transit time for an ion to ground from an HVDC conductor is on the order of $3 \mathrm{~s}$, the chemical nature of the ions will depend on what the impurities in the air are and what the relative humidity is.

During mist and fog conditions, the space charge resides on very low mobility aerosols which can acquire more than the single charge considered above for snall ions. The low mobllities, large numbers of particles, and high corona astivity in these circumstances can result in extremely high fields. Consequently these conditions appear to be most conducive for perception of the field and ion currents.

\section{OTHTR FLECTRICAL PARAMETERS}

An operating HVDC transmission line has other electrical characteristics which are of a secondary nature. A $d-c$ current flows in an operating line which creates a magnetic field. Measurements of the magnetic field under the $d-c$ Intertie with $1800 \mathrm{~A}$ flowing in each pole, are compared with calculated values in Figure 5. The maximum d-c magnetic field at the ground is about $2 \times 10^{-5} \mathrm{~T}$. The large error bars result because of the crudeness of the measurements and because the fields from the line are less than the d-c magnetic field of the earth which must be subtracted from the measured values.

Harmonics of sixty-hertz are introduced on to a d-c line by the conversion 
process of $60 \mathrm{~Hz}$ to d.c. Voltage at the various harmonics will cause a-c fields at ground level. The magnitude of the currents coupled by these fields will depend on the field magnitude and the frequency. Using voltage measurements reported by Eichin (Private Communication, 1978) for the

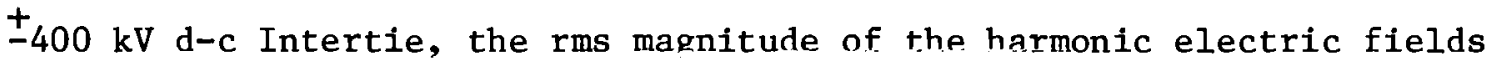
and coupled currents are estimated in Table II. The $d-c$ nominal field for the $\pm 400 \mathrm{kV} \mathrm{d}-\mathrm{c}$ Intertie is $8 \mathrm{kV} / \mathrm{m}$. Therefore the a-c fields for voltages exnressed in percent ripple are given by the same percent of $8 \mathrm{kV} / \mathrm{m}$.

Here the maximun ripple from measurements on both poles is used and possible phase cancellations have not been considered. The maximum field of $17 \mathrm{~V} / \mathrm{m}$ occurs at $60 \mathrm{~Hz}$ and $120 \mathrm{~Hz}$. The maximum displacement current density of $.24 \mu \mathrm{A} / \mathrm{m}^{2}$ occurs for the 12 th and 24 th harmonics. These values are all considerably below the 60-Hz displacement current density of $27 \mu \mathrm{A} / \mathrm{m}^{2}$ (rms) under a typical 500-kV transmission line. However, they are comparable in nagnitude to the conductive $d-c$ current densities under HVDC transmission lines.

The magnitude of the harmonics on the line from the conversion process will depend on the adequacy of the filters at the converter stations. Gertsik et al. (1973) have estimated much higher fields at $300 \mathrm{~Hz}$ and $600 \mathrm{~Hz}$ for a proposed $\unlhd_{-750 \mathrm{kV} \mathrm{HVDC}}$ line in the Soviet Union. But no filtering was assumed. An electric field of $4 \mathrm{kV} / \mathrm{m}$ at $300 \mathrm{~Hz}(\mathrm{n}=6$ for $50 \mathrm{~Hz})$ was calculated. This corresponds to a $10 \%$ ripple and to a current density of $66 \mu \mathrm{A} / \mathrm{m}^{2}$. In this case, hamonic field levels are significant in terms of induced currents. However, in most instances the filtering necessary to eliminate problems with communication lines will keep induced currents at low levels compared to current densities where ELF effects have been reported. 
TABLE II

ESTIMATED HARHONIC CURRENTS FOR THE $₫ 400 \mathrm{kV}$ D_C INTERTIE

\begin{tabular}{|c|c|c|c|c|}
\hline Harmonic & Frequency & Ripple & Maximum Field & Current Density \\
\hline $\mathrm{n}$ & $\mathrm{Hz}$ & $\%$ & $\mathrm{~V} / \mathrm{m}$ & $\mu \mathrm{A} / \mathrm{m}^{2}$ \\
\hline 1 & 60 & 0.21 & 17 & .06 \\
\hline 2 & 120 & 0.20 & 17 & .12 \\
\hline 3 & 180 & 0.04 & 3 & .03 \\
\hline 4 & 240 & 0.05 & 4 & .05 \\
\hline 5 & 300 & 0.009 & 1 & .02 \\
\hline 6 & 360 & 0.12 & 10 & .2 \\
\hline 12 & 720 & 0.07 & 6 & .24 \\
\hline 18 & 1080 & 0.02 & 2 & .12 \\
\hline 24 & 1440 & 0.04 & 3 & .24 \\
\hline 30 & 1800 & 0.02 & 2 & .20 \\
\hline 36 & 2160 & 0.01 & 1 & .12 \\
\hline
\end{tabular}


The current on the $d-c$ Intertie is modulated up to $3 \%$ for stability purposes. This results in a current of approximately $50 \mathrm{~A}$ and a magnetic field of $6 \times 10^{-7} \mathrm{~T}$ at $0.33 \mathrm{~Hz}$. Thus, the varying magnetic field from this source is very small.

\section{OTHER CORONA PHENOMENA}

The presence of corona on HVDC conductors is manifest in other ways besides the presence of ions. Audible noise is generated and can be characterized as sporadic crackling and hissing. It is much less noticeable than on an a-c line and the $120-\mathrm{Hz}$ hum of an a-c line is absent. Coronagenerated, electromagnetic interference (EMI) levels are also lower from an HVDC line than from a comparable a-c line. Ozone produced by an HVDC line is very low and difficult to detect (Droppo, 1978). These other corona-generated parameters can be considered insignificant in terms of biological exposures when compared with the electric field and ions. However, ozone can be of concern when generating ions in a laboratory enclosure using a corona source.

\section{MTASURTMRNTS}

Measurements under the $d-c$ Intertie and the BPA HVDC Test Iine at The Dalles demonstrate the significant effects that wind and corona can have on the principal electrical parameters (Bracken et al. 1978a, 1978c). The current profiling system, electrical transducers, anemometer, and data acquisition system used in making these measurements have been described elsewhere (Bracken and Furumasu, 1978b). Real time changes in the electrical quantities can be correlated with the changes in wind. For example, the electric field varies considerably as space charge is blown in "clouds" over the field meter. The recordings of electric field and collected 
charge at ground level shown in Figure 6 demonstrate the need to average the electrical quantities over all winds.

Another demonstration of the effect of the wind is shown in Figure 7 which presents data collected under the $d-c$ test line at $\pm 500 \mathrm{kV}$ during a period of several weeks. The electric field at $2 \mathrm{~m}$ beyond the conductors is plotted as a function of perpendicular wind speed. Only winds in the positive direction, i.e., blowing from the negative pole to the positive pole were present during this period. The positive field reaches a maximum when there is a slight positive wind. As the wind increases, the field diminishes tecause the space chorge is being carried out beyond the field meter.

The current profiles shown in Fisure 8 a-d dramatically demonstrate the effect of wind on the ion current. For wind speeds between 0 and $1 \mathrm{r} / \mathrm{s}$, the current profile is almost symmetric (Figure 8a). However, as the wind increases in the positive direction (Figure $8 \mathrm{~b}-\mathrm{d}$ ), the negative ions are carried from the negative to the positive conductors shifting the positive peak further out beyond the conductor. The threshold for the effect of the wind varies with voltage. For the $\pm 500 \mathrm{kV}$ line the wind effects becone significant at around $1-2 \mathrm{~m} / \mathrm{s}$. For higher voltages, the area around the conductors where the electric forces doninate for a Eiven wind speed vill be larger. Consequently, the threshold for wind effects will occur at higher wind speeds.

Measurements of ion concentration with ion counters at the location of the field meters also demonstrate the effects of the wind on the space charge (Bracken et al. 1978c). There is a peak in the ion density at low 
wind speeds and the density falls to zero at the higher wind speeds. The measurement of ion density simultaneously with field and current allows a determination of the mobility from the relationship $j=\rho \mathrm{kE}$. The mobility of ions determined from simultaneous measurements of $E, j$, and $\rho$ under the HVDC Test Line at $\pm 500 \mathrm{kV}$ were $1.7 \times 10^{-4} \mathrm{~m}^{2} / \mathrm{V}-s$ for both polarities. Given the uncertainty in the operation of the ion counters, the agreement between these values and the generally reported mobility values for small ions is considered good. We therefore conclude that the ions reaching the ground are, in fact, small ions and that the constitutive relationship for conductive current is valid at ground level under an HVDC transmission line for low wind speeds.

Corona activity on the conductors also affects the ground level parameters. During a wat snow the corone current was approximately four times greater than during fair weather on the same day. Figure 9 shows the current profiles during these periods. The maximum current density during snow was about $80 \mathrm{nA} / \mathrm{m}^{2}$. A couple of hours later, the sun came out, the conductors were dry and clean, and the maximum current density dropped by a factor of four to $20 \mathrm{nA} / \mathrm{m}^{2}$. The mean maximur current for all fair weather data was approximately $40 \mathrm{nA} / \mathrm{m}^{2}$.

Variations exemplified by these examples require long term averages for an adequate description. All types of weather conditions are needed in these averages. For the profiles shown here, the data has been characterized somewhat arbitrarily, by the mean, $10 \%$ and $90 \%$ levels. Whether these or other levels are appropriate for biological exposures requires further investigation. 


\section{ANALYTICAI MODELS}

The behavior of the corona-generated ions and resultant fields and currents is easy to describe in qualitative terms. The ions generated at the surface of the conductors are subject to electric forces and convective transport. As the voltage on the line increases, corona activity will increase, and the electric fields and ion currents will increase. As the wind increases, the ions are transported away from the line and the magnitude of the electrical parameters near the line will change accordingly. The windward side will have different characteristics than the lee side. The line geometry is going to make a difference: lower conductors will result in increased fields and ions. Conductor size and surface conditions will determine the level of corona activity. The amount of corona current also deperds on weather conditions.

This intuitive description of the electrical paraneters can be expressed more analytically by writing the field, current density, and space charge as functions of several independent variables:

$$
\begin{aligned}
& I=I(x, y, z, u, v, w, G, V, I+, I-, \ldots) \\
& J=J(x, y, z, \ldots \\
& \rho=\rho(x, y, z, \cdots
\end{aligned}
$$

where:

$$
\begin{aligned}
& x, y, z \text { are the coordinates of the field point, } \\
& u, v, w \text { are the three components of the wind, } \\
& G \text { represents the line and conductor geonetry, } \\
& \text { V is the voltage, and } \\
& \text { I+, I- are the positive and negative corona currents, respectively. }
\end{aligned}
$$


Because of the large number of independent variables and the statistical nature of some of them, developing an analytical model for the d-c environment is a monumental task.

Obviously, all these variables cannot be addressed initially in modeling the field. As a first approximation the presence of ions can be neglected and the electric field becomes a solution of Laplace's equation. The nominal field, $\mathbb{E}_{n}$, is then a simple model of the transmission line field which can be expressed as:

$$
I=E_{n}(x, y, z, G, V)
$$

In certain instances, this model is adequate: (1) when the conductors are below corona onset, and (2) at upwind locations when the wind is strong.

The next level of sophistication in modeling the field is to introduce the corona-generated space charge. A model which we have used (Harrington and Kelley, 1977), is based on work by Sarma and Janischewskyj $(1969 a, 1969 b)$. In order to solve the set of nonlinear differential equations which describe the field, conduction current, and space charge, the following assumptions are made:

1) the magnitude but not the direction of the electric field is changed when space charge is introduced.

2) the onset gradient for corona is the same for both polarities and an input parameter for the model.

3) there is no diffusion of the ions. 
4) ion mobility is independent of the electric field.

In this case, the ions traverse the electric field lines and the total field is written as a multiple of the nominal field. The electrical parameters now include the field point, the geometry of the line, the voltage, and the corona current. To characterize the source we have generally taken the corona onset gradient as $14 \mathrm{kV} / \mathrm{cm}$, which colncides with the results from The Dalles Test Iine (Hill 1977). With this model, equation ( $3 a$ ) then becomes:

$$
E=B(x, y, z, G, V, I+, I-)
$$

Depending on the choice of onset gradient, this ideal no-wind model gives an upper bound for the field and is the one used to calculate the fields in Figure 2.

Another possible approach introduces the corona current directly as a source in the no-wind model calculntion. This technique allows the full range of observed corona currents to be included in an analysis and is equivalent to varying the onset gradient in the 1deal no-wind model. Morozov and Yakobson (1973) described in general terms a model of this type. Using it they were able to make estimates of fields and currents durins foul weather when corona current has increased significantly.

More recently Janischewskyj and Gela (1978) have reported a charge sirulation model which offers the possibility of including the wind. Hoppel (1979) has generated a simple monopolar model which includes the effects of wind. 
Given that theoretical models are difficult to develop, it might be advantageous to use an empirical approach for describing the electric field and Ion currents under existing lines and for predicting performance of future similar lines. Instead of using a continuous analytical function such as (5), a distribution as a function of wind for the field at fixed locations is determined by measurements. Then, say, the average field for a fixed voltage and corona level is expressed in a matrix of empirically determined values for locations $x_{i}$, and winds $u_{j}$ :

$$
E_{i j}=E\left(x_{i}, u_{j}, G, V, I+, I-\right)
$$

The average value of the field at a particular site can be obtained by summing over all winds with the appropriate weighting factors for that location: $\quad E_{i}=\sum_{j} E_{i j} \nu_{j}$ where $\nu_{j}$ is the fraction of time the wind is in the $j$ th wind interval from $u_{j}$ to $u_{j}+\Delta u$.

To generate all the elements in the empirical electric field matrix, $\mathrm{E}_{i j}$, requires many measurements under different conditions. For application to a future line, data must have been obtained from a line with an identical geometry.

In summary, the predictive or descriptive modeling procesis for real transmission lines can be conceptually divided into two aspects:

1) Developing functional dependence of the electrical parameters on the independent variable related to line geometry and meteorological conditions.

2) Developing suitable statistical approaches and selection of the appropriate levels for a particular application. 
The first step can be done olther analytically or empirically but will ultimately require measurements for confirmation. The second process w1ll require considerable judgement. For example, what is the appropriate level to use in conducting biological experiments on long term effects? Is it the $90 \%$ level, the $50 \%$ level, or even the $99 \%$ level?

\section{PROXIMITY EFHECTS}

Under certain conditions it is possible to perceive the electric field under an HVDC transmission line. From our experience at The Dalles this seems to occur only for fields above about $30 \mathrm{kV} / \mathrm{m}$. However, perception does not occur frequently. The majority of times when the field was greater than $30 \mathrm{kV} / \mathrm{m}$, we did not experience this phenomenon. The Dalles is very dry and before these results can be taken as anything more than anecdotal a wider range of climatic conditions needs to be investigated. Nevertheless, it is interesting that the d-c fleld level where we observed perception is comparable to the $32 \mathrm{kV} / \mathrm{m}$ peak gradients reported as the $50 \%$ level for perception of the a-c field at Project UHV (Deno, 1978).

The current densities under an HVDC transmission line are so small that a very large object would be required to collect a perceivable d-c current. (Bracken, 1978d) Thus, in contrast to a-c lines, steady state current shocks are not of significance under an HVDC trangmission line. Nevertheleas, the applicability of the a-c current collection models developed at Projeot UHV (Deno, 1978) should be explored for the d-c case.

Spark discharges are also not slgniflcant under a d-c line (Bracken, 1978d). The degree of insulation required for a large voltage to build up is not experienced under normal conditions. However, we have had isolated instances where people wearing a facket of synthetic material 
such as nylon, have accumulated sufficient charge to get a noticeable discharge. In practical situations and under laboratory conditions spark discharges should be negligible.

\section{SUMIURYY}

The principal parameters of the HVDC environment are the $d-c$ electric field, the ion current, and the ion density or space charge. Because of the dependence of the location and nature of the ions on wind, weather, and air quality, the HVDC electrical environment is a very complez and dynamic one. It requires a statistical description in order to meaningfully transfer exposures under a transmission line to a laboratory system.

There are several other parameters which are also present near a d-c transmission line. However, in assessing possible biological impact their influence must be considered secondary to that of the parameters identified above. These less significant effects include d-c magnetic fields, a-c electric and magnetic fields, audible noise, IMI, and ozone.

The following tasks are 1dentified as required to more fully characterize the HVDC environment and to facilitate biological studies in this area:

1) Perform additional measurements of electrical parameters under all weather conditions.

2) Develop meaningful averaging techniques for determining exposure levels.

3) Investigate the properties of corona-generated ions such as mobility, chemistry, humidity dependence, and air quality dependence. 
4) Determine atgnificance of harmonic levels under d-c transmission levels.

5) Investigate phenomena occurring during heavy fog and mist conditions.

6) Identify conditions for perceptible proximity effects.

7) Develop exposure models and dosimetry for d-c fields and ions.

8) Develop prediction models for HVDC transmission lines. 


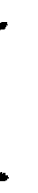




\section{RETFERENCES}

Bracken, T. D., A. S. Capon, and D. V. Montgomery, 1978a, "Ground Level Electric Fields and Ion Currents on the Celilo-Sylmar $\pm 400 \mathrm{kV}$ DC Intertle During Pair Weather," IEEE Trans. (PAS), PAS 97: 370-378.

Bracken, T. D., and B. C. Furumasu, 1978b, "Field and Ion Current Measurements in Regions of High Charge Density Near Direct-Current Trangmission I1nes," Proceedings of Amertcan Meteorological Societr Conference on Cloud Phystcs and Atmospheric Electricity, Iseaquah, Washington, Auguat 4, pp. 544-551.

Bracken, T. D., R. D. Stearns, B. C. Furumasu, and V. I. Chartier, 1978c, "Corona Performance of the Bonneville Power Administration HVDC Test Iine to ${ }_{-600 \mathrm{kV}}$, Proceedings of 1978 Minnesota Power Systems Conference, Minneapolis, Minnesota, October 17.

Bracken, T. D., 1978d, "Electrical Parameters of the HVDC Transmission Line Environment," Proceedings of the 18th Annual Hanford Life Sclences Symposium, Richland, WA. NTIS, Springfield, VA, January, 1980. CONF-781016.

Chalmers, J. A., 1967, Atmospheric Electric1ty, Pergamon Press Itd., Oxford, Fngland, p. 450.

Deno, D. W., 1978, "Electrostatic and Electromagnetic Effects of Ultra High-Voltage Transmission IInes," EPRI Report HL-802, Electric Power Research Institute, Palo Alto, Calffornia.

Droppo, J. G., 1978, "Ozone Field Studies Adjacent to an HVDC Test Line," Proceedings of the 18th Annual Hanford L1fe Sciences Symposium, R1chland, WA. NTIS, Springfleld, VA, January, 1980. CONF-781016. 
Gertsik, K. A., N. S. Kislova, S. S. Klyamkin, Yu. A. Morozov, V. N. Tolstopyatov, and B. G. Yalkobsen, 1973, "Protection from Electric Fields and Aerial Ions on Very High Voltage DC Tranamdsaton Lines," in Protection from the Action of Electromagnetic Fields and Electric Current in Industry, V. I. Filippov and Yu. A. Morozov, Moscow: All-Union Central Scientiflc Research Institute of Work Safety, DOE

Harrington, S., and R. Kelley, 1977, "Analys1s of Electrlc Fields Under Direct Current Conductors in Corone," Appendix 7 of Hill (1977), pp. 96-100.

Hill, H. I., A. S. Capon, O. Ratz, P. E. Renner, and W. D. Schmidt, 1977, Transmission Iine Reference Book: HVDC to $\pm 600 \mathrm{kV}$, pp. $73-100$, Electric Power Research Institute, Palo Alto, California.

Hoppel, W. A., 1968, The Ions of the Troposphere: Their Interactions with Aerosols and the Geoelectric Field, PhD. Dissertation, Catholic University of America.

Hoppel, W. A., 1979, Study of Drifting Charged Aerosols from HVDC Iines, Work in progress for the Electric Power Research Institute, Palo Alto, California.

Janischewskgf, W., and G. Gela, 1978, "Finlte Element Solution for Electric Fields of Coronating DC Transmission Lines," IEEE Paper F78 708-0, presented at the PaS Sumer Power Meeting, Ios Angeles, California, July 18, 1978. 
Kasemir, H. W., 1978, "Corona Discharge and Thunderstorm Fields," Proc. of American Meteorological Society Conference on Cloud Physlcs and Atmospheric Electric1ty, Issaquah, WA, August 4, pp. 569-573.

Mohnen, V. A., 1974, "Formation, Nature, and Mobility of Ions of Atmospheric Importance," Proc. of the Fifth Intl. Cont. on Atm. Elec., Garmisch-Partenkirchen (Germany), Setpember 2-7, pp. 1-17. Morozov, Yu. A., and B. G. Yakobson, 1973, "Calculation of Electric Field Intensity, Concentration of Aerial Ions and Ion Current Density on Overhead DC Power Lines," in Problems of Blectrical Safety in the National Economy, Moscow: All Union Central Scientific Research Institute of Work Safety, DOE-tr 21, p. 36 .

Sarma, M. P., and W. Jantschewskyj, 1969a, "Analysis of Corona Losses on D-C Tranmission Iines: I-Untpolar Iines, IEEE Trans. (PAS), PAS 88: 718.

Sarma, M. P., and W. Janischewskyj, 1969b, "Analysis of Corona Losses on D-C Transmission Iines: II-Bipolar IInes, IEEE Trans. (PAS), PAS 88: 1476. 


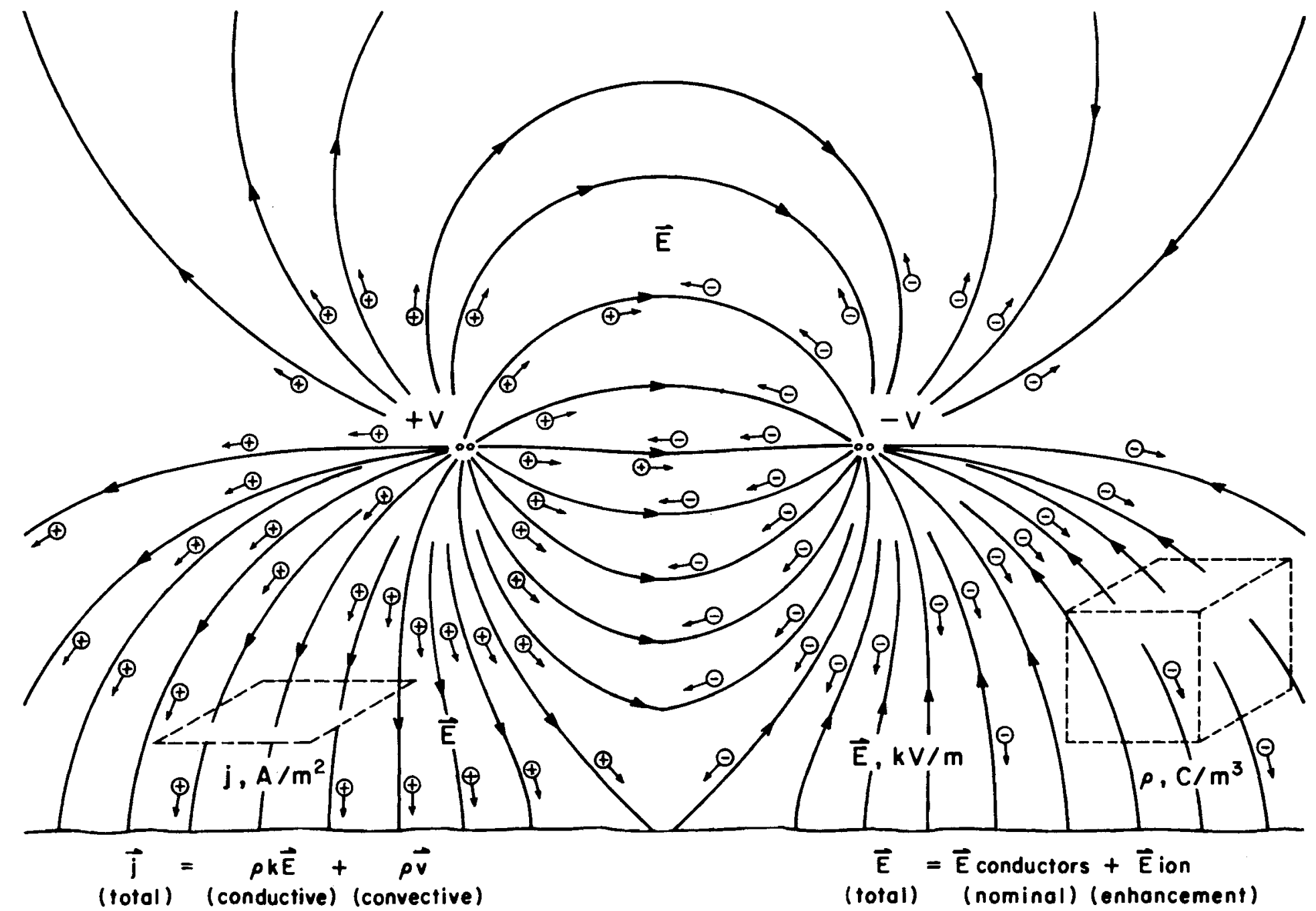

Figure 1. HVDC electrical environment 


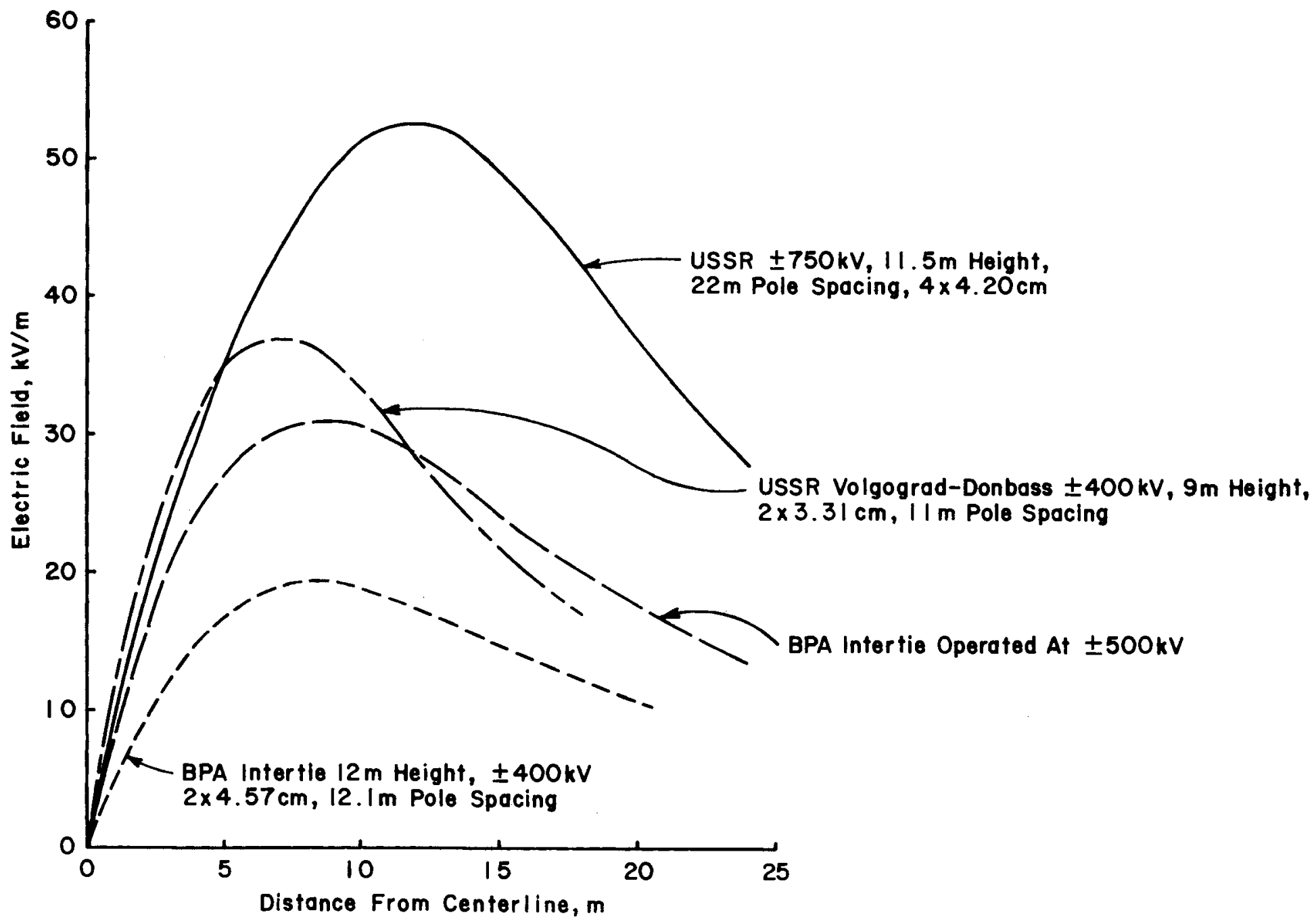

Figure 2. Calculated electric field profiles for various HVDC transmission lines 

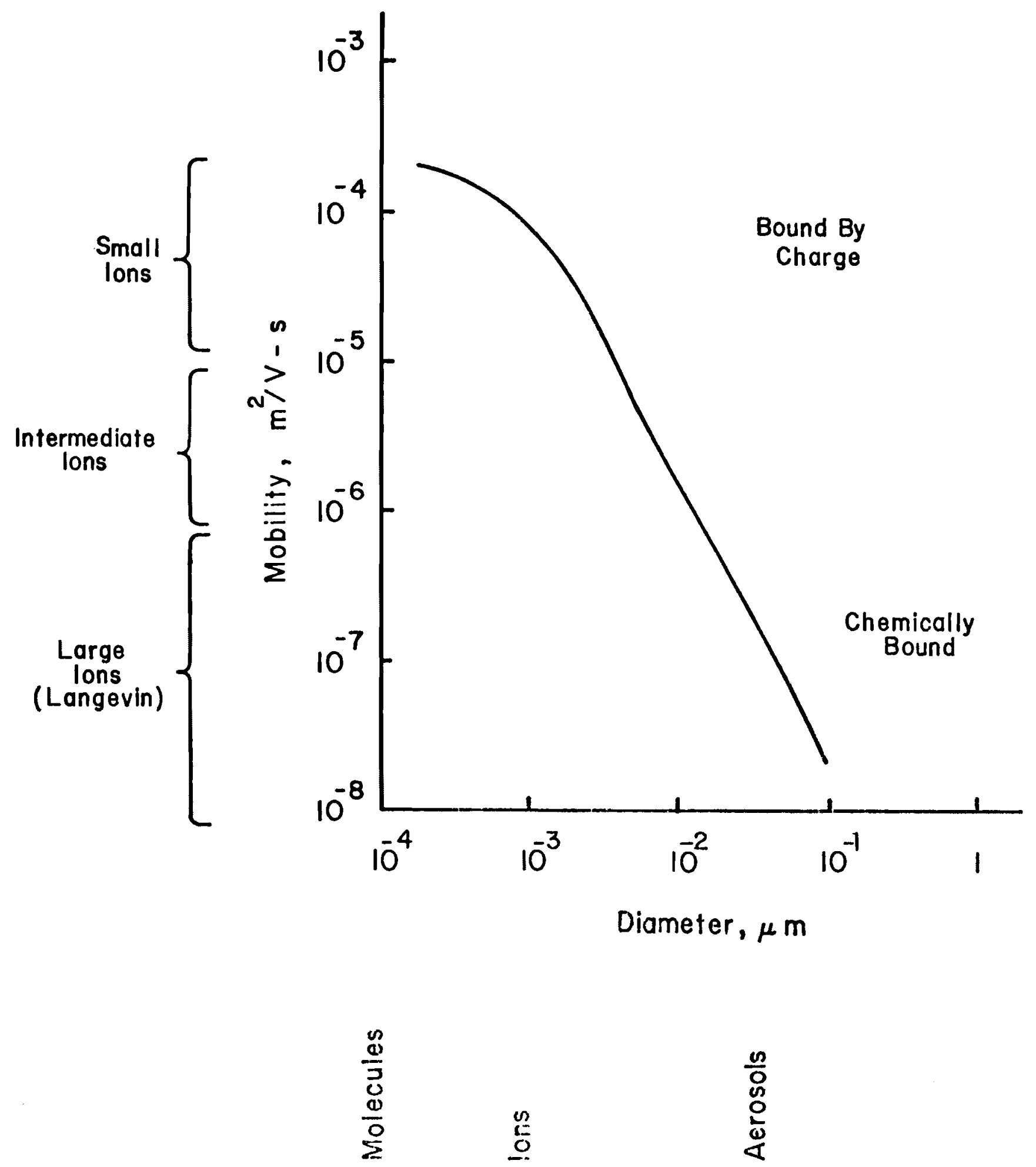

Figure 3. Ion mobility versus size 


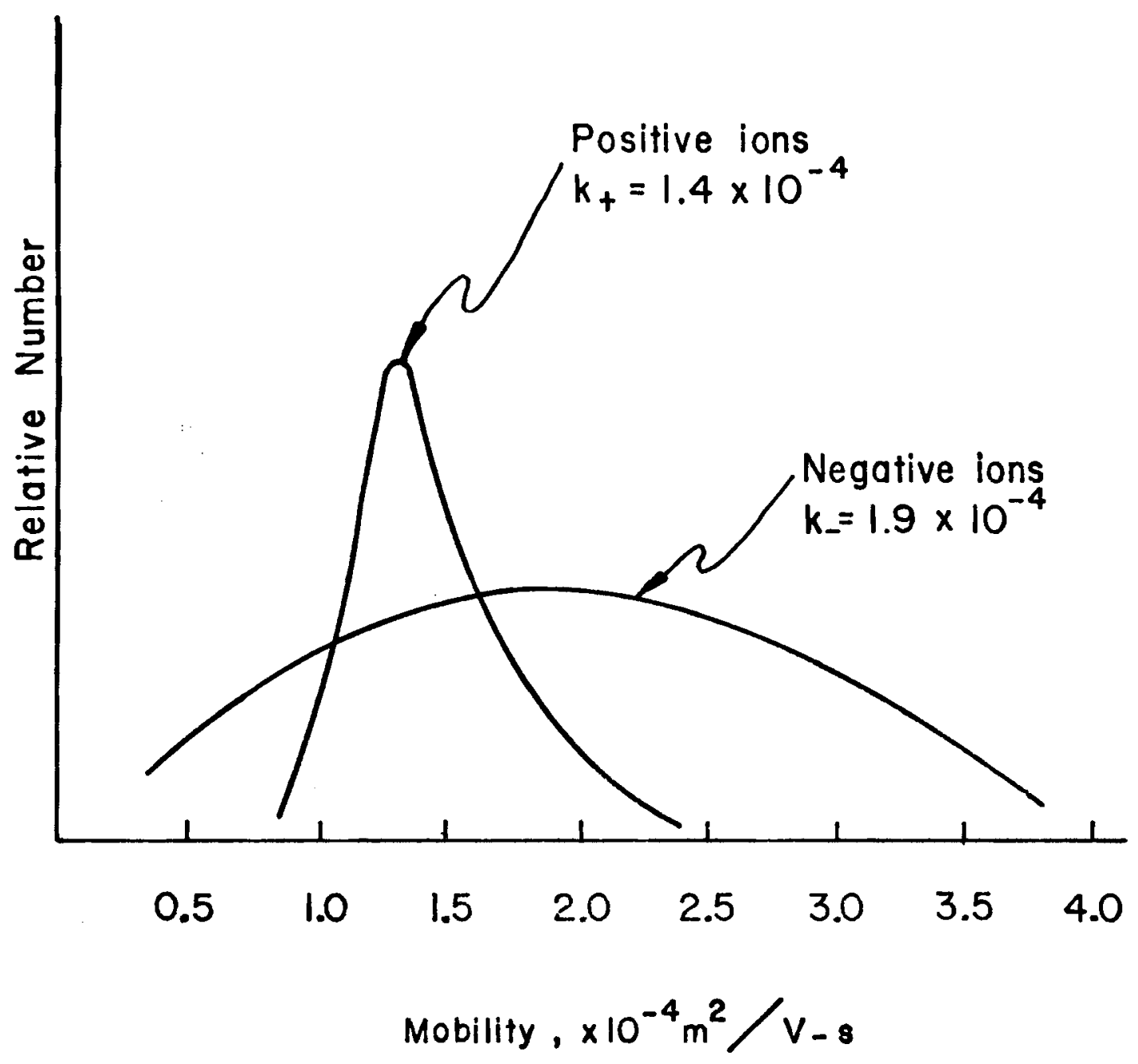

Figure 4. Ion mobility spectra for dry air. For atmospheric ions $\mathrm{k}_{+}=1.14 \times 10^{-4} \mathrm{~m}^{2} / \mathrm{V}-\mathrm{s}$ and $\mathrm{k}_{-}=1.24 \times 10^{-4} \mathrm{~m}^{2} / \mathrm{V}-\mathrm{s}$. Adapted from Hoppel (1968). 
a) Vertical Component

West

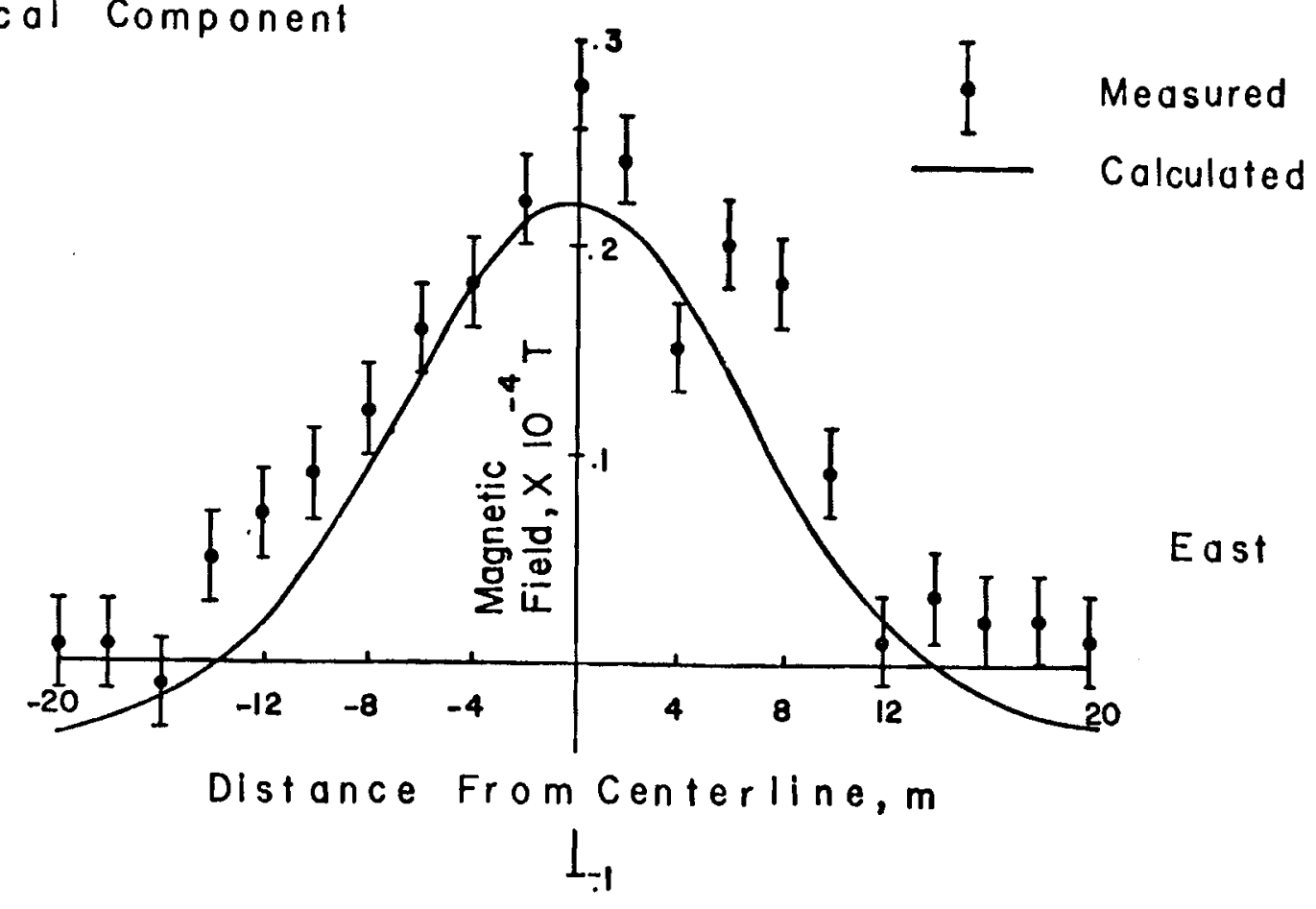

b) Horizontal Component

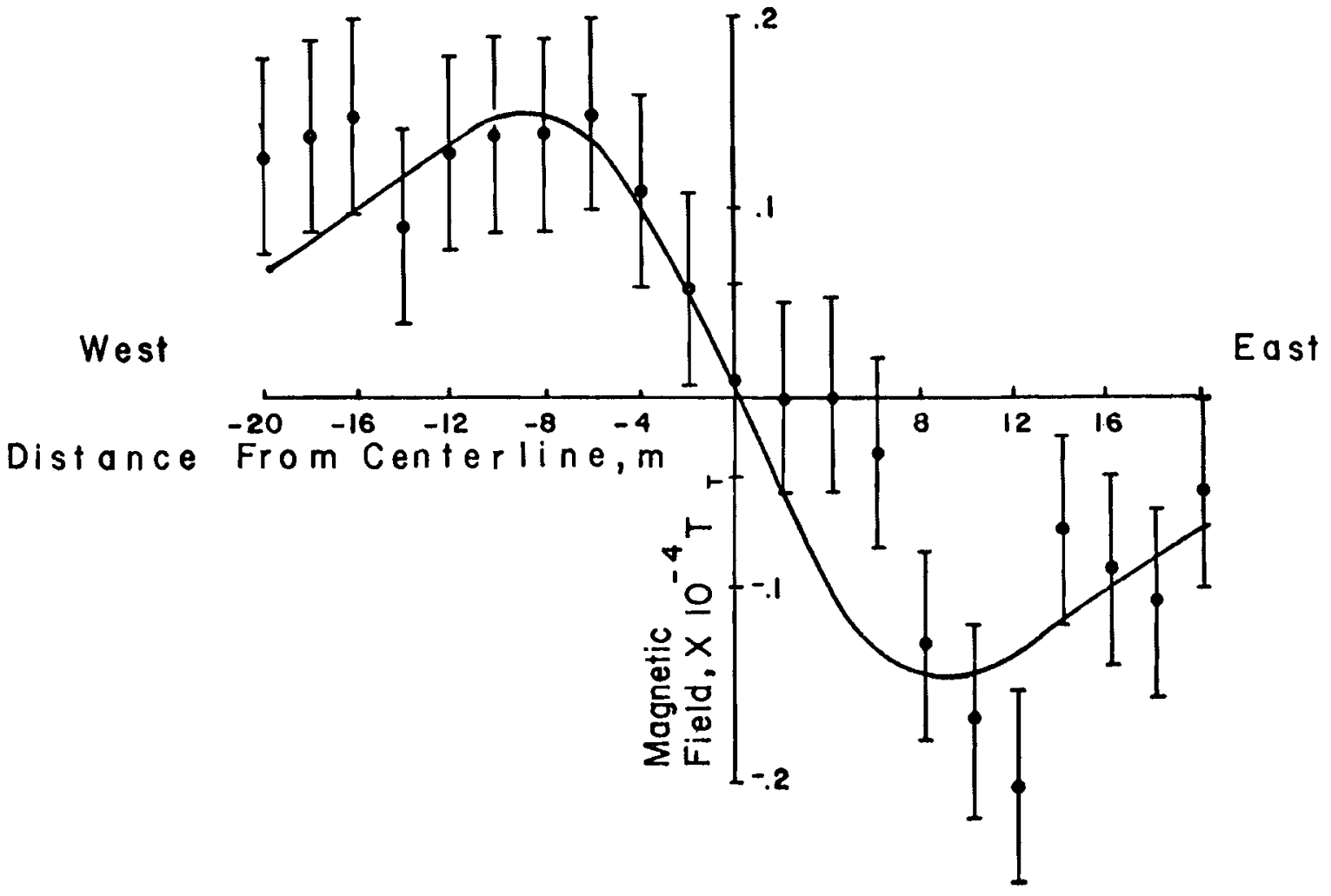

Figure 5. Magnetic field under the HVDC Intertie. Voltage, $\pm 400 \mathrm{kV}$; current, $1800 \mathrm{~A}$; height, $13.1 \mathrm{~m}$; pole spacing, $13.2 \mathrm{~m}$. Measured earth's field: vertical, $5.9 \times 10^{-5} \mathrm{~T}$; horizontal $7 \times 10^{-6} \mathrm{~T}$ (east). 


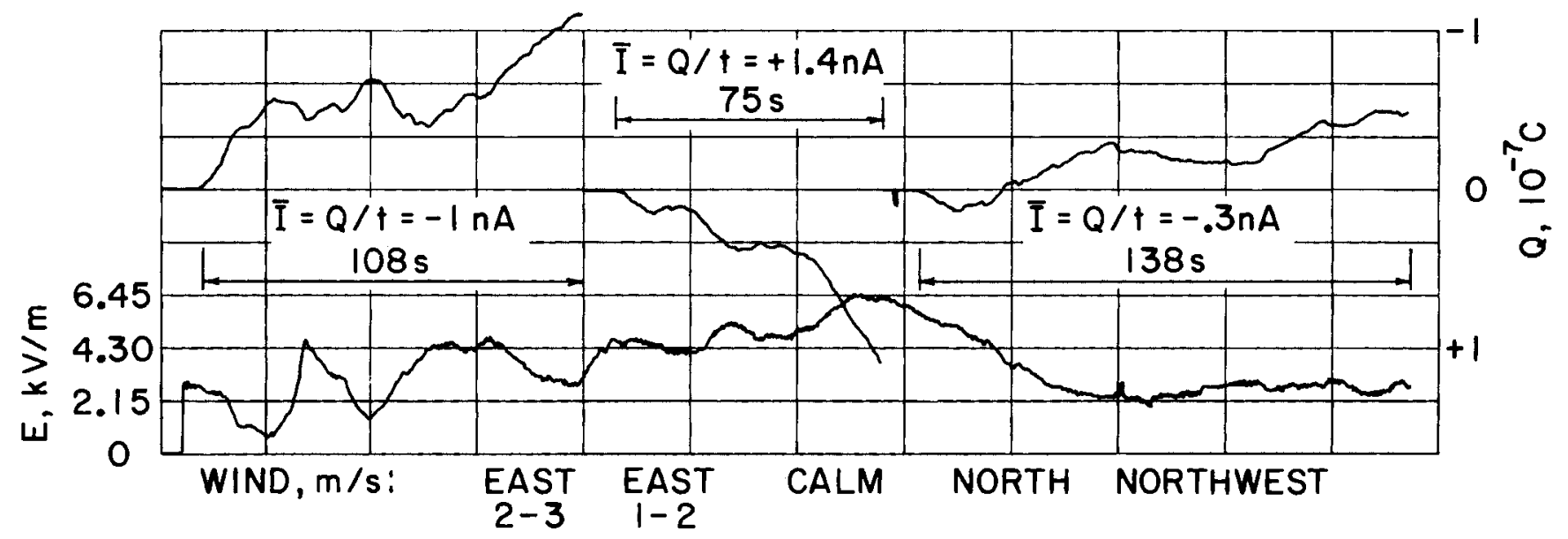

Figure 6. Electric field and collected charge measurements at ground level during unstable wind conditions. Recordings made $12 \mathrm{~m}$ beyond positive pole of $\pm 400 \mathrm{kV} \mathrm{d}-\mathrm{c}$ Intertie. 
Fair Weather Distribution Of One Minute Average Electric Field at $8 \mathrm{~m}$ Versus Perpendicular Wind Speed For The Dalles DC Test Line At $\pm 500 \mathrm{kV}$
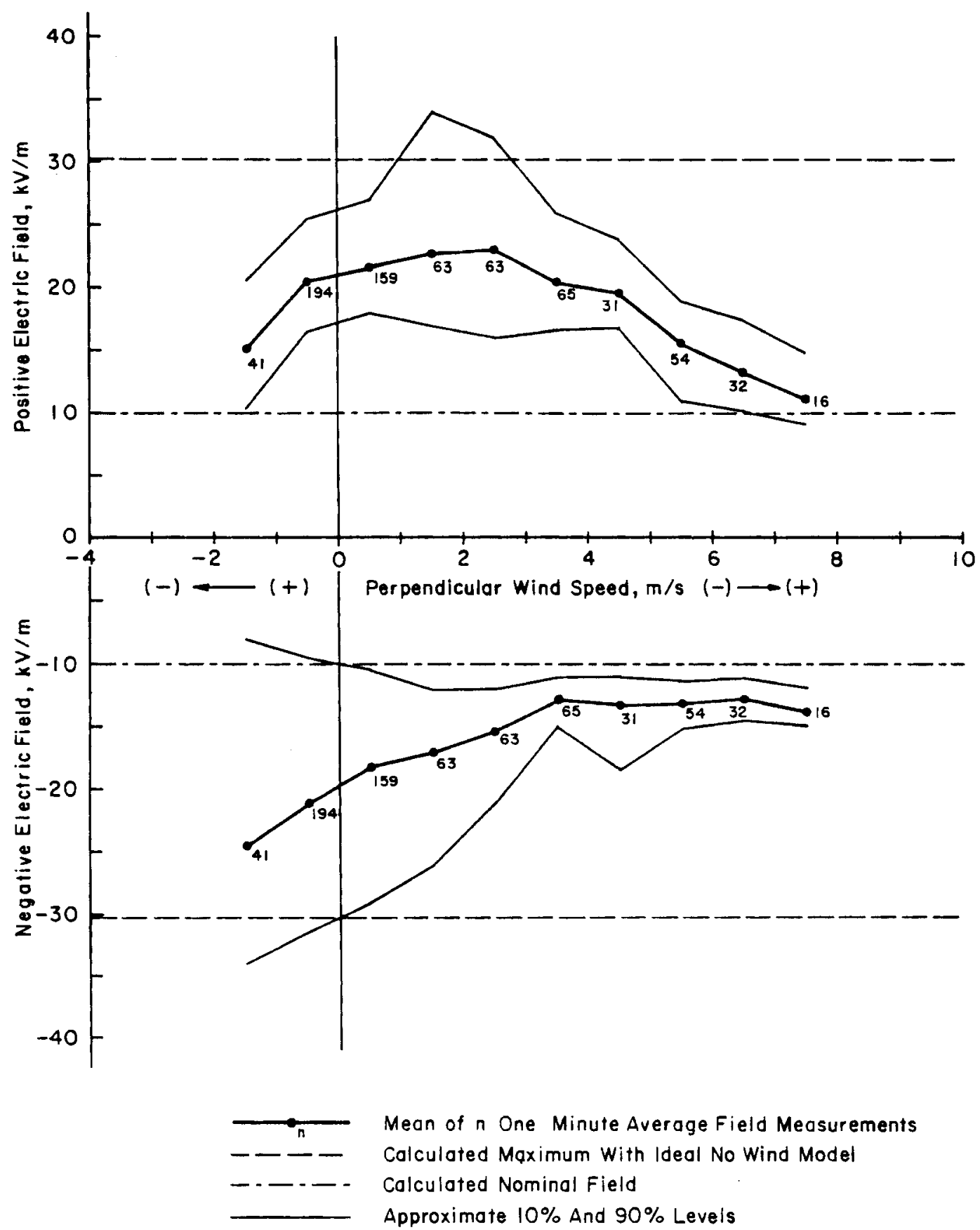

Figure 7. Electric field versus perpendicular wind speed for The Dalles HVDC Test Line at $\pm 500 \mathrm{kV}$ 


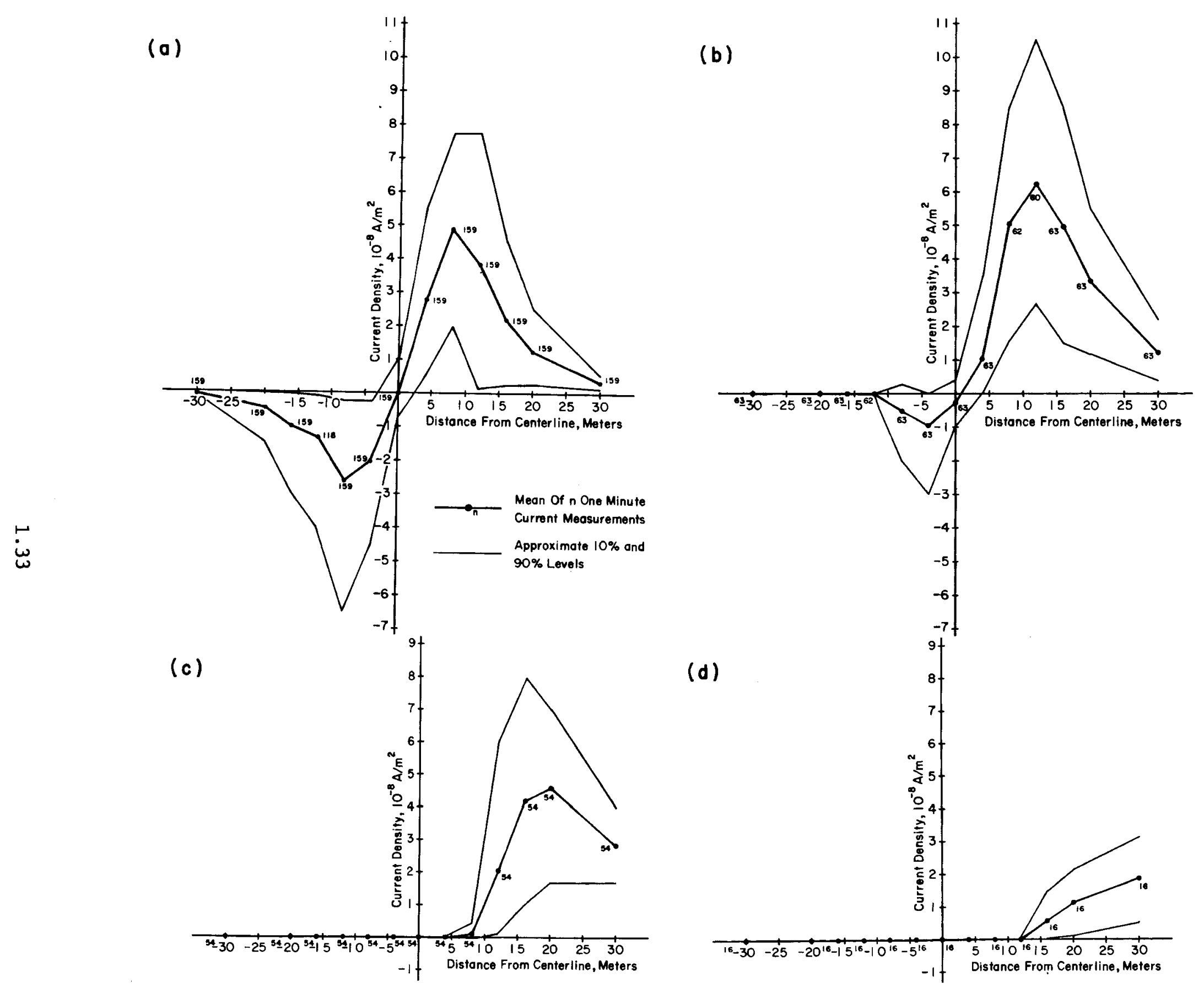

Figure 8. Fair weather current density profiles for the Dalles HVDC Test Line at $\pm 500 \mathrm{kV}$ as a function of perpendicular wind speed: a) $0-1 \mathrm{~m} / \mathrm{s}$ b) $2-3 \mathrm{~m} / \mathrm{s}$ c) $5-6 \mathrm{~m} / \mathrm{s}$ d) $7-8 \mathrm{~m} / \mathrm{s}$ 


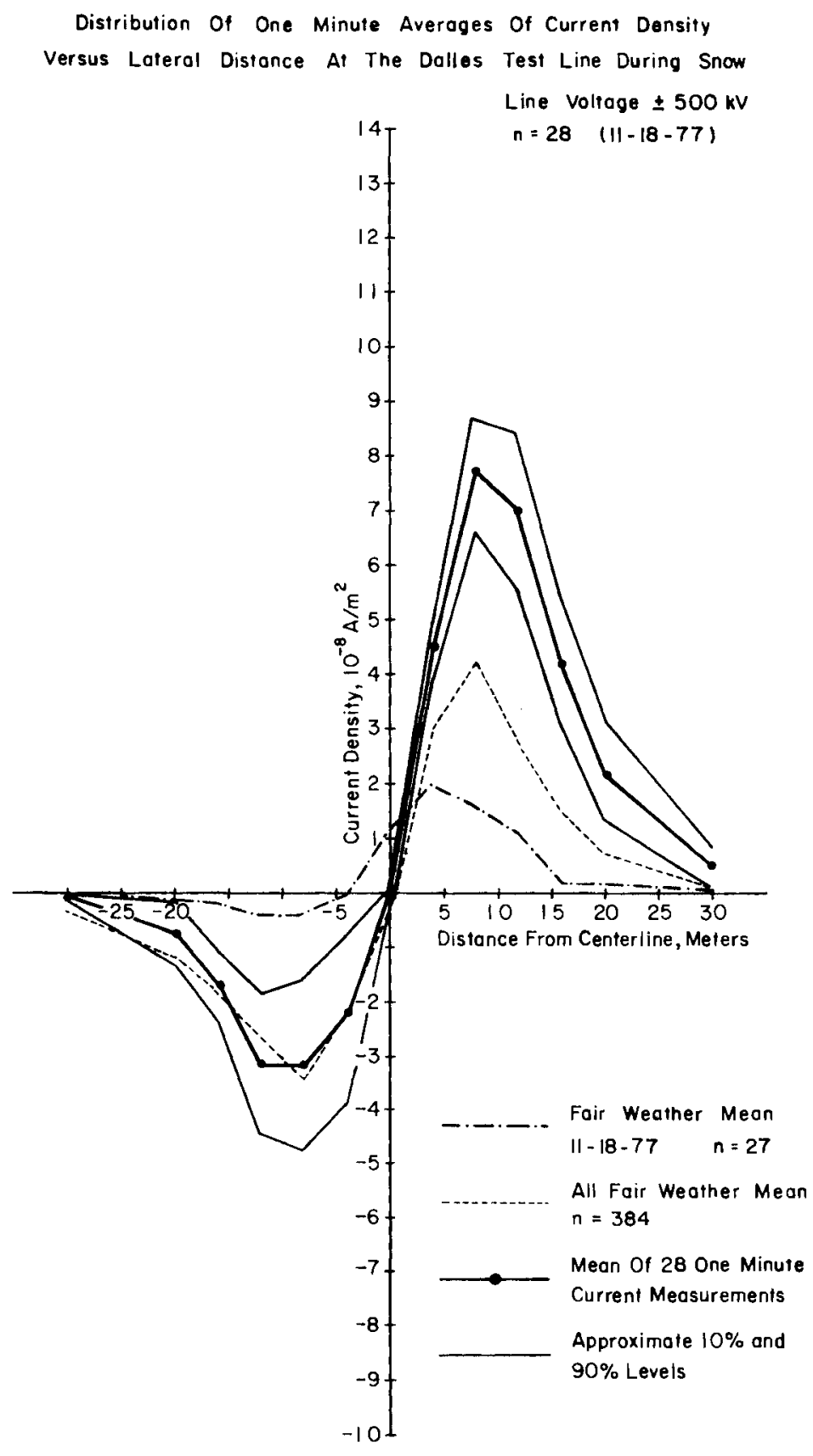

Figure 9. Current density profiles during snow ans fair weather for The Dalles HVDC Test Line at $\pm 500 \mathrm{kV}$ 


\section{DISCUSSION}

MW Miller: How can a conductor be in corona and be quiet? I had assumed that when the line was in corona it was making noise. Does it not do that on a dc line?

D. Bracken: The dc line is quieter, there is some noise, but it is quieter because the plume activity is less. Essentially all the noise comes from the corona on the positive pole because of the corona plumes there. It is the plumes that are prevelant on an ac line that give it a noisy character. There is also corona present on the negative conductor of a dc line but it's more of a glow type.

MW Miller: Let's take two situations: two very clear days, nice weather, two $500 \mathrm{kV}$ lines, one ac and one dc. I would anticipate the ac line would be quiet. It would be noisy on a foggy morning but it would be quiet on a nice clear day. Would your dc line be quiet on the same day?

D. Bracken: Not necessarily. If it had rained the day before then it would probably be quiet because all the dust and bugs would have been washed off the conductor. However, if there had been a long dry spell and there had been time for protrusions to build up on the conductors, then it would be more noisy than normal. Then when the rain came it would quiet down again. The line actually quiets down when it rains.

C. Lindh: That is also true for ac lines.

D. Bracken: I think it's much more apparent on the dc line. I have gone out on different occasions under the dc line to the same site in seemingly the same weather conditions; however, the line was much quieter and the fields were much less, because the corona activity was significantly reduced:

S. Maruvada: On the dc lines, under fair weather conditions, you get most of the noise, and in fog and rain, the noise goes down. But in the case of the ac lines you have noise mainly under fog and rain conditions. There is one exception to this, when there is snow, then the noise on dc lines is also higher. When it is wet snow, rain, or fog, the noise comes down. 
MW Miller: Would I be correct in saying that in this relatively dry area, that you expect to have, on average for a year, more noise. In other words, that you could hear this line fairly frequently.

D. Bracken: Again, it depends on the level of the line. At $500 \mathrm{kV}$ you are going to hear more than at $400 \mathrm{kV}$. The dc Intertie which is $400 \mathrm{kV}$, you can just barely hear.

A. Valentino: You have shown that 90 percent of your measurements are below one curve, or 90 percent are above another curve. Unless your measurements are spaced uniformly with time and over average weather conditions and so on, you don't have all the information with which you are concerned.

D. Bracken: Yes, that is definitely true. I think Sarma Maruvada has found out in measuring RI and audible noise from their test line that it is very seasonally dependent. In order to give real meaningful statements about 90 percent or mean values, you have to identify whether it is an annual mean, or the mean during a particular season. So, yes, you do have to state how the mean and the 10 and 90 percent levels are obtained.

T. Norris: When you talk about perception in a field, what is the phenomenon per se?

D. Bracken: Normally it is just hair stimulation, as it is under ac 1 ines. Under certain conditions your hair will stand on end. Usually the field will be greater than $30 \mathrm{kV} / \mathrm{m}$ when this occurs. One of the times when we perceived the field, my hair was actually pushing down on my head. So, hair stimulation is the main mecranism for field perception.

W. Kaune: In ycur harmonic distortion measurements, what if you have one set of valves bypassed so that one line is running at $267 \mathrm{kV}$ and the other at 400 ? How does that affect the distortion?

J. Vithayathil: Even among the values that were given, there are two types. Some of them are in phase in both poles, and some are canceling each other. When you bypass a group, those harmonics which are canceling each other no longer provide complete cancellation. So you would find some increase in the 
field due to those types of harmonics. As far as harmonics to ground are concerned, when you bypass a group you reduce them. So, I would say in general, you are likely to find less harmonics when a group is out, but actual magnitudes depend on which group.

W. Kaune: In these calculations, you assume the air ions travel along the field lines. Aren't you saying that the total field lines are colinear with the nominal field lines? Since the total field is at least twice the nominal field, why would that be true? I can't think of any argument that convinces me.

S. Maruvada: The field line magnification is a function of the position along the field line, it varies as you go away from the conductor to ground. It is maximum at the ground level. The assumption that the field lines with and without the space charge remain the same depends on the current density. If you are talking about corona where the current densities are quite small then the assumption is more valid than in the case of electrostatic precipitation. As you increase the current densities, the assumption breaks down. Also the validity of the assumption is not the same for all flux lines. If you are taking the flux line between conductor and ground which is the shortest distance, then the assumption is quite true in that region. If you are starting at the top of the conductor, the field line goes all the way around and the assumption is not as good. Thus, it depends on symmetry and current density.

B. Scott-Walter: It seems from physical grounds that when wind speed is high and the ion velocities are not along the field lines, that those assumptions would begin to break down, but at low wind speeds that these assumptions would be quite good.

R. Kotter: What about the problem of ion generation from the ground because of the high field? Has any consideration been given to how you might handle that, or whether it is something you can safely ignore.

D. Bracken: I don't know if anyone has considered putting a source term at the ground, but if you saw the levels that Kasemir reported during thunderstorms the generation rate was about $4 \times 10^{-10} \mathrm{~A} / \mathrm{m}^{2}$. The current densities 
under the line are on the order of $10^{-8}$ or $10^{-7} \mathrm{~A} / \mathrm{m}^{2}$ during fair weather. Thus, I think the generation from the ground is small, unless you are out away from the line. 
2. CHARACTERIZATION OF THE ELECTRIC ENVIRONMENT UNDER HVDC TRANSMISSION LINES: INSTRUMENTATION AND MEASUREMENT TECHNIQUES

\author{
F. Ralph Kotter \\ National Bureau of Standards \\ Washington, DC
}




\section{CHARACTERIZATION OF THE ELECTRIC ENVIRONMENT UNDER HVDC TRANSMISSION LINES: INSTRUMENTATION AND MEASUREMENT TECHNIQUES}

\section{Introduction}

There exists a large volume of literature documenting many years of atmospheric electricity research. Much of that work has rather direct application to measurements of electric field and ion effects in the vicinity of high voltage direct current (HVDC) transmission lines. Many series of measurements from balloons, rockets and airplanes as well as at ground level of electric field strength, ion density, conductivity and mobility distribution have been reported. In general the measurement accuracy sought in this research has been somewhat lower than that considered desirable in the neighborhood of the HVDC lines; however, the basic measurement techniques and instrumentation are directly applicable. It is anticipated that modifications and adaptations of the measuring devices already developed will permit their use with adequate accuracy in the somewhat more hostile transmission line environment.

Unfortunately the extent of the need for the instruments designed for atmospheric electricity research has not warranted significant commercial exploitation. In general, each research group has constructed its own instruments. Instruments have been developed for measuring the electric field strength, ion current density, electrical conductivity of the air, polar and net space charge densities and the mobility spectrum of the ions. These instruments are considered below in that order, 
first with respect to their use at or near ground level and then with respect to precautions which must be taken for measurements above ground level.

\section{Electric Field-strength Measurements at or Near Ground Level}

Two techniques have been used successfully in atmospheric studies for measurements of the electric field strength. The first of these involves use of a probe to measure the potential at a point in space a known distance above the surface of the ground. The average field strength near the ground is then obtained as the potential divided by the elevation of the probe. The typical probe consists of a disc or wire coated with a low-level radioactive material. [1,2] The weak ionization produced in the vicinity of the probe improves the coupling to the space and reduces the time required for the probe to reach the potential of its surroundings. An electrometer is used to measure the potential assumed by the probe. It seems likely that the disturbing effect of the local ionization and the fact that the procedure provides only a measurement of the field averaged over a considerable distance will preclude extensive use of this technique in HVDC line studies.

The generating voltmeter or "field mill" as it is commonly known has been highly developed and extensively used for electric field strength measurements. [3] The principle of operation is illustrated in Fig. 1. The rotating, grounded, rotor vanes, $v$, alternately shield the sensing 
electrodes, $s$, from, and expose them to, the incident field. When exposed, the electrodes receive an induced charge proportional to the field strength. The alternating current resulting from this periodic charging and discharging action is measured by a sensitive ammeter. One form of field mill is shown in Fig. 2. In general these instruments are' considered reliable only in fair weather although some success has been achieved with special modifications for use in rain or light snow. [4]

In the vicinity of HVDC lines the ion current to ground is likely to be orders of magnitude larger than that existing in routine atmospheric electricity studies. The ion current arriving at the sensitive electrodes of a field mill is chopped and constitutes an error signal which must be dealt with. The fact that there is a quadrature relationship between this error current and the field-strength signal current, in principle at least, makes possible their separation by phase sensitive detection techniques.

Another possible source of error associated with this type of instrument results from the difficulty of attaining the same value for the work function on two metal surfaces. Two surfaces are never identical with regard to surface roughness and contamination coating and thus, while contact potentials can be reduced, they can not be eliminated. During the part of the cycle when the stator elements are shielded from the external field they are exposed to the under side of the rotor blades. The spacing is close so that even a small potential difference between the two surfaces can produce a significant disturbing signal. [3] 
Also of concern in using the field mill to measure the electric field incident on a ground plane is the location of the effective measuring surface of the instrument. If that effective surface protrudes above the ground plane there exists a field enhancement problem; whereas, if the effective surface is below the ground plane the instrument is partially shielded by the surrounding plane. Fortunately this is a source of error which can be dealt with in the calibration process.

Although designed for use in laboratory and industrial plant applications, the vibrating-plate field meter is also being used for measurements in the vicinity of HVDC lines. [5] A small plate electrode, centered under a circular hole in a shielding electrode vibrates approximately sinusoidally in the direction of the electric field to be measured (see Fig. 3). The charge induced on this sensing electrode thus varies sinusoidally and provides an alternating current signal proportional to the field strength. In one adaption of this principle a voltage of appropriate polarity is applied to the shield plate to provide a signal $180^{\circ}$ out of phase with the one produced by the incident electric field. When these signals are equal in magnitude a null is obtained and the voltage applied to the shield plate is then proportional to the incident field strength. [6] With only relatively minor modifications this type of instrument has been used successfully to map the electric field strength at ground level under HVDC lines. [7] Fig. 4 shows an instrument of this type mounted on a "ground-plane sled" for this purpose. 
The limitations imposed by contact potentials, by a departure from coplanarity with the ground surface and by foul weather conditions are similar to those associated with the field mill. Both instruments have been used successfully under light snow conditions; however, rain has proven a more severe problem with the vibrating plate device. [8]

As in the case of the field mill the question of error being introduced by the flow of ions to the probe used in the HVDC line environment is of concern. Analysis of the circuits used with these probes suggests that errors from this source are small enough to be neglected but, so far as the author is aware, experimental proof of this is lacking.

\section{Electric Field-strength Measurements Above Ground}

At ground level, since the earth is a relatively good conductor, the electric field is vertical and a single field meter suffices to determine its magnitude. When interest is in the electric field at a point in space above the ground plane in general a horizontal as well as a vertical component must be considered. The horizontal component arises from the geometry of the transmission line as well as from the fact that space charge makes a significant contribution to the total field. One, perhaps obvious, solution is three field meters mutually orthogonally oriented. However, even a single field meter distorts the field so that the field it indicates is not that which existed prior to its introduction into the space. 
For example, an electrically-isolated spherical conducting probe introduced into a uniform vertical electric field distorts the field to such an extent that the field at the poles of the sphere is three times the original uniform value. For an infinitely-long circular cylinder with its axis perpendicular to the field the corresponding factor is two. This enhancement factor can be calculated only for simple geometries. It must be determined experimentally in most cases.

There is another field enhancement problem which arises when the object introduced into a field region carries a net charge. This, of course, is the situation which exists if a grounded instrument is located at a point in space where the potential was not zero prior to its placement there. There are ways of avoiding error from this source. One approach is to mount two identically shaped field meters together, oppositely directed but parallel to the original field vector. [9] The sum of the two meter readings is then proportional to the self charge and the difference is a measure of the geometrically enhanced field.

Another approach is to provide a means for bringing the field meter to the potential of the point in space where it is located either by means of a biasing supply or by isolating it from ground and equipping it with a means for "bleeding off" the accumulated charge. [10]

The cylindrical generating voltmeter, Fig. 5, can be made free of error from self charge. [11] As the cylinder rotates the charges induced 
on the two halves by the ambient field flow through the meter. Any self charge which exists is not modulated by the rotation and thus does not influence the meter reading. An instrument operating on the same principle consisting of two spheres rotating about an axis perpendicular to the line joining their centers has been used suspended from a balloon to measure the horizontal component of the electric field in the vicinity of clouds. [12] The current-measuring and telemetry circuits are contained in the spheres -- which also serve as a dipole antenna.

\section{Vertical Ion Current Density at Ground Level}

The "Wilson Plate" has been extensively used in atmospheric electricity research for ion-current density measurements at ground level. [13] It consists simply of a guarded horizontal plate of known dimensions with a sensitive current-indicating instrument for measuring the current to the guarded section. The guarding is simply an effort to avoid errors from distortion of the field near the edges of the sensing plate and has been omitted by some experimenters. It becomes less important as the linear dimensions of the plate become large relative to its separation from the effective ground plane.

While simple in principle, in actual use the Wilson Plate requires considerable care if unambigious results are to be obtained. It has long been recognized that current density measurements with the Wilson Plate are greatly complicated by its sensitivity to induced currents 
from a changing electric field. Several approaches have been taken to reduce the error from this source. Perhaps the most obvious is to integrate the current over a period sufficiently long that the net induced charge remaining on the electrode at the end of the integration period is negligible relative to the total conducted charge. Another approach is to measure simultaneously field and charge and to end the current integration period at a time when the field has the same value as existed at the beginning of the integration period.

More sophisticated techniques have been used. Since the two components of current are in quadrature -- with the one a function of the conductivity of the air and the other a similar function of its permittivity -- a current detector which incorporates a parallel RC network having the same constant as the air is used. [14] The current through the resistive portion of the detector impedance then is the desired conduction component of the total current. It seems this approach would be useful only in situations where the air conductivity remains reasonably constant with time - not likely to be the case in the vicinity of a HVDC line.

Another technique which has proven successful involves use of a field meter near the Wilson Plate to monitor changes in the field. With that information it is possible to remove from the Wilson Plate output signal the component due to the changing electric field. $[15,16]$ 
At first glance it would seem that even in rain conditions the Wilson Plate should provide a measurement of the total current reaching the ground -- that carried by the rain drops as well as that due to ion flow. However, precautions are necessary since charge separation can occur during splashing and the splashing of drops on or near the plate can introduce significant errors. [17]

Until relatively recently there seemed to be no reason to question the accuracy of the measurements made with the Wilson Plate when used with proper precautions. The accuracy had been assumed to be principally a function of the accuracy with which the plate dimensions and the current could be measured. However, experiments have recently been reported $[18,19]$ which seem to indicate that there may be significant contributions to the current by wind-induced charge deposition on the plate--such that under some circumstances the current measured may bear little relationship to the electric field-induced vertical flow of ions to it from the space above. These results argue for caution in interpreting the results of Wilson Plate current density measurements except for those made under no-wind conditions.

\section{Conductivity Measurements}

In theory a knowledge of the electric field vector, $\vec{E}$ and of the conductivity, $\lambda$, of the air permits a calculation of the current density, $\vec{j}=\lambda \vec{E}$. While one must also recognize the possible existence of a 
convection current component in addition to the conduction component, conductivity measurements are of value. The "Gerdien capacitor", Fig. 6, has been used successfully for this purpose in atmospheric electricity research. [20] As indicated schematically in Fig. 7 it consists of two coaxial cylinders. The air is aspirated through the space between them. There are alternative connections possible $\mathrm{e}^{[21]}$ but with the one shown in the figure negative ions which enter the outer tube are attracted toward the central electrode. If the voltage and air speed are chosen appropriately those ions which arrive at the central electrode produce a current which is proportional to the conductivity of the air. It can be shown that the measured direct capacitance of the structure (vieved as a simple cylindrical capacitor) and the applied voltage are the only parameters required to permit calculation of the conductivity from the current measurement. [22]

One may expect diffusion losses to the walls of any entrance ductwork used. Bends in such ducts will further increase the loss of ions. One study of this source of error indicated that the error could be kept very small by using straight entrance tubes $10 \mathrm{~cm}$ or larger in diameter. [23] The error from this source can also be reduced by increasing the air speed through the tube; however, errors from triboelectric charging can be expected to increase with higher air speed. [24,25] 


\section{Polar Charge Density Measurements}

In principle the Gerdien capacitor can be used to measure the polar charge density (charge density of ions of one sign). Figure 8 represents the current-voltage characteristic for a Gerdien capacitor with constant air speed. The dotted line indicates the curve which would be expected if ions of only one mobility were present. In all practical cases a distribution of mobilities exists giving rise to the solid curve shown. The linearly rising portion of the curve is the conductivity region. The saturation portion of the curve is the "ion counter" region in which all ions which enter are being collected and the chargs they carry contribute to the current. While frequently referred to as an "ion counter", in fact it provides a measure of the total charge of one polarity entering the outer cylinder per unit length of time. If the volume flow rate of the air and the capacitor dimensions are known, the polar charge density may be determined from the current measurement. [26]

The coaxial cylindrical geometry is not ideal for charge density measurements. The usual construction employs parallel plates as shown in Fig. 9. ${ }^{[27]}$ The closer spacing permits reaching the saturation current level at lower voltages. 


\section{Net Charge Density lleasurements}

Net charge density may be obtained as the difference between the positive and negative charge densities determined by two "ion counters" of the type described above. However, in many situations this involves taking the difference between two relatively large and nearly equal numbers -with a serious loss of accuracy.

Somewhat more direct approaches have been used successfully in atmospheric electricity research. One of these involves use of a "Faraday cage". $[28,29]$ The cage is constructed of screen mesh large enough to permit free air movement into the cage without excessive loss of ions to the screen and yet small enough to shield the interior from external fields. With the assumption of uniform charge distribution throughout the volume, the potential at the center of the cage, as determined with a radioactive potential probe, provides the information necessary for calculation of the net charge density. Alternatively, the field at the center of one wall of a cubical cage measured by a flush-riounted field mill can be used for such a calculation.

Another successful technique has involved use of an ion filter. $[29,30]$ Air is pulled through a so-called "absolute" filter which is capable of removing $99.97 \%$ of al1 particles exceeding $0.3 \mu$ meter in diameter. It has been demonstrated that such a filter removes essentially all ions -including "small" ions, i:e., those with mobilities of the order of 
$1-21-2 \times 10^{-4} \mathrm{~m}^{2} /$ ss. Measurement of the volumetric air flow rate and of the current from the filter unit provides a direct measurement of net space charge density.

\section{Mobility Measurements}

An aspiration device similar to the Gerdien capacitor can be used to determine mobility spectra. In this application the collecting electrode is divided into two or more insulated sections. For the case of two sections the current to the second (or downstream) section $\left(i_{2}\right)$ is measured as a function either of the applied voltage $(V)$ or of the volumetric air speed (U). It can be shown that the slope of the curve obtained by plotting $i_{2} / V$ against $U / V$ yields the mobility distribution function. [31]

The "time-of-flight" method has been successfully used for air ion mobility measurements. [32] Pulses of ions from a field free region are introduced into a region of known uniform field strength a measured distance from an ion detector. The shape of the current pulse to the detector together with the time interval between the introduction of the ion pulse and the arrival of the ions at the detector provides the mobility distribution function. 
Measurements with Aspiration Type Instruments Above Ground Level

It seems apparent that an electric field at the entrance to an aspiration-type device would either increase or decrease the density of ions in the air being drawn into it and thus introduce an error regardless of whether it is measuring conductivity, charge density or mobility. From Fig. 10 it can be argued that this is not necessarily the case. ${ }^{[33,34]}$ If the field is such as to attract ions of the sign being measured to the entrance tube it can be seen that ions which are brought into the flow tube by the field are removed from it before they reach the collecting electrode. This is, of course not true if the ions contributing to the measurement are repelled by the charges on the entrance tube on which the external field lines terminate. That this analysis is valid has been verified experimentally. $[25,34]$

\section{Conclusions}

This review of the atmospheric research literature indicates that many of the instruments and measuring techniques developed for that purpose can be adapted for use in the vicinity of HVDC transmission lines. Some extension of ranges, improvements in accuracy and better protection from perturbing influences will be required. 


\section{References}

1. Chalmers, J. A. Atmospheric Electricity, 2nd Edition Permagon Press, New York, (1967), p. 128.

2. Carroll, J. S., Hammond, S. B., and Stewart, E. H., "Measuring and Recording Atmospheric Potentiā", AIEE Trans (PAS) 74 (1955), pp. $517-520$.

3. Gathman, S. G. and Anderson, R. V., "Improved Field Meter for Electrostatic !leasurements", Rev. Sci. Inst. 36 (1965) pp. 1490-1493. (References are given to earlier designs).

4. Gunn, R., "Electric Field Meters", Rev. Sci. Inst. 25 (1954) pp. $432-437$.

5. Gohike, W. and Neubert, U., "Bemerkungen zur Hoch- und Höchstspannungsmessung", Zeit. Tech. Phys. 21 (1940) pp. 217-222.

6. Vosteen, R. E., "D.C. Electrostatic Voltmeters and Fieldmeters", Conference Record of 9 th Annual Meeting of the IEEE Industry Application Society, (oct. 1974).

7. Bracken, T. D., Capon, A. S., and Montgomery, D.V., "Ground Leve1 Electric Fields and Ion Currents on the Celilo-Sylmar $\pm 400 \mathrm{kV}$ DC Intertie During Fair Weather", IEEE Trans. (PAS) 97 (1978), pp. $370-378$. 
8. Bracken, T. D. and Furumasu, B.C., "Field and Ion Current Measurements in Regions of High Dénsity Near Direct Current Transmission Lines," Conference Record American Meterological Society Conference on Cloud Physics and Atmospheric Electricity, Issaquah, Washington, (Aug. 1978).

9. Gathman, S., "Guarded Double Field Meter," Rev. Sci. Inst. 39 (1968) pp. $43-47$.

10. Chalmers, J.A., loc. cit., pp. 123-144.

11. Kasemir, H. W., "The Cylindrical Field Mill," Meteorologische Rundschau 25 (1972) pp. 33-38. (In English).

12. Winn, W. P., and Byerley II, L. G., "Electric Field Growth in Thunderclouds," Quart. Jour. Roy. Meteor. Soc. 101 (1975) pp. $979-994$.

13. Chalmers, J. A., "The Measurement of the Vertical Electric Current in the Atmospheric," Journ. Atmos. Terr. Phys. 24 (1962) pp. 397-302.

14. Kasemir, H. W., "Measurement of the Air-earth Current Density," Proc. of the (First) Conference on Atmospheric Electricity, Portsmouth, NH, (May 1954). 
15. Adamson, J., "The Compensation of the Effects of Potential-gradient Variations in the Measurement of the Atmospheric Air-earth Current," Quart. Jour. Roy. Meteor. Soc. 86 (1960) pp. 252-258.

16. Hutchinson, W. C. A., "Atmospheric Electric Field-change Compensation When Measuring Air-earth Conduction and Precipitation Currents," Jour. Atmos. Terr. Phys. 28 (1966) pp. 823-830.

17. Chalmers, J. A., loc. cit. p. 83.

18. Aspinal1, W. P., "Mechanical-transfer Currents of Atmospheric Electricity", Jour. Geophys.. Res. 77 (1972) pp. 3196-3203.

19. Dayaratna, L. H., and Hutchinson, H. C. A., "Atmospheric Electrical Mechanical Transfer Currents to Plate Antennas, in Electrical Processes in Atmospheres. (Proc. 5th Int. Conf. on Atmos. Elect.) Ed by H. Dolezalek and R. Reiter, D. Steinkopff, Darmstadt, Germany (1977) pp. 225-230.

20. Chalmers, J. A., loc. cit. p. 196.

21. Knoll, M., Eichmeier, J. and Schön, R. W., "Properties, Measurement, and Bioclimatic Action of "Small" Multimolecular Atmospheric Ions," in Advances Elect. Electron. Phys., 19 (1964) pp. 177-254. (This is an extensive review with a bibliography of 377 entries). 
22. Swann, W. F. G., "The Theory of Electrical Dispersion into the Free Atmosphere...", Terr. Magn. Atmos. Elect. 19 (1914) pp. 81-92.

23. Stergis, C. G., "Study of Atmospheric Ions in a Nonequilibrium System". Geophysical Research Paper No. 25 p. 28 (April 1954). Air Force Cambridge Research Center, Cambridge, MA.

24. Cobb, W. E., "Ion Losses in the Gerdien Condenser Intake System," Jour. App, Meteor. $7:(1968)$ pp. 456-458.

25. Kraakevik, J. H., "The Airbourne Measurement of Atmospheric Conductivity," Jour. Geophys. Res. 63 (1958) pp. 161-169.

26. Chalmers, J. A., loc. cit. p. 93.

27. Bracken, T. D. and Furumasu, B. C., loc cit.

28. Blanchard, D. C., "Positive Space Charge from the Sea," Journ. Atmos. Sci. 23 (1966) pp. 507-515.

29. Anderson, R. V., "Absolute Measurements of Atmospheric Charge Density," Jour. Geophys. Res. 71 (1966) pp. 5809-5814.

30. Bent, R. B., "The Testing of Apparatus for Ground Fair-weather Space-charge Measurements," Jour. Atmos. Terr. Phys. 26 (1964) pp. $313-318$. 
31. Whipple, E. C., Jr., "An Improved Technique for Obtaining Atmospheric Ion Mobility Distributions," Jour. Geophys. Res. 65 (1960) pp. 3679-3684.

32. Cabane, M., Krien, P., Madelaine, G., and Brichard, J., "Mobility Spectra of Ions Created in Gases Under Atmospheric Pressure," in Electrical Processes in Atmospheres. (Proc. 5th Int. Conf. on Atmos:

Elect.) H. Dolezalek and R. Reiter Ed. Pub. by D. Steinkopff, Darmstadt, Germany (1977) pp. 30-39.

33. Cobb, W. E. and Phillips, B. B., "Atmospheric Electric Measurement Results at Mauna Loa Observatory," Technical Paper \#46 (1962) U.S. Weather Bureau, U.S. Department of Commerce.

34. Coroniti, S. C., Parziale, A. J., Callahan, R. C., and Pattern, R., "Effect of Aircraft Charge on Airborne Conductivity Measurements" Jour. Geophys. Res. 57 (1952) pp. 197-205. 


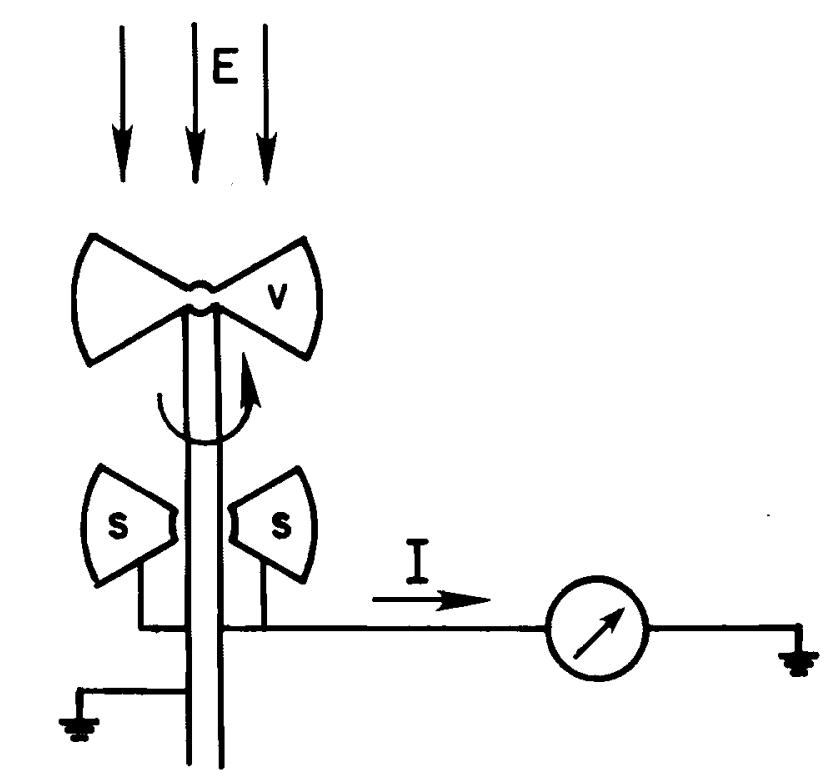

Figure 1 Field Mi11--Operating Principle 


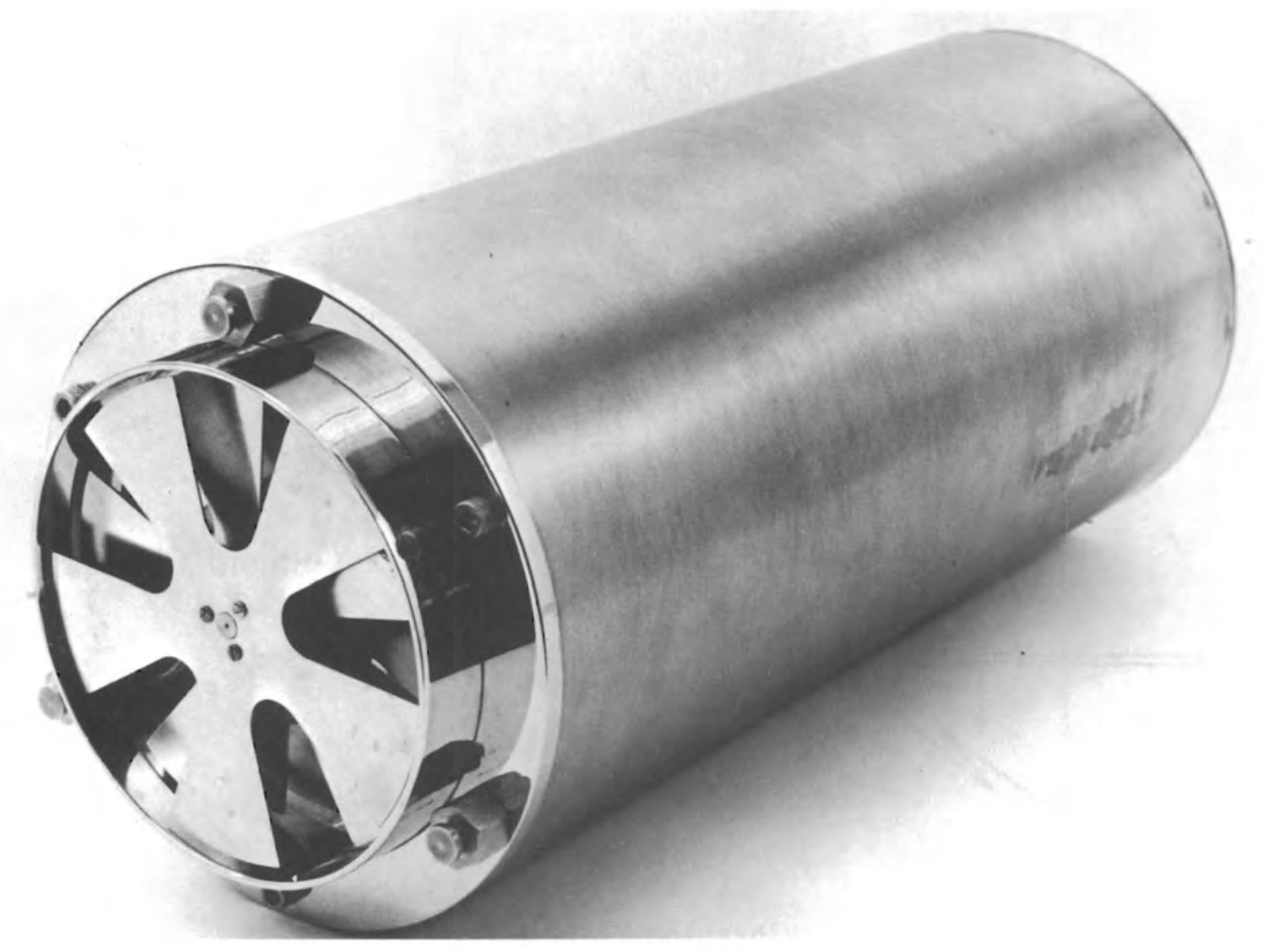

Figure 2. Field Mill 


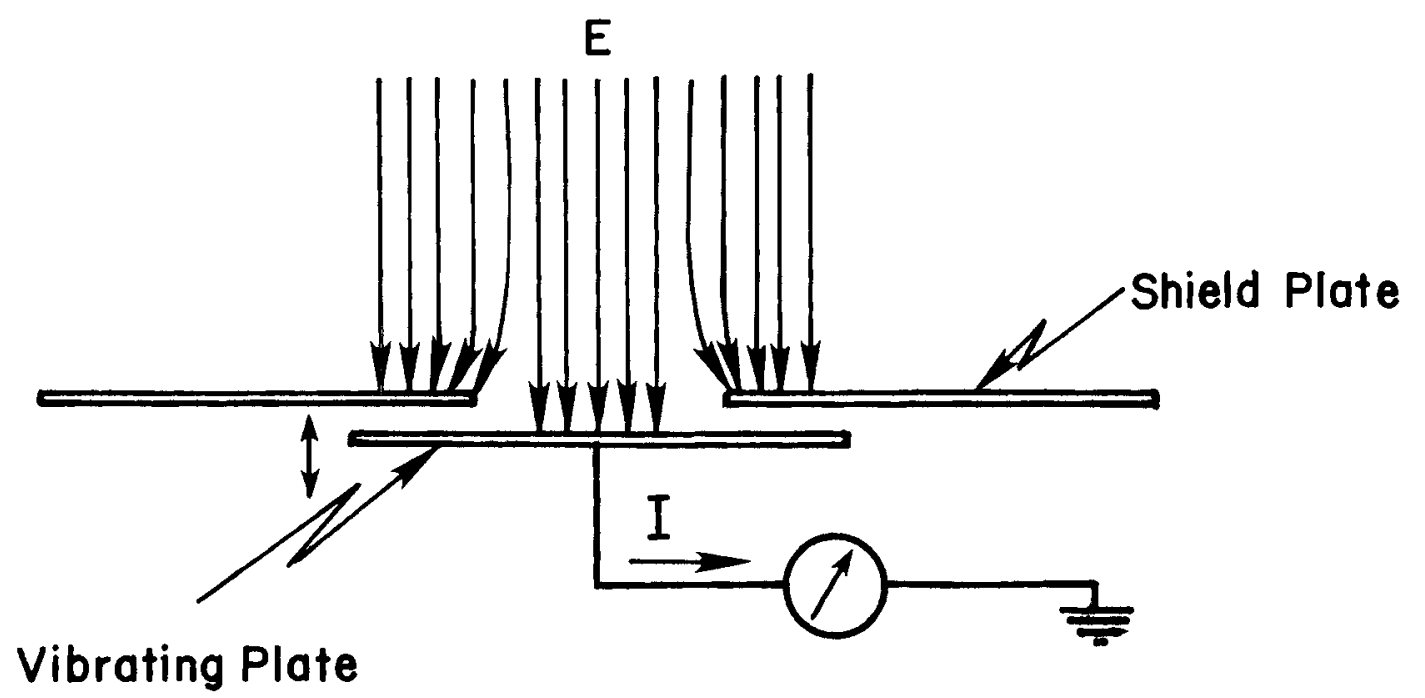

Figure 3. Vibrating-Plate Field Meter-Operating Principle 


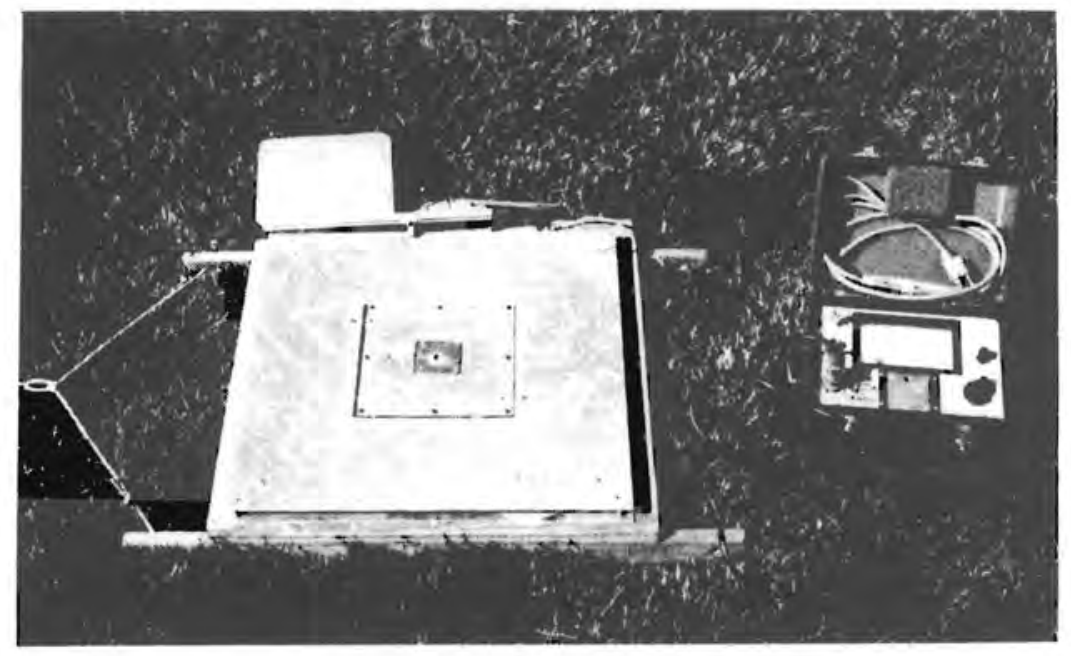

Figure 4. Vibrating-Plate Field Meter Mounted for Mapping Under an HVDC Line (from Transmission Line Reference Book HVDC to $\pm 600 \mathrm{kV}$. Published by Electric Power Research Institute, Palo Alto, CA) 


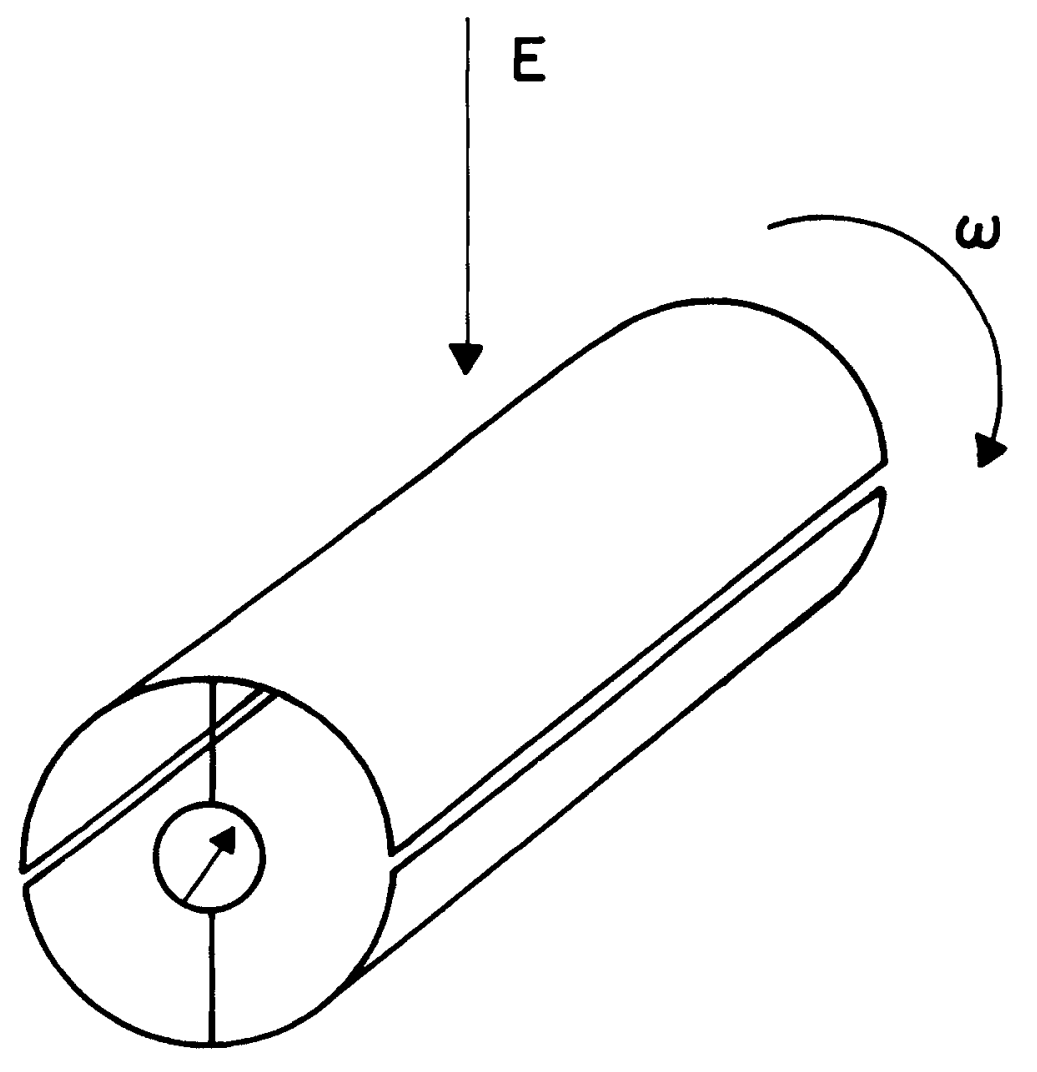

Figure 5. Cylindrical Generating Voltmeter-Operating Principle 


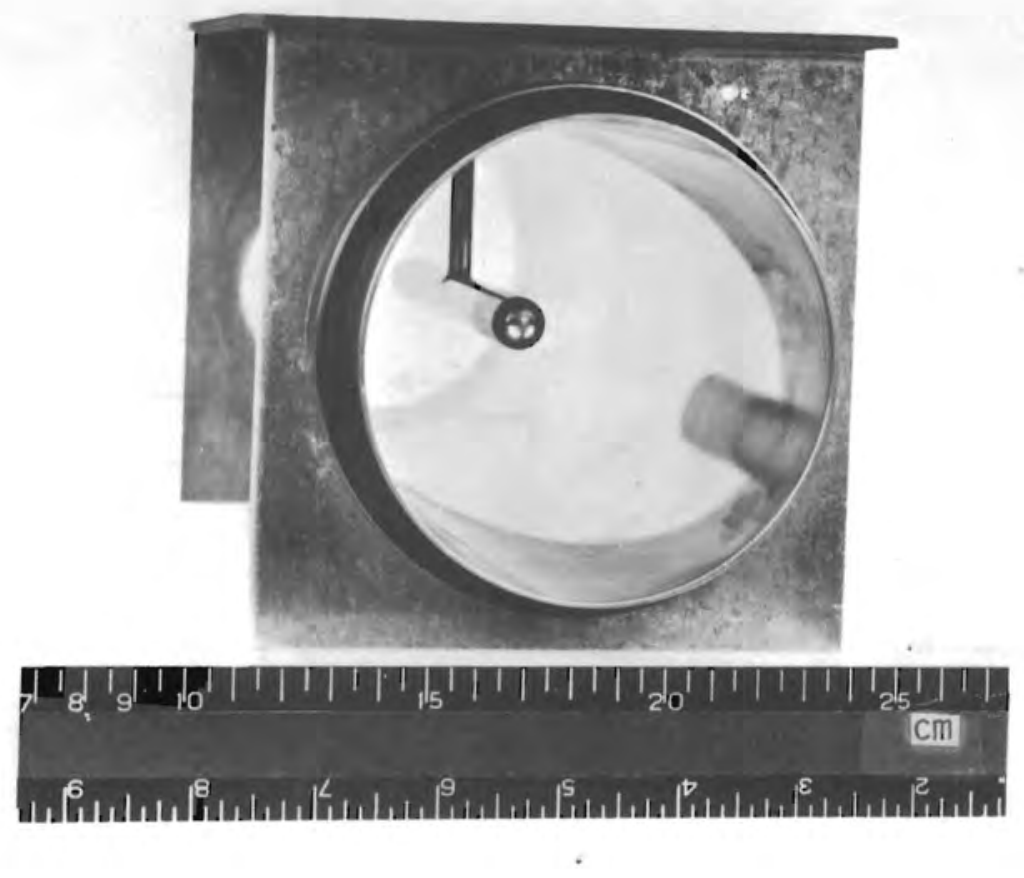

Figure 6. Gerdien Capacitor 


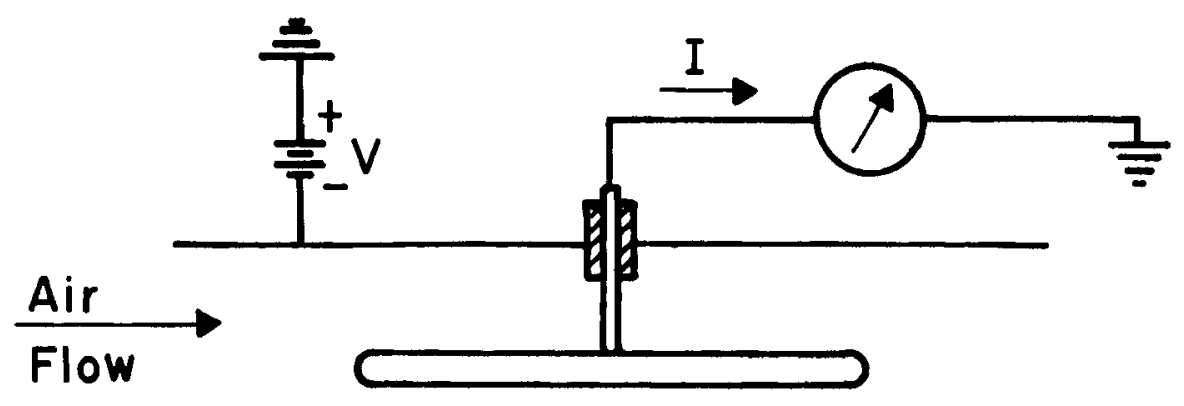

Figure 7. Gerdien Capacitor--Operating Principle 


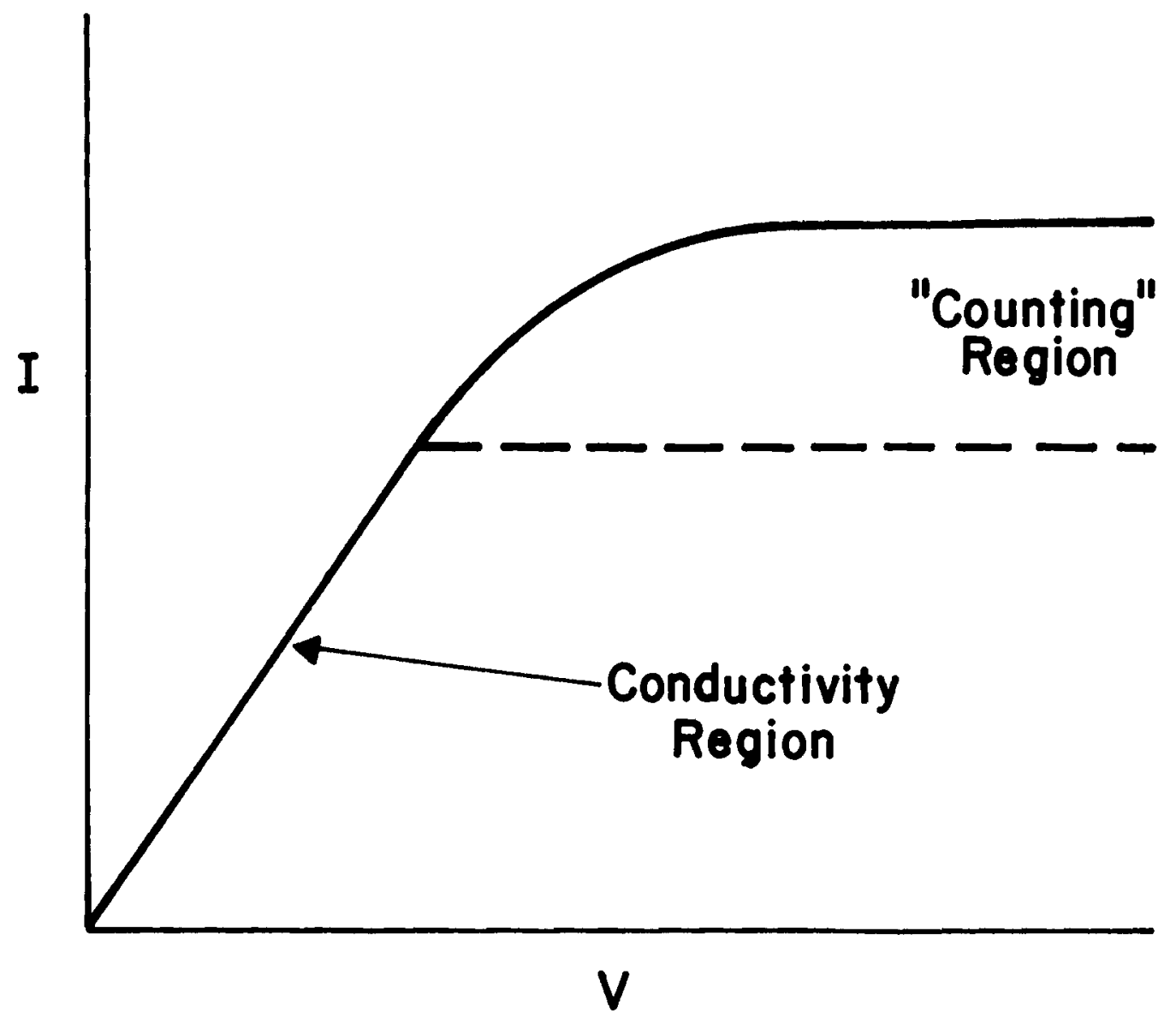

Figure 8. Characteristic Curve for Gerdien Capacitor 


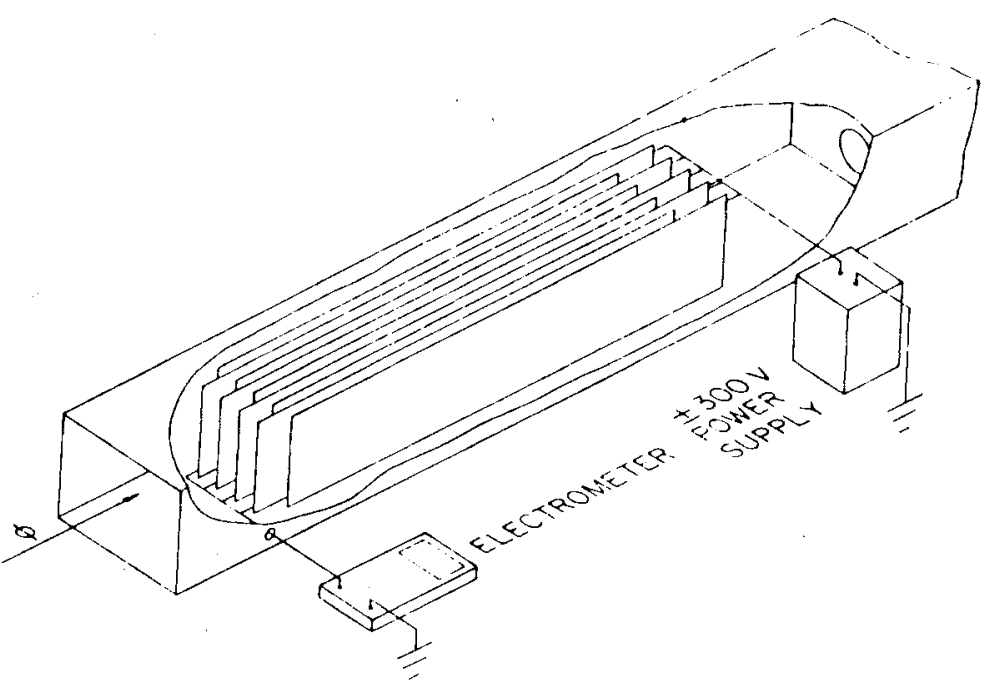

Figure 9. "Ion Counter" for Polar Charge Density Measurements (from Reference 8) 


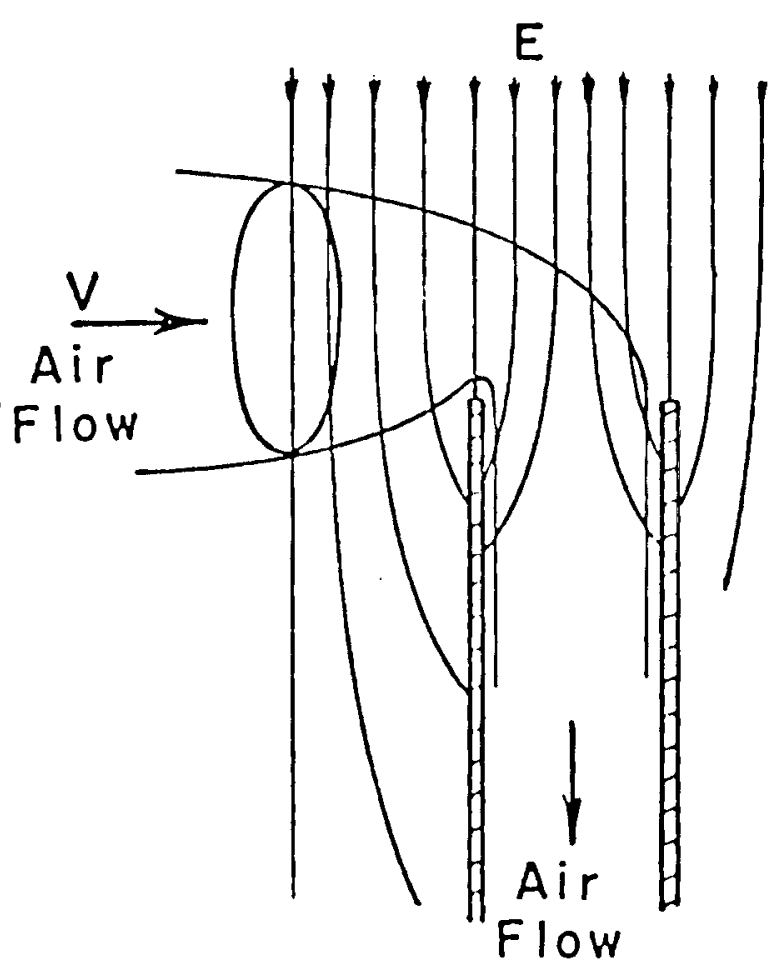

Figure 10. Typical Air-Flow and Electric Field Pattern at Entrance of Aspiration-

Type Instrument (from Reference 33) 
.

, 


\section{DISCUSSION}

C. Chowaniac: Aren't you really interested in the total current?

R. Kotter: That is a good question. I don't know what significance there is to the current entering the ground in a biological situation. What you are interested in, perhaps, is the current entering the human body or accumulating on an insulated object that may become a source of shock at a later time. So, I agree, that depending on really what you are interested in, you may want that total current.

W. Kaune: Is it fair to say that these plates measure the total charge reaching the ground per unit time?

R. Kotter: Yes. I think that's right, the total current reaching the point at which they are located. But many people have attempted to interpret that as the conduction component of the current, which is flowing in response to the field, and that is not necessarily true.

M. Gillis: To us biologists, I guess your point is important because you can calculate the space charge density from $j=k p E$, from the total current. You would like to get rid of any convective contribution, in order to calculate the proper space charge.

R. Kotter: As noted earlier, a serious problem in using this device for measuring current is the fact that it is sensitive also to displacement current. For this and other reasons, Dan found it advantageous to measure charge by integrating the current signal.

J. Decker: Dan, I noticed that if you differentiated the plots of charge as a function of time that you showed, then the current actually was negative in some cases.

D. Bracken: Yes. Negative current would occur on the positive side of the line when you had a change in field that would give you a negative displacement current. There were other periods when enough negative charge was carried over to the positive side of the line by the wind to give a negative current. 
J. Decker: This points up pretty well that we certainly can't ignore the wind factor in the accumulation of charge on these plates.

D. Bracken: You have to do some kind of an averaging to eliminate wind variations and also the displacement currents.

T. Michel: It seems to me, as far as the biological people are concerned from a pragmatic point of view, that they would be interested in the net charge associated with that plate: that is, a flux meter type of arrangement. They would not be interested in generating an idealized steady-state model: that can be done in a laboratory. If you are looking for bioeffects on animals and plants, or people, under dc transmission line, the real world out there is going to have all of these variables. This instrument is going to see real conditions in operation under lines, not a defined condition that could be or would be replicated in a lab.

R. Kotter: I think I agree with you.

M. Gillis: I would agree if you determine finally that the displacement current can be neglected. It goes back to the calculation of space charge again. As far as total current goes, we are just interested in total current in the body, and the displacement current contributes to that too. But for calculations of the space charge in the region of the animal, we would like to eliminate that term unless it is small.

R. Kotter: Does the measurement of current at the ground surface tell you anything about current to the body?

M. Gillis: I don't know... it might be a start.

T. Norris: If you are interested in the current through the body then you should include the displacement current. On the other hand you might be interested in the species of charge that accumulate on the surface. You might be interested to know, for example, if you get ammonia ions on the surface. In this case, you would be interested in the ion current and not the displacement current; but, then you would also need to know more about the chemical species, which is a problem of another order of magnitude. 
T. Valentino: Briefly, it seems to me what we are trying to do is understand the fields and all the components in them, so that we can with assurance simulate them in a biological experiment. Maybe in the end we will come to some simplified conclusion that says: what we want to simulate is a plate which is collecting all the charge. But I don't think we are at that point yet. It is important that we try to understand what all the components are and get the proper instrumentation together to separate them.

W. Kaune: It has always seemed to me that the volume of air that these aspiration devices require is going to be so large that it represents a significant perturbation in a small system such as an exposure system for small animals. Do you think that this is a valid problem?

R. Kotter: I do. I think that is a source of real concern.

W. Kaune: With mobility devices you assume that you are sampling from an essentially "infinite sink of ions" and that you are assuming a constant concentration and probably a constant mobility spectrum. But, these currents will change not only with your applied voltage, but also with the concentration coming in. When you are trying to compute a first derivative, then you are going to be extremeiy sensitive to these changes. My guess is that it will never work in the kind of environment Dr. Bracken has discussed. From what I have been able to gather from Steve Sebo they even see these fluctuations in their laboratory models.

H. Kornberg: While the physical science part of me is fascinated with this, the biologist in me asks why are we doing this. Now, we are not going to run a biological experiment in the rain, and certainly, I don't think anybody is going to stand out under a dc line in the rain. Although it is interesting to do this, I think we are introducing a jot more problems than are necessary at this stage of time. I agree some day they should be done. However, if we are doing biological research, we have got to remember that biological variability of $5 \%$ is fantastically good. Usually, it is no better than $10 \%$. If a meter is as good as 10\%, then I am satisfied with it.

R. Kotter: I appreciate that comment. However, I think we have problems of order of magnitude in some of these measurements. My intent was to indicate 
the type of instrumentation that seems to be available to us, and I agree that much of it may not have application in the real world which we face.

R. Finger: What I see reflected here doesn't necessarily reflect all of the equipment that is available and all that has been used, because some has not been made public. The answer to the question that Bill Kaune raised about study chambers is essentially: that when you get into a microclimate which is, say, 18 cubic meters or smaller, the instrumentation which they are describing and discussing here is not useful. There are products available that can move smaller quantities of air. The problems that are related to study chamber work are first, the design of the chamber, and second, that you don't distort the atmosphere by using this type of instrument. 
3. BIOLOGIC EFFECTS OF STATIC ELECTRIC FIELDS AND AIR IONS IN RELATION TO DC POWER TRANSMISSION

\author{
Asher R. Sheppard \\ J. L. Pettis Memorial Veterans Hospital \\ and Department of Physiology \\ Loma Linda, California 92357
}




\section{Introduction}

High-voltage direct current transmission lines introduce two prominent changes in the physical environment, air ions and large static electric fields, and both are suspected agents of biological change. In both cases the evidence for biologic effects is not well established or accepted in the scientific community. In both cases the physical and biological mechanisms for interaction are unknown and the proposed mechanisms are unclear and unproven.

This situation may be a characteristic of a pioneering stage in research into valid effects or it may be indicative of false steps in the research and conclusions developed so far. If one is generous and overlooks the experimental imprecision that might be expected when something is done for the first time, the orderliness of the reported results from different laboratories is quite surprising. However, DC static fields appear to have little biological information content and the scientific questions raised by air ions or static electric fields are distant from current trends in biological research. For these reasons it is unlikely that much progress in understanding their effects will occur in the normal course of research over the next few years.

\section{Static Electric Field Exposure}

Neglecting the small ion current, there is no current flow in a static electric field. However, the field distortions of the type observed in an AC field still occur and, for example, at the head of an average man the electric field would be enhanced to about 15 times the unperturbed value. If there is motion in the field, a quasi-alternating field is created, but any practical implications for that appear ignorable. By far, the greatest distortions in the field occur because of the establishment of ion clouds near the charged conductors.

\section{Animal Experiments in Static Electric Fields}

One of the most dramatic results reported with static electric fields occurred in research conducted by Becker and Marino and co-workers (Marino, et. al. 1974, Mitche11, et. al. 1978) using apparatus similar to that used in subsequent studies with $A C$ fields. A 30 day continuous exposure of rats 
in plastic chambers at field strengths of 19.7, 5.6, 2.8 and 0.5 kilovolts per meter $(\mathrm{kV} / \mathrm{m})$ produced a large number of exposed rats exhibiting glaucoma of the right eye. Although laboratory animals are predisposed to uveitis, the excess of cases and the peculiar occurrence in only one side were never explained. In this study there was also a change of about $10 \%$ in the blood concentration of the protein albumin. In another experiment chromosome abnormalities were observed in tumor cells that were injected into rats exposed for 14 days to an 8 to $16 \mathrm{kV} / \mathrm{m}$ horizontal electric field. In contrast to the marked changes in the tumor cells, there was no histopathologic evidence of an effect on the tissues of the host animal, nor were any behavioral changes observed. How did such results occur and what are the implications? In the absence of more data, these questions are unanswerable. Methodological questions can be raised for, as with other early experimentation with electric fields, shock artifacts, ozone or even air ions may be an issue, although it is certainly difficult to link such factors to chromosomal alterations. In summary, these results suggest dire effects beyond the grasp of a recognized mechanism for chromosomal alterations and, if confirmed, would raise serious questions.

In another experiment showing strong effects, rats or guinea pigs were exposed at $10 \mathrm{kV} / \mathrm{m}$ for about 90 minutes (Lott and McCain, 1973) to obtain recordings of brain activity utilizing either surface or implanted electrodes. Using the surface electrodes, total brain activity (measured without frequency discrimination) was sharply increased at the time the $10 \mathrm{kV} / \mathrm{m}$ field was turned on, and activity remained elevated for the duration of the exposure. When the field was turned off, there was again an increase in brain activity, suggesting an alerting response. Using different animals with electrodes implanted into the hypothalamus, a slight decrease in hypothalamic brain activity was seen. Data from nine experiments is reported in graphic form, but these preliminary studies allow no clear explanation and the authors do not suggest a mechanism by which the fields were sensed.

Möse and co-workers (Möse and Fischer, 1970, Möse, Fischer and Porta, $1971)$ performed several studies on mice and guinea pigs exposed to a fairly strong field of $24 \mathrm{kV} / \mathrm{m}$ for 15 days continuously, and observed decreased 
concentrations of serotonin (or 5-hydroxytryptamine, 5-HT) in the brain and uterus, and increased concentrations in the gut. 0ther data showed increased activity of the mice and guinea pigs, a large increase in food and water consumption and the indication of elevated metabolic rate was supported by data showing increased oxygen consumption of the excised liver tissue and elevated rectal temperature. In another study, a four-month exposure of mice indicated that fewer progeny were born to the exposed females. Unfortunately, the experimental details are unclear and the possible influences of electric shock, ozone or air ions were not considered separately.

An experiment performed by Mayyasi and Terry (1968) utilized a behavioral test to examine rats exposed at 1.6 and $16 \mathrm{kV} / \mathrm{m}$. Regardless of age or other factors, the exposed animals executed a Lashley Maze with faster time scores. A reduced error rate was also seen when a comparison was made of adults versus young reflecting an unaltered error rate in the young rats although they too had faster time scores.

Edwards (1961) observed a delay in pupation and a slightly greater pupa 1 mortality when insects were continuously exposed to an $19 \mathrm{kV} / \mathrm{m}$ electric field. In addition, eggs were positioned away from the field plate and they were fewer in number. Studies with an intermittent field showed little or no effect.

A few studies report on human exposures to static fields. In one (Jones, 1974), the observation of ten emotionally distrubed children exposed to a $1.2 \mathrm{kV} / \mathrm{m}$ field showed increases in attentivity and arithmetic performance, while the degree of trouble-making seen in the group decreased. In another study at a similar field strength, Carson (1967) cites Air Force research in which subjects exposed for two hours to $1 \mathrm{kV} / \mathrm{m}$ fields showed improved performance in tests of typing or soldering skill.

Effects on activity, on respiration of liver tissue and on the imnune system are reported by Fischer (1973) who exposed mice to electric fields of up to $24 \mathrm{kV} / \mathrm{m}$ for periods of 8 to 15 days. In comparison to a control group exposed to ambient fields, the exposed animals had changes in spleen weight, spleen cell counts and blood agglutination rates which were interpreted as an effect tending to improve the systemic capability of producing 
antibodies. In this study the mice kept in a Faraday cage (wherein the electric field was reduced from the ambient levels) showed changes indicative of reduced immunocompetence in comparison with the control animals.

In another class of experiments, the effects of small direct currents passed through tissues have been studied. In the case of the research into bone growth and development, it is now quite apparent that microampere currents stimulate bone formation whether applied by implanted electrodes or applied inductively. There is still controversy over the nature of the interaction but it is well accepted that patterns of bone growth can be altered by electric currents (Lavine, 1972; Lavine, et. al. 1974; Bassett, et. al. 1974, Becker, et. al. 1964).

Even more remarkably, it has been demonstrated that similar currents promote regeneration of differentiated tissue after surgical amputation. For example, currents of the order of a microampere promote regeneration of a limb in frogs, sometimes even to the development of the digits (Smith, 1974; Becker, 1972; Becker and Spadaro, 1972). Such experiments have been performed with electrodes implanted into the tissue in which case the current densities are considerably greater than those which occur during whole body exposures to electric fields. In the studies of bone formation and limb regeneration the role of electrochemical effects remains uncertain.

\section{U.S.S.R. Studies of Humans in Static Fields}

In the Soviet Union a field level of $50 \mathrm{kV} / \mathrm{m}$ has been proposed as an environmental standard for human exposure to static electric fields (Gertsik, et. al. 1973). This proposal is based on experimentation with humans exposed to 30,60 and $90 \mathrm{kV} / \mathrm{m}$ for 2 hours a day over a period of 12 months. In the Krivova, et. al. report (1973), the results with groups of 12 subjects exposed at $30 \mathrm{kV} / \mathrm{m}$ showed no significant health changes, but at $60 \mathrm{kV} / \mathrm{m}$ blood pressure was elevated by $15 \mathrm{~mm}_{\mathrm{Hg}}$ and heart rate was lowered by 10 to 14 beats per minute, surprisingly large changes. The subjects recovered to normal values of heart rate and blood pressure in about 24 hours. Tests of neuromuscular excitation thresholds also indicated depressed function.

The Soviet authors also report no effects on blood composition, no effect on the electrocardiogram, and no effects on reflexes or reaction times. 
In summary, the researchers state that the effect of the $60 \mathrm{kV} / \mathrm{m}$ field on humans involves a sub-cortical functional lability.

Exposures at $90 \mathrm{kV} / \mathrm{m}$ were performed in another laboratory (Krivova, 1973) with a different exposure system. Tests were conducted for $2 \frac{1}{4}$ hours per day over a period of 30 days with only 3 subjects. These subjects were tested using an ergograph, apparently a novel device designed to test small muscle function by a task that requires the subject to draw a briefly viewed picture under varying conditions of force applied to the hands, and on other related tests of neuromuscular control. The findings were a deficit in accuracy for 2 of the subjects, and these persons also had depressed pulse rates and blood pressures which persisted for 4 or 5 days after termination of the field exposure. In this study the hematologic findings indicated depressed thrombocyte levels. In none of the above studies was there an indication of an attempt to control the atmosphere for air ions or ozone and the studies are strengthened by the use of a control group in some cases.

The Soviet work has also addressed the issue of the ion currents due to a DC field, and Krivova (1973) reports on a proposed $1.0 \mu \mathrm{A}$ ion current limit that is based on laboratory experimentation with a $5 \mu \mathrm{A}$ ion current.

In summary, the data base for bioeffects of DC electric fields is very limited. Al though the full body of research in the literature is greater than the examples cited here, no definite conclusions are possible and the suspicion remains that few of the studies deal with the electric field to the exclusion of other factors. The possible role of ion effects in these experiments has not been considered, nor has the possibility that ozone acts as a confusing variable been considered. As in indication of how limited the scientific base is, it is significant that no serious discussion of mechanisms has begun.

\section{Air Ion Sources, Interactions and Dilution Factor}

Now we turn to the issue that perhaps causes more concern: the air ions produced by DC fields. Naturally occurring sources of air ions are found in radioactive elements of the earth, radioactivity of the a tmosphere, cosmic rays, and by the motion of large masses of air, especially when a dry mass of air moves over a desert region as happens in 
Southern California, North Africa or in the Alpine region of Europe. Another source of air ions is the formation of water droplets which results in the removal of electric charge from the surface of the water and the production of a charged droplet. In this way air ions naturally occur near waterfalls and during rain formation. Air ions are also produced by natrually occurring corona such as that associated with lightning. In DC transmission at high voltage, the corona at the conductors is the source of air ions which can form a cloud-like concentration near to the conductors. Air ions are usually well hydrated, often more than $f i v e$ water molecules are associated with each negative ion, of which the oxygen ion $\left(\mathrm{O}_{2}^{-}\right)$, the hydroxyl ion $\left(\mathrm{OH}^{-}\right)$and the carbonic ion $\left(\mathrm{CO}_{\overline{3}}, \mathrm{CO}_{4}^{-}\right)$are cited as most significant (Krueger, Andriese and Kotaka, 1968; Goldman and Rivolier, 1976). Positive ion species are few in number: principally, the proton $\left(\mathrm{H}^{+}\right)$, carbon dioxide $\left(\mathrm{CO}_{2}^{+}\right)$and the hydronium ion $\left(\mathrm{H}_{3} \mathrm{O}^{+}\right)$, each hydrated. Because molecules other than water can also cluster about the ion, the chemistry can be more complex.

How could living tissue be affected by air ions? The exposed surfaces of the skin and the respiratory system are most likely target tissues, but what happens within the respiratory system is unclear. In experiments designed to show how many ions are retained, the retention rate is measured at 75 to $90 \%$ (Crandell and Bachman, 1968), so that the inspired ions stay within the body and introduce charge into the body. Penetration into deep lung tissue does not occur because there is so much surface area in the respiratory system. Thus, the sites of interaction are likely to be in the respiratory tract. Presumably, any systemic effects would be disseminated by the blood or lymphatic systems but local effects on the target tissues may be of concern because the airway tissues are important in reducing the impact of infectious agents and otherwise processing the air we breathe.

The greatest problem that arises in considering a physical mechanism for an interaction of air ions with biological matter is the enormous dilution factor: there are very, very few air ions in a cubic centimeter $\left(\mathrm{cm}^{3}\right)$ of air. The largest concentration experimentally obtainable is not much more than $10^{6}$ ions per $\mathrm{cm}^{3}$, which is a far greater concentration of air ions than in any natural situation. These ions are diluted by the $10^{19}$ 
other molecules which comprise a cubic centimeter of air. Thus, the dilution factor is at least $10^{13}$ to 1 , an astronomical number in comparison with ordinary toxicologic situations where dose ratios are often measured in parts per million or parts per billion. Despite the implausibly small concentration, it is important to note that each ion bears enough energy (several electric volts) to trigger or activate biochemical processes and, in principle, a significant biochemical effect might ensue. By comparison, ozone, which naturally occurs at about $5 \mathrm{ppb}$, is far more concentrated than any air ion, and its high degree of chemical reactivity is considered of potential health significance in certain situations at concentrations greater than fifteen times the natural level.

\section{Experimental Data on Animals Exposed to Air Ions}

Effects of air ions on the trachea of rabbits and guinea pigs were reported by Krueger and Smith (1960), and later, (Krueger, et. al. 1968), blood levels of 5-HT (serotonin) in mice were observed to decrease in the presence of negative ions at concentrations of about $5 \times 10^{5} \mathrm{~cm}^{-3}$, at which dose, in other studies, an increase in the oscillatory rate of the cilia of tracheal epithelium is seen. In the case of positively charged ions of about the same concentration, blood levels of serotonin are increased and ciliary beating is slowed. Similarly, the positive ions reportedly increased vasoconstriction and elevated the tissue respiratory rate while the negative ions had the opposite effects (Krueger and Smith, 1960). In these studies Krueger made use of the strong vasoconstrictive properties of 5-HT by pre-treating the samples, thus reducing the ciliary rate. Within a period of 1 to 4 hours the tissues treated with negative ions recovered a normal ciliary rate.

Attempts to replicate these experiments have generated controversy. Several groups of researchers (Guillerm, et. al. 1967; Kensler and Batista, 1966; and Anderson, 1972) replicated Krueger's work with contrary results. For example, Anderson observed no effect on the ciliary rate using ion concentrations about the same as those used by Krueger al though the study did not employ a 5-HT pre-treatment. However, in earlier work, Krueger reported a less dramatic change in ciliary rate without use of the pre-treatment technique. 
Despite this contrary evidence, Krueger's hypothesis that air ions alter serotonin levels is still regarded by many as a suitable hypothesis. Serotonin (5-hydroxytryptamine, or 5-HT) is a neural transmitter of special importance in the limbic system of the brain and particularly with regard to sleep regulation. It is locally synthesized elsewhere in the body, too, especially in the gastrointestinal tract and liver. Serotonin acts as a strong vasoconstrictor and it is found concentrated in thrombocytes. It also acts as a smooth muscle stimulant. In the central nervous system the effects of reserpine and LSD are altered by 5-HT. LSD is an antagonist of 5-HT so that at first LSD effects were attributed to its direct effect on serotonin levels in the brain.

Krueger and Smith (1960) hypothesized that positive ions increase levels of $5-\mathrm{HT}$ by blocking the action of monoamine oxidase (MAO), the enzyme that destroys 5-HT. The negative ions, it was believed, act to catalyze oxidation by that same enzyme thereby depleting the level of 5-HT. The evidence for this hypothesis is found in Krueger's work where, for example, positive ions at a concentration of $5 \times 10^{5} \mathrm{~cm}^{-3}$ affected blood levels of 5-HT. Mice exposed for a week to positive ions showed elevated blood levels of 5-HT, while those exposed to negative ions had depressed blood levels of 5-HT. A similar study with rat brain (Krueger and Kotaka, 1969) gave different results because both negative and positive ions depressed the levels of 5-HT in tissue.

In 1965 Frey performed a study which showed a decrease in lever pressing rates for rats exposed to negative ions - consistent with the claimed "tranquilizing" effect of negative ions. The interpretation of the experiment was that the rats were less anxious when exposed to negative ions although they still received an electric shock.

In an experiment relating to the serotonin hypothesis, Ta1, et. al. (1976) placed blood in a petri dish at room temperature and exposed it to either positive or negative ions. They found changes of about 30 to $40 \%$ which indicated that negative ions depressed 5-HT levels and positive ions increased those levels. Presumably this study examines thrombocytebound $5-\mathrm{HT}$, but the authors suggest that the erythrocytes also are involved 
in serotonin release.

Because it is reasonable to suggest an interaction between air ions effects and stress reactions which result in al tered steroid hormone levels, experiments utflizing swimming pool maze tests were conducted to examine rats under stress (Duffee and Koonte, 1965; Terry, et. al. 1969). One result was that 14-month old rats exposed to the negative ions showed an improvement in maze time whereas the control and positive ion exposed groups showed no appreciable change. But other aspects of the data appear less significant.

From a similar hypothes is others have investigated for the effect air ions might have on resistance to infectious agents. Using groups of 40 mice exposed intranasally to influenza virus Krueger, et. al. (1970) found that during the 7 to 16 days following innoculation the positive ion-exposed animals exhibited greater mortality, and thus, by the end of 16 days, 85 percent of the test animals had died whereas only 30 percent of the controls were dead. A number of similar experiments were conducted which, taken together, define a more complex picture because sometimes the effects occur earlier in the test period (at days 3-6) and in other cases the onset of effects was much delayed. Interestingly, the animals studied for effects of the deprivation of air ions (Felici, et. al. 1976) showed no important changes.

Studies of Human Beings Exposed to Air Ions

Finally, we consider the studies of humans exposed to air ions. In one case, U.S. Air Force pilots were tested early in the day by exposure for one hour to $10^{3}$ negative ions $/ \mathrm{cm}^{3}$; they were simultaneously exposed to an electric field of about $10^{3} \mathrm{~V} / \mathrm{m}$ (Barron and Dreher, 1964). The men showed no change in tests of performance. The authors comment that conducting tests on such highly trained, healthy individuals at $80^{\circ}$ 'clock in the morning was not the most sensitive test for a weak effect on performance. The complete data set included measurements of blood chemistry and standard clinical measures of physiological well-being 
with no indication of an effect by the ions or field. It must also be noted that the ion concentration utilized reported here is $1 / 100$ th that used in many other studies.

In other experiments with human beings, tests of athletic ability disclosed some effects for exposures to negative ion concentrations of $5.10^{4} \mathrm{~cm}^{-3}$ (Goldman and Rivolier, 1976). Thirty or forty men were exposed by inhalation and then asked to perform exercises. During three weeks of observation no effects attributable to air ions were found. However, when the air ion exposure was given following the exposure period, a short-term effect on the rate of change in respiration occurred so that the return to normal occurred faster among those who had been exposed, but no effect on heart rate was seen. Unexpectedly, one of the exposed athletes exhibited unusual endurance enabling him to run a second race immediately and with remarkably good performance. In another study of the human response to air ions, the subjects were exposed nightly for 8 hours for 5 nights to a concentration of $5 \times 10^{4}$ negative ions $/ \mathrm{cm}^{3}$. The results were interpreted as a demonstration of improved respiratory economy.

Hawkins and Barker (1978) report that humans exposed to negative ions at moderately low concentrations of $4.10^{3} \mathrm{~cm}^{-3}$ showed improvement in tests of task performance but those exposed to the positive ions were unaffected. The negative ion effect was small and became statistically significant only after corrections were made for the normal circadian pattern in task performance.

A major contribution to the literature on air ion effects involves the studies of people who are exposed to exceptional meteorologic conditions, such as the dry, positive-ion-bearing winds (the Santa Ana, Mistral, Chinook, Khinsin, or Foehn). Correlations are reported between behavior and meteorologic conditions associated with changes in air ion concentrations (Sulman, et. al. 1964, 1973; Muecher and Ungeheur, 1961). These changes precede any pressure or temperature changes. Positive ions appear to be "bad": suicide rates go up, accident rates go up, etc. In contrast, other data suggests that the negative ions may be beneficial (Goldman and Rivolier, 1976; Duffee and Koontz, 1965). 
In the Soviet Union Minkh (undated) reports that large concentrations of negative ions $\left(10^{5}\right.$ or $\left.10^{6} \mathrm{~cm}^{-3}\right)$ generally improve athletic performance, strength, reaction time, and endurance. Numerous measures of the urine and blood levels of vitamins were also made.

\section{Experimental Concerns}

Air ion experimentation is subject to a number of very serious problems that affect all these studies on humans and animals (Frey, 1965) and perhaps invalidate many. Rarely is it stated whether the subject was grounded, seriously undermining any claim to dosimetric accuracy or repeatability, nor is it reported how and where the ion measurements are made with respect to the subjects position. Nor is the normal convective air flow in the room described and only occasionally is the humidity adequately monitored or controlled. For these and other reasons it is doubtful that many reported exposure levels are accurate, and in some instances they could be in extreme error. Additionally, if the ion source produces corona the experiment may be confounded by the effects of ozone. In some of the early ion sources the positive and negative ions were not separated, so that recombination of the ions may have significantly altered the exposure to the subject.

\section{Conclusions}

What conclusions are available from the very preliminary data available on biological effects of air ions? There appears to be a remarkable uniformity of reports that negative ions in sufficient concentration have a slight beneficial effect especially in experiments at above $10^{5} \mathrm{~cm}^{-3}$, levels well above those in the normal atmosphere, where concentrations are below $10^{3}$ ions per $\mathrm{cm}^{3}$. Although a mechanism for effects is obscure, the serotonin hypothesis is plausible, although incomplete and unproven. It does not indicate the nature of the fundamental interaction and thus does not explain the purported efficacy of an agent so diluted by the other molecules of air. The suggestion that positive ions appear detrimental at high levels is best supported by some of the laboratory work on serotonin and tissue reactions, but considerable doubt remains. 
Before one can be reasonably confident of the purported effects, there is a strong need for corroborative data obtained under strict experimental safeguards and presented with vigorous statistical technique. Those data should also address the need for information on thresholds. To address the environmental questions related to the DC transmission line, experiments combining air ions and electric fields should also be considered. In addition, a complete investigation should examine for possible potentiation of drug effects, especially the mood altering drugs, if indeed air ions affect serotonin levels in the brain. Other questions which are unanswered concern the time course during which air ion effects are manifested, and determination of long term effects which may show either increased or decreased sensitivity. Finally, there are suggestions that certain individuals are particularly sensitive to the effects of positive ions, so that sufficiently large populations must be investigated to determine the range of sensitivity. 


\section{References}

1. Andersen, I. 1972. Effects of natural and artifically generated air ions on mammals. Int. J. Biometeor., 16 supp: 229-238.

2. Barron, C.I. and J.J. Dreher, 1964. Effects of electric fields and negative ion concentrations on test pilots. Aerospace Med., 35: $20-23$.

3. Bassett, C.A.L., R.J. Pawluk and A.A. Pilla, 1974a. Augmentation of bone repair by inductively coupled electromagnetic fields. Science, 184: 575 .

4. Bassett, C.A.L., R.J. Pawluk and A.A. Pilla, 1974b. Acceleration of fracture repair by electromagnetic fields: a surgically noninvasive method. Ann. N.Y. Acad. Sci., 238: 242.

5. Bassett, C.A.L., A.A. Pilla and R.J. Pawluk, 1977. A non-surgical salvage of surgically resistant pseudarthroses and non-unions by pulsing electromagnetic fields. A preliminary report. Orthopaedic Research Laboratories. Columbia University College of Physicians and Surgeons, New York, N.Y. 10032.

6. Becker, R.0. 1972. Stimulation of partial limb regeneration in rats. Nature, 235: 109.

7. Becker, R.O., C.A.L. Bassett and C.H. Bachman, 1964. Bioelectric factors controlling bone structure. In: Bone Biodynamics, $\mathrm{H}$. Frost, ed. Little Brown and Co., and Boston, p. 209.

8. Becker, R.0. and J.A. Spadaro, 1972. El ectrical stimulation of partial limb regeneration in mammals. Bull. N.Y. Acad. Med., 2nd Series, 48: 627 .

9. Carson, R.W. 1967. Antifatigue device works by creating electric fields. Product Engineering, pp. 52-55. 
10. Crande1 1, M.E. and C.H. Bachman, 1968. Retention of inhaled air ions by humans. Aerospace Med., 39: 972-974.

11. Duffee, R.A. and R.H. Koontz, 1965. Behavioral effects of ionizied air on rats. Psychophysiology, 1: 347-359.

12. Edwards, D.K. 1961. Influence on electrical field on pupation and oviposition in Nepytia phantasmaria stkr. (Lepidoptera: geometridae). Nature, 191, 976 and 993.

13. Felici, N., C. Sumeire, G. Carraz and H. Beriel, 1976. Does air ion deprivation have a lethal effect? In: Atmospheric Ions and Pollution, a Study Conference of the Society of Electricians, Electronics Engineers and Radioelectricians, March 11-12, 1976, Pau, France.

14. Fischer, B. 1973. Die bioklimatologische Bedeutung des elektrostatischen Gleichfeldes. Zbl. Bakt. Hyg. I. Abt. Orig. B 157: 115-130.

15. Frey, A. 1961. Human behavior and atmospheric ions. Psych. Rev., 68: 225.

16. Frey, A.H. 1965. Experimental controls and biological experiments with atmospheric ions. Aerospece Med., 36: 121-123.

17. Gertsik, K.A., N.S. Kislova, S.S. Klyamkin, Y.A. Morozov, V.N. Tolstopyatov and B.G. Yakobson, 1973. Protection from electric fields and aerial ions on very high voltage $D C$ transmission lines. In: Protection from the action of electromagnetic fields and electric current in industry, V.I. Filippov and Y.A. Morozov, eds. All-Union Central Scientific Research Institute of Work Safety, Moscow, 1973. DOE translation, p. 78.

18. Goldman, M. and J. Rivolier, 1976. Study of the biological effects of excess negative ionization. In: Atmospheric Ions and Pollution, 
a Study Conference of the Society of Electricians, Electronics Engineers and Radioelectricians, March 11-12, 1976, Pau, France.

19. Guillerm, R., R. Badre and J. Hee, 1966. Effects of light atmospheric ions on the ciliary activity of sheep and rabbit tracheal mucosa in vitro. C.R. Acad. Sci., (D) (Paris), 262: 669-671.

20. Hawkins, L.H. and T. Barker, 1978. Air ions and human performance. Ergonomics, 21: 273-278.

21. Jones, F. 1974. The effects of a positive electric field on the behavior of emotionally disturbed children. Ph.D. Thesis. University of Kansas. University Microfilms, Ann Arbor, MI. 183 pp.

22. Kensler, C.J. and S.P. Battista, 1966. Chemical and physical factors affecting mammalian ciliary activity. Amer. Rev. Resp. Dis., 93: 93-102.

23. Krivova, T.I., V.V. Lukovkin and A.V. Uakubenko, 1973. Effect of $D C$ electrical field on human organism. In: Protection from the action of electromagnetic fields and electric current in industry, V.I. Filippov and Y.A. Morozov, eds. All-Union Central Scientific Research Institute of Work Safety, Moscow, 1973. DOE translation, p. 78.

24. Krueger, A.P. 1972. Are air ions biologically stgnificant? a review of a controversial subject. Int. J. Biometeor., 16: 313-322.

25. Krueger, A.P., P.C. Andriese and S. Kotaka, 1968. Smal1 air ions: their effect on blood levels of serotonin in terms of modern physical theory. Int. J. Biometeor., 12: 225-239.

26. Krueger, A.P. and S. Kotaka, 1969. The effects of air ions on brain levels of serotonin in mice. Int. J. Biometeor., 13: 25-38. 
27. Krueger, A.P., S. Kotaka, E.J. Reed and S. Turner, 1970. The effect of air ions on bacterial and viral pneumonia in mice. Int. J. Biometeor., 14: 247-260.

28. Krueger, A.P. and E.J. Reed, 1976. Biological impact of smal1 air ions. Science, 193: 1209-1213.

29. Krueger, A.P. and R.F. Smith, 1960. The biological mechanisms of air ion action. I. 5-Hydroxytryptamine as the endogenous mediator of positive air ion effects on the mammalian trachea. J. Gen. Physiol., 43: 533-540.

30. Lavine, L.S., et. al. 1972. Electric enhancement of bone healing. Science, 175: 1118.

31. Lavine, L.S., et. al. 1974. Clinical and ultrastructural investigations of bone healing. Ann. N.Y. Acad. Sci., 238: 552-563.

32. Lott, J.R. and H.B. McCain, 1973. Some effects of continuous and pulsating electric fields on brain wave activity in rats. Int. J. Biometeor., 17: 221.

33. Marino, A.A., T.J. Berger, J.T. Mitche11, B.A. Duhacek and R. Becker, 1974. Electric field effects in selected biologic systems. Ann. N.Y. Acad. Sci., 238: 436-444.

34. Mayyasi, A.M. and R.A. Terry, 1969. Effects of direct electric fields, noise, sex and age on maze learning in rats. Int. J. Biometeor., 13: 101-111.

35. Minkh, A.A. (undated). The effect of ionized air on work capacity and vitamin metabolism. (no further identification).

36. Minkh, A.A., et. al. 1972. Characteristics of the physiological action of ionized air. Vestn. Akad. Med. Navk. SSSR., 27: 3-13. 
37. Mitche11, J.T., A.A. Marino, T.J. Berger and R.0. Becker, 1978. Effect of electrostatic fields on the chromosomes of Ehrlich ascites tumor cells exposed in vivo. Physiol. Chem. Phys., 10: 79-86.

38. Móse, J.R. and G. Fischer, 1970. Zur Wirkung electrostatischer Gleichfelder, wietere tierexperimentelle Ergebnisse. Arch. Hyg. Bakteriol., 154: 378-386.

39. Möse, J.R., G. Fischer and J. Porta, 1971. Die Wirkung des elektrostatischen Gleichfeldes auf den Sauers toffverbrauch der Mauseleber. Arch. Hyg. Bakteriol., 154: 549-552.

40. Muecher, H. and H. Ungeheuer, 1961. Meteorological influence on reaction time, flicker-fusion frequency, job accidents and medical treatment. Perceptual and Motor Ski11s, 12: 163-168.

41. Smith, S.D. 1974. Effects of electrode placement on stimulation of adult frog 1 imb regeneration. Ann. N.Y. Acad. Sci., 238: 500 .

42. Sulman, F.G., Y. Pfeifer and N. Hirschman, 1964. Effect of hot dry desert winds (sharav, hamsin) on the metabolism of hormones and minerals. Harokeach Haivri, 10: 401-404.

43. Sulman, F.C., Y. Pfeifer and E. Superstine, 1973. Adrenal medullary exhaustion from tropical winds and its management. Israel Journal of Medical Sciences, 9: 1022-1027.

44. Tal, E., Y. Pfeifer and F.G. Sulman, 1976. Effect of air ionization on blood serotonin in vitro. Experentia, 32: 326-327.

45. Terry, R.A., D.G. Harden and A.M. Mayyasi, 1969. Effects of negative air ions, noise, sex and age on maze learning in rats. Int. J. Biometeor., 13: 39-49. 


\section{DISCUSSION}

D. Humphreys: With regard to the Lott and McCain study of brain activity could you explain what the electrodes were doing? Were they applying the field or were they measuring the effect in the brain?

A. Sheppard: They were for measurement purposes. A pair of plate electrodes was used to apply the field.

R. Humphreys: I was hoping they weren't going to apply $10 \mathrm{kV} / \mathrm{m}$ with an implanted electrode.

A. Sheppard: The reason for making clear the issue about the electrodes is that the implanted electrodes are going to cause some field enhancement at the tip of the electrode located in brain structure. So, in that region, the field is not quite the same as for a $10 \mathrm{kV} / \mathrm{m}$ field exposure without implanted electrodes.

A. Valentino: I wonder what the time scale was?

A. Sheppard: The time scale was exposure for 90 minutes during which the increased activity peak spanned 8 minutes or so.

R. Phillips: I might give an update of dc research in the Soviet Union. I was over there in August, and the Research Institute at Kiev, which is a municipal hygiene laboratory, is now in the process of building a dc exposure system. Thus far they have had miserable results, with many problems. However, they are now ready to get into this in some detail, because they feel they don't have enough information to establish the standard over there, at least for the general population. Also, the group in Leningrad, which is doing work in Dr. Morosov's laboratory, is now preparing to do some dc studies. And, hopefully this next June at the Biolectromagnetics Meeting and URSI meeting in Seattle some papers will be presented on this. It is something to look forward to, I think.

M. Gillis: I always have trouble with Russian translations and it sounds like maybe you understand them, Asher. Could you explain what they mean by "increased functional lability?". 
A. Sheppard: In my understanding those words describe the situation in which regulatory processes that are controlled by subcortical portions of the brain, say, for example, the hypothalamus, are affected by an agent - the electric field in this case. The sense of the effect, whether an increase or decrease in some physiologic parameter, may occur due to a non-specific alteration in the regulatory mechanism. As far as I can see, the regulatory mechanism is not specified beyond the understanding that the CNS controls, say, blood pressure (and even blood composition) so that effects in which blood pressure or blood chemistry occur in both directions are understood as evidence for interference in regulatory mechanisms and they are not viewed as a contradictory effect involving some linear mechanism.

A. Frey: Back in 1960 I did an analytical review of the literature on air ionization. It looked like a very confused mess at the time. My general conclusion in the published review was that nobody really knew whether air ions had an effect or not because there were problems in experimental controls. About 1961, the Office of Naval Research funded me to look into the question of what effects air ions have. I started experimentation by looking at the controls that are necessary to use in air ion research. I found quite a few things that were necessary to use as controls: how the air ions were put into the environment, the loss of the ions to the walls, whether or not the subject was grounded, and many other things. My general conclusion was that maybe the air ions have an effect, but we don't really know. There were too many controls that were necessary that had not been used in the previously published experiments.

I reassessed the experimental data in the light of the controls and came up with the idea that maybe the serotonin mechanism, the 5-HT mechanism, was involved. Interestingly enough as we discovered later Krueger, working from a different standpoint altogether, with tissues, was coming up with the same idea at about the same time. I carried out a number of different experiments, one of which Asher has mentioned. It seemed to me that if the 5-HT mechanism was involved, then there would be some specific effects in the brain, which could be assessed rather easily and cleanly in a technique that is called the "conditioned-emotional response." In essence you have an animal who learns to 
push on a lever to get food. He bangs away on the lever very happily. Then you start sounding a buzzer from time to time for one minute and then give him a shock on the tail when it terminates. After a few repetitions of this, the animal gets a little upset when he hears the buzzer. He tends not to push the lever during the buzz. He has, what you might call, anxiety. If you then inject a tranquilizer into him, you find that he seems not to worry too much about the shock on the tail that is going to come. He continues to press on the lever. He still knows he is going to get hurt, but he doesn't really care any more. I ran a series of experiments using this technique, incorporating all the various controls for ions I had found. In an experiment with one group of rats getting the air ions, we found rather consistent results indicating that with the air ions the rats are kind of happy for they don't seem to mind getting shocked. This was with negative air ions. I also looked at some of the brain chemistry, but that is another story.

Let me make a comment on the Air Force study. It was well done, however, there is good reason to bel ieve they never got an air ion near the person. Again, it was a matter of controls. This area is a very, very tricky one. The controls are incredible and it is very easy to miss a control that is necessary.

There is good reason to believe in many experiments that people never got an air ion near the subject of interest. For example in my experimentation with rats, one of the things I had to do as a control was to wash the rats in Breck creme-rinse every three days or so. Because of the nature of the fur and the charge, you have to use Breck creme-rinse. We tested many creme-rinses and found that only Breck worked right, so it had the approriate electrical characteristics. Actually I got the active component of the Breck creme-rinse and used it. That is an example of some of the controls you have to use in the air ion game.

Aside from whether or not the air ions make you happy or sad, which I think is a relatively small problem, there is another aspect to the ions and that is how they attach to particulates and the implications of that. In essence the air ions are charged particles. Most of the particles are less than 1 micron in size. The particles one inhales depend very much upon the charge on a person's 
body, the fields about the person, and the charges on the particles. In the context of a dc line in an industrial area, where you have various groups of chemicals, there could be some implications which I don't think have really been looked into.

To bring out the nature of questions regarding particulates that can be used, I'll briefly sketch some experimentation in the olfactory area. There is a lot of controversy in the olfactory area of research and little reliability in experimental results. Because of the things I had done in air ion research it occurred to me that maybe there were some implications of air ions and electric fields for olfaction. I did a rather simple-minded physics paper that was published in the Psychologcal Bulletin in which I was able to show that you can get all kinds of results in terms of odor sensing, depending upon the nature of the charge on the person, the electrical field environment, the charge on the ordorants and whether the person is in an acrylic or PVC olfactometer. This air ion dependence holds also for what kinds of particulates a person will inhale, and where they will be deposited in the respiratory system.

In another experiment I studied the electrofactogram, the electrical signal generated by the olfactory tissue in the nose in response to odorants. There was a great deal of argument about the wave shape of the EOG. Different labs were getting all kinds of wave forms. I took the electrofactogram technique and I controlled the charge on the odorants, the electrical environment, the charge on the animal, etc. Then I showed I could generate every single wave form that was ever published depending upon how I manipulated the electrical characteristics of the set up.

I have also looked at what happens to charged particles as they move about in a space. I have used fluorescent powders, for example, and looked at them with uv lights to see how the particulates distribute themselves as I manipulated the field and the charges on them. I have also done some work using holography to look at particulates in a volume. Wild things happen as a result of space charge characteristics. I developed and worked with a laser light-scattering device looking at what happens in a room as we manipulate the charge. In fact, unexpected results sometimes occur. For example, one of the women in the lab 
had to wear a cotton lab coat instead of a dress one day. Her dress was made of a synthetic fabric. It disrupted the electric field in the room in which we were making particle measurements whenever she walked in the hall outside the room. This field disruption caused gross changes in our particle measurements. These are the kinds of things you have to worry about in terms of controls.

The question was raised about aspiration type devices for measuring air ions: this is a real headache. I have worked with parallel plate devices, Becker probes, etc., and you get all kinds of wild, erratic field effects and measurements. Ted Rich and I designed a measuring device which was an aspiration device, but rather different from the usual parallel plate device. Once we started measuring with our instrument we got some very interesting results that we could never see with the other devices because they were so unstable.

These devices called air ionizers are starting to be sold again. In general, none of them do any good because the way these toys put air ions in a room, is like filling a sieve. But, we are going to run into some real problems; there is going to be a resurgence of emotionalism; claims and counterclaims for health effects of air ionization. The dc lines will inevitably be drawn into this morass and the public will be confused.

In sum, we may have direct effects of dc line air ionization on the biological organism and indirect effects via the control they can exert on pollutants, contaminants, etc. In addition, when the issue of dc line construction comes to public notice, it is likely that old arguments and strong emotionalism will surface about air ion generators having health effects, good and bad.

J. delorge: Why did you wash your rats?

A. Frey: If you take a rat with a nice fur coat and have him in a chamber where he can rub and build up a highly variable charge on him, that can create some problems in terms of the controls. If we washed both experimental and control rats, we pretty well eliminated that charge buildup and had that as a stable factor.

J. Grissett: I have a comment going back to the high voltage experiments in a dc field. I think it is pretty clear that if we do such an experiment in a 
conducting cage that you simply are going to get separation of charges on the cage and you are going to have a zero field inside. But if you work with a plastic cage, which is completely insulated, it seems to me that you have another problem whose effect is similar, but the phenomenon is quite different. The ions inside the cage, which are coming in from outside are generated by the animal burrowing in nesting material, are going to separate themselves and collect on the upper and lower surfaces or the side walls of the cage. Eventually, thie ions should effectively cancel out the field inside the cage. Assuming that his is true, then I would like to ask Asher if, in his review of the literature, this kind of thing was taken into account. Were completely enclosed plastic cages with appropriate ventillating holes used?

T. Michel: Yes. It is true. We have done some work with experimental animal cages in the past. Plastics, expecially acrylics, polymers and polycarbonate (Lexan) take extremely high bound surface charges, and you get charge separation. The answer is: don't make your cages out of plastic. Wood is a very good construction material because you can control its conductivity quite easily. Charge separation gets to be even more of a problem when there is dust in the air. It depends on the support medium for the animal. If there is a wire mesh bottom with any kind of a woody type material, then there can be dust in the air. In addition, the animals chew their food, their nares, and they put more dust in the air. Unless you have positive ventilation as well as good ion control, measuring the input and the affluent air both at the same time, you can really get confused as to what ion dosage your animals are getting, if any.

J. Grissett: So you are saying that wood would be an acceptable material because it would bleed off the charge slowly and not act as a highly conductive material.

T. Michel: Yes, wood would bleed off the charge much better than plastic. When you have a high voltage, high gradient situation, the resistors are all nonlinear. Depending upon which materials you choose, you will get different kinds of surface voltage effects and current bleed-off effects.

A. Sheppard: I am equality disturbed by the problems with the bound charge on the plastic surfaces. The only reference in any of the experimental literature 
was Krueger commenting that he found it took a considerable amount of time for plastic to equalibrate its bound charge. I believe the time he mentioned was on the order of hours. He was aware of the problem but it wasn't a focus of any investigation that I could see, just an experimental aside.

J. Grissett: The one particular experiment where I remember that you specifically mentioned a plastic cage was Marino's experiment. I believe that was a longer term experiment involving a time in which I would expect equilibrium to be reached, if in fact he did use an enclosed cage. If it were an open cage, it would be a different story.

R. Finger: I would say, from the volume of study work, we have accumulated and from what Tom said, that you would be grossly dissatisfied trying to seek an answer to the question of controls for bound charge. No one accounts for fields, field effects, ions, or atmosphere disturbances as a result of the materials they use in their study chambers. Also, the quality of the air ion detectors and instrumentation, prior to a few years ago, was questionable. There was considerable doubt regarding what it was measuring, where it was measuring, and how it was measuring. If you want to also question the nature of the corona discharge devices which people used, maybe not the tritium sources, you need to ask whether there was or was not output from the device. And if there was, what was the distribution of ions.

J. Grissett: Is it reasonable then to assume that we are not ready to really do some good biological experiments until we get this caging problem solved?

T. Michel: No. Caging is not a problem. (See discussion by T. Michel following paper by J. Decker.)

M. Gillis: This is an anecdotal observation which deals with this topic. Frank Hungate is studying the genetic effects of dc fields using both drosophila and bacteria. They are placed between two copper plates that are held apart by a lucite spacer. He put adult flies in a sealed plastic bottle and put them between the plates. When we turned on the field we noticed their wings came up,--which we expected in the very high field. The wings came up and they couldn't get them down. They kept brushing them with their hind legs and they were very agitated. It took about 3 hours for them to get their wings down, 
but they finally did get them down. When we shut off the power, the wings came back up. So this 3 hour figure that we observed, which is very rough, sort of agrees with what you said.

J. Grissett: This is really the first time I have been exposed to a review of the air ion literature like this, and there must be something I am missing here completely, which I honestly would like somebody to clear up for me. Any aqueous phase medium in the body is going to have a lot of ions in it: sodium, potassium, and so on. I am just at a loss to see what adding a few more ions for its charge content is going to do to that situation, unless we are really talking about a particular species of molecule whose distribution is being affected by the air ions. However, I hear very little discussion about the species of ion; so far just air ions have been discussed without regard as to what they are.

T. Miche1: Relevant to that question, there was an article in Science three weeks ago about the electrostatic transport of enzyme sight activity within cells. What they are saying is that there are electrostatic phenomena within the cell and without the cell that influence both the velocity of chemical propagation, i.e., the thermodynamics of the chemical reactions, and the phase or the boundary conditions under which chemical reactions occur. Now if you take free ions, energy quanta from the atmosphere, and introduce them into the lung, you are changing the electric balance of the cell system that you are working with. It doesn't make any difference, what kind of ion you are dealing with: sodium, potassium, calcium, or some steriod. In a cell that is reacting with an enzyme,--that really doesn't make any difference. You are putting energy into that system, and if you are changing the driving forces which make those chemical reactions run, then there is going to be an influence due to the ions on that cell system. This is just a hypothesis, from my point of view.

J. Grissett: But isn't the quantity of ions which you are adding miniscule compared to the quantity that is already there?

T. Michel: Not necessarily. You have two alternatives, you can talk about atmospheric levels of inhalation, $1 \times 10^{7}$ ions $/ \mathrm{cm}^{3}$ to $2 \times 10^{3} \mathrm{ions} / \mathrm{cm}^{3}$, or 
you can talk about, and I hesitate to use this term, "therapeutic dose" which might be $3 \times 10^{7}$ ions $/ \mathrm{cm}^{3}$. The latter no longer is a miniscule amount of charge. You are talking about nanoamps of ion current entering the body directly, perhaps.

J. Grissett: But the number of ions already there is so much larger: we are talking about millimoles of ions available in the aqueous phase.

T. Michel: But the reactions inside the cells and on the cell surface membrane don't take place in terms of millimoles. They take place in terms of numbers of molecules.

J. Grissett: That is my point entirely. The number of molecules already there to react, if charge is the only thing we are concerned with, is extremely large compared to what we add. This is the old argument of why worry about a little bit of energy when $k T$ is already so high. I am rephrasing the argument: why worry about a few ions when we already have so many.

A. Frey: I don't know what the mechanisms are and I thirk to a certain extent this is a fruitless discussion at this stage of the game. We are making the assumption here that we know more about biology than we really do by saying: here is what I can tell you about the charge in the body, therefore why should these exterior charges make any difference. In that context it could be perfectly true. However, there is so much we don't know in biology that we may not even be asking the right question.

B. Scott-Waiton: It seems to me that the lifetime of these lons must be very short in biological systems. If you put an ion in the lung, immediately the charge becomes free. It runs to the outside surfaces of the body. If you have ions inside your lungs, there may be a relative field between your lungs and the outside of your body, but the ions are not going to do much inside your system. They become unionized very quickly, unless I am quite wrong.

D. Poznaniak: I am vaguely famillar with another study that Asher did not mention, which was done by Krueger. He did studies to try to determine the effects of the polarity of the ions on plant growth. I believe he arrived at the conclusion that negative ions led to enhanced growth, and positive ions 
led to depressed growth in plants. However, if you examine his experimental design a little bit more closely you find that the carrier molecules that he used were his negative ions which I believe, were oxygen molecules, and the carrier molecules that he used for the positive ions were carbon dioxide or oxygen when he was conducting the various studies to determine the effects of negative or positive ions. So I question whether the effects that he found were due really to positive or negative ions, or whether they were due to artifacts: the enrichment of oxygen, the enrichment of carbon dioxide. There were several other experiments described today about which we didn't get enough information. It is difficult to really tell whether the effects that were noted were truly due to positive or negative ions or if they were due to some other artifact.

M. Gillis: I think that the dilution factor comes up in this work again. The number of oxygen or carbon dioxide molecules that $\mathrm{Dr}$. Krueger used was less than $10^{-11}$ of those that were already there. Again, a vanishingly small amount, so he didn't really supplement the atmosphere with either one.

R. Finger: The work that he did indicated that both under negative and positive ionization there is plant growth enhancement. It was not limited to negative being beneficial and positive being not beneficial. The comments that have been raised are comments that have been raised continuously about his work by outsiders who believe that trace gas elements are responsible for the changes that took place. His study atmospheres were similar, and the data which he has produced to people who have raised that question, substantiates that the only difference of any significance was the air ion concentration and its polarity. The data on biological effects that was presented here is very, very limited. There are a number of studies which indicate that the presumed biological effects of the air ions are much broader and much greater than what was demonstrated here today. But let me caution you that the use of the word "presumed" is well taken in this regard. These studies vary from metabolism issues through work performance, into serotonin, into respiratory response in children, and into plant turgidity. There has been work done in deionized atmospheres as well as ionized atmospheres. There is a great body of information in the 
1iterature which directs itself not only to biological effects in human beings, but also in plants and in animals. We ourselves have done a number of projects in plant growth and stimulation, and at one time had 18 piers of greenhouses operating in a controlled study project to see what changes took place horticulturally and agriculturally. The indications are that there can be some rather dramatic results that are worthwhile pursuing. 


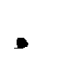

. 
4. NEEDS OF UTILITIES FOR INFORMATION ON BIOLOGIC EFFECTS OF HVDC TRANSMISSION AND THE ROLE OF ENVIRONMENTAL STUDIES

Jack M. Lee, Jr.

Bonneville Power Administration

Portland, Oregon 
. 


\section{NEEDS OF UTILITIES FOR INFORMATION ON BIOLOGIC EFFECTS OF HVDC TRANSMISSION AND THE ROLE OF ENVIRONMENTAL STUDIES}

Jack M. Lee Jr.

Bonneville Power Administration

Portland, Oregon

\section{INTRODUCTION}

An upsurge in public and scientific interest in transmission lines has occurred in recent years. In the U.S. there are probably few, if any, places where a utility or power company can construct an EHV (extrahigh-voltage, above $230 \mathrm{kV}$ ) transmission line without drawing some opposition. The nature and intensity of the opposition can vary greatly by locale. Issues which are raised can concern every aspect of the design, location, construction, and operation of the line. Seldom is only one issue raised and it is often difficult to determine just what the real issues are. When several interest groups attempt to influence the location of a line the more "ammunition" which can be brought to bear, in the form of issues raised, the greater the chance a group will prevail.

This is not to imply, however, that legitimate concerns and issues should not continue to be raised. It does mean, however, that utilities 
face an increasingly difficult job in determining how much emphasis should be placed on developing data for responding to the various concerns.

One of the most visible issues presently confronting utilities is the possibility of adverse biologic effects resulting from transmission line electric and magnetic fields. Although this issue has some unique aspects, it also has close similarities to interest which has developed around a number of subjects having known or potential adverse environmental effects. Examples include chemical pesticides, food additives, ionizing radiation, and microwaves. In all of these, some controversy has arisen among the scientific community and the public as to interpretation of available data for predicting the environmental costs of the technologies associated with each of these subjects. HVDC transmission promises to be no exception to this trend.

In this presentation I would like to briefly outline some of the important aspects of the topic of "biologic effect" for transmission lines in general and $d-c$ transmission lines in specific. I will then describe some basic information needs pertaining to this topic from the viewpoint of an environmental specialist with a power marketing agency. I hope that the needs and experience of BPA will be somewhat representative of utilities in general. Last, I will outline the basic approach in designing and conducting environmental studies of transmission lines. Following this presentation Mr. John Decker will discuss laboratory studies including considerations and problems associated with simulating the HVDC transmission environment. 


\section{BACKGROUND}

In brief, the controversy over the existence of adverse biologic effects due to electrical factors of a-c transmission lines and substations, can be attributed to four main sources. These are: 1) Soviet reports about health problems of EHV substation workers (Asanova and Rakov, 1966), 2) popular literature critcal of ways transmission lines are constructed and operated (e.g. Young, 1973), and 3) some laboratory studies which attributed adverse biologic effects to electric field exposure (e.g. Marino et al., 1976). The above factors were largely responsible for the extensive hearings in New York State over the possible health and environmental effects of $765 \mathrm{kV}$ transmission lines. A continuing flow of newspaper and magazine articles has served to bring the subject of transmission lines to the attention of the public. A parallel situation could develop for d-c lines.

To date most concern has been over a-c transmission lines no doubt due to the fact that relatively few $d-c$ transmission lines have been constructed. In 1977, only two d-c transmission lines were in operation in the U.S. These were the $1,354 \mathrm{~km}$ long Celilo-Sylmar $+400 \mathrm{kV} \mathrm{d}$-c line in Oregon and California, and the $\pm 250 \mathrm{kV}$ MP\&L/Minnkota Square Butte line in Minnesota. A second $d-c$ intertie is planned for construction near the Celilo-Sylmar line and $\mathrm{a} \pm 400 \mathrm{kV}$ line was recently constructed from Underwood, North Dakota to Delano, Minnesota. This latter line drew nationwide attention because of intense local opposition to the line in 
some areas (Banks et al., 1977; Ames 1978). Hingorani (1978) cited a total of 16 overhead $d-c$ transmission lines worldwide.

One of the few areas of common agreement regarding the issues described above, is the need for additional data on the effects of transmission lines. Past this, however, there is still some disagreement as to who should conduct the objective and unbiased research necessary to obtain these data. To date, almost all research pertaining to transmission lines has been for a-c lines. Some laboratory studies have been done on the biologic effects of $d-c$ electric and magnetic fields and ions. Few studies, however, have been designed specifically to duplicate all or part of the electrical environment of an HVDC transmission line. One environmental study of an HVDC transmission line has been conducted (Griffith, 1977), and a study of human perception of transmission line audible noise sponsored by DOE and NBS is considering noise from a-c and d-c lines.

\section{INFORMATION NEEDS}

The need for information on the possible biologic effects of HVDC transmission facilities can be attributed to requirements of numerous Federal and state environmental and regulatory laws. For example, as a Federal agency BPA is required to prepare environmental statements on all major projects as required by the "National Environmental Policy Act of 1969." Non-federal agencies may be subject to requirements of State facility siting commissions, and also in many cases must go through extensive procedures to meet requirements of certain Federal agencies. 
In most of the above, provision is made for public review and comment on proposed transmission projects. The amount of public interest and comment generated can vary greatly by project. In addition, the nature and sophistication of the comments may be highly variable. At BPA we generally provide a written response to all substantive comments received.

Because of the wide subject range covered by comments, considerable data are required to adequately respond to them. Much of the data can be obtained from past research or operating experience. At other times, however, additional research is required. I would like to point out that the comment-response process is not an end in itself. Comments from the public, and from other agencies and utilities, often contain valuable information which can influence design, location, or operation of a proposed facility.

In brief, the total impact of a transmission facility is of interest. Information obtained on construction and maintenance impacts of a-c transmission lines can largely be applied to d-c lines. Information from a-c environmental studies, however, cannot provide data for addressing questions about the effects of $d$-c electric and magnetic fields and ions. Information on these parameters must come from both environmental and laboratory studies.

To be usable by utilities, laboratory studies must be designed to be relevant to the environment of an HVDC transmission line. Although it may be desirable to isolate one or more parameters i.e., ions, for initial study a complete program should include provision for study of 
combined related parameters e.g., ions plus electric and magnetic

fields. For example, in a study of birds the possible effects of coronagenerated audible noise in combination with electrical factors would more closely represent actual exposure conditions. The effects of mini shocks, which occur to animals in a natural environment, should also be factored into the design of laboratory studies.

In addition, the selection of test organisms should be relevant. Information is needed, to assess the potential for effects on people, wildlife, and plants. A study of rodents for example may provide information for initially assessing potential effects on people, however, rodents in a natural environment may be largely shielded from electric fields by vegetation. Larger animals, such as cattle, may be more appropriate test subjects as these animals are more exposed to the electrical environment.

For both laboratory and environmental studies it is important that the research be conducted using a sound scientific approach so the results are credible. This includes the use of an interdisciplinary team in both the design and conduct of the study. 
ENVIRONMENTAL STUDIES

The Approach

Regarding "existing environment" studies Bridges (1975) observed, "such studies have the advantage of providing useful answers in a relatively short time and are also satisfying from a pragmatic and practical viewpoint. Such studies also automatically take into account the total. environment produced by transmission lines and the actual exposures involved."

A paper presented during the Hanford Biological Symposium which preceded this workshop (Lee et al., 1978) addressed the relationship between effects due to transmission line construction and maintenance activities and effects due to electric and magnetic fields. Although that paper was concerned primarily with a-c lines it has some application to d-c lines. Regardless of line type (a.c. or d.c.), ultimately, information is needed on the overall impact of the line.

One important point when considering $d-c$ and a-c transmission lines is that the former produces electric and magnetic fields which are of the same nature as the earth's field. From birth, plants, animals, and people live in an environment which contains natural d-c fields. Some animals have apparently developed mechanisms for detecting subtle changes in natural electric and/or magnetic fields. At present it is difficult to say how natural $d-c$ fields may influence plants and animals and how artificial d-c fields may interact with these. 
As used in this presentation, environmental studies will include those conducted near an operating or test HVDC line which may involve plants, animals, and land use. Environmental studies generally follow one of two basic approaches: 1) a "before and after" study in which baseline data are collected prior to construction and compared with data collected following energization, and 2) a "treatment and control" study in which data collected in treatment areas (right-of-way) are compared with data from similar control access (off right-of-way) (e.g. Goodwin, 1975; Griffith, 1977). Some studies may be designed to utilize both of these basic approaches (e.g. Rogers et al,,1979). A primary consideration in the design of these studies is to allow for effects due to climate and other factors which may vary greatly from site to site. Ideally, treatment and control areas should be identical except that the treatment area contains the transmission line. In actual situations ideal study areas are seldom found and some provision for site differences must be made. One technique is the use of a ratio (e.g. treatment/control) in testing for differences between treatment and control areas over time.

The selection of control areas depends in part on the transmission line parameters which are being investigated. For example, to obtain data on the overall impact of a line, a control area would consist of a site having characteristics similar to what existed on the site where the line is located, prior to its construction. To study effects of the transmission facilities, a control area would contain a road similar to the transmission line access road, be in similar habitat, and if forested, have a cleared right-of-way of similar width as that of the line rightof-way. 
Effects of corona and/or electric and magnetic fields on animal behavior could be studied if a transmission line could be periodically de-energized for short periods of time. In reality this is probably not practical. Another possibility is to study lines of similar construction and located in similar habitat but operating at different line voltages. This is difficult because there are so few $d-c$ lines in existence.

A variation to the above would be to plan studies to concide with a scheduled voltage upgrading of a line. Of course if a test line is available where voltages can be varied and the line easily de-energized these problems would be solved. However, such lines may lack a magnetic field component of equivalent magnitude as an operating line.

Separating possible effects of audible noise from those of the electric field, poses additional problems because varying the line voltage would affect both these parameters. One possibility is to study lines with similiar voltages but with different conductor configuarations and corona characteristics. Alternatively, different conductor configurations could be utilized on the same line. As before a test line may be needed for this approach.

Regardless of the approach, considerable intrepation will probably be required to determine the parameters responsible for effects observed in environmental studies. 
As Dr. Bracken pointed out in his presentation earlier today, the electrical environnent of an HVDC transmission line is extremely complex. Exposure considerations involving plants and animals must include not only magnitude and duration but also spatial fluctuations of electric fields and ion concentrations. Study sites in even close proximity may vary considerably due to effects of localized wind conditions. Dr. Bracken has also described some interesting perception effects he and fellow researchers experienced during their studies at $\pm 500 \mathrm{kV}$, i.e. effects on body hair. It is not known whether similar effects would be experienced by livestock or wildlife near such a line. Although the environmental study described below did not specifically include livestock, cattle and horses were frequently observed on the right-of-way of the $\underline{+}$ $400 \mathrm{kV}$ line. Casual ovservations of livestock would probably not yield information on possible behavorial effects which may result from the effects of the electric field. Additional research would seem to be warranted to determine the possible significance of such behavorial effects on people and animals.

\section{CASE STUDY: ENVIRONMENTAL STUDIES OF THE}

$$
\text { CELILO-SYLMAR D-C INTERTIE }
$$

A study of the Celilo-Sylmar $\pm 400 \mathrm{kV}$ line will be discussed as an example of an application of the approaches described above. The Celilo-Sylmar line which extends from near The Dalles, Oregon to Los Angeles, California was energized in 1970. A literature review and research plan for studying the environmental effects of the line was completed by BPA's Biological Studies Task Team in early 1976. A study 
was designed to provide information to support an environmental analysis which was to be prepared for a proposed second $d-c$ intertie line. The study approach was to establish study areas on the d-c line right-of-way and in control areas off the right-of-way.

Field work was started by BPA personnel. Mr. Brad Griffith, an intern with the Western Interstate Commission for Higher Education was sponsored by $\mathrm{BPA}$ to review the study plan and collect and analyze data on the project. The intern was supported by a BPA interdisciplinary advisory committee. Such support was especially necessary to insure that the complex electrical characteristics of an HVDC line would be given proper consideration during the study. The study which concluded in July 1977, is described in a final report (Griffith, 1977) and preliminary results were described in one published account (Lee and Griffith, 1978).

The study involved natural vegetation, crops, and wildlife. In Oregon, the $\mathrm{d}-\mathrm{c}$ line is located in crop land, range land, and high desert country. The researcher who conducted the study camped near the line during much of the time and spent thousands of hours working and living on and near the right-of-way. Results of the study indicated most effects detected during the study could be attributed to construction and maintenance activities (Griffith, 1977.) I believe that if effects due to the electric or magnetic field were present they were either 1) too subtle to detect by the methods employed, 2) masked by other effects, or 3) were inadvertently attributed to construction or maintenance activities. 
Results of the study showed that construction related impacts on natural vegetation were still evident even in the sagebrush habitat, 8 years after construction. Impacts were greatest in the juniper/sagebrush habitat. There, juniper and sagebrush were less abundant on the rightof-way than in control areas and weedy annuals such as cheatgrass were more abundant on the right-of-way (Figure 1).

Some differences were noted in bird and small mammal populations on and off the right-of-way, although the differences were generally not statistically significant. Species such as the sage thrasher which prefer more undisturbed habitats were slightly more abundant on the control areas than the right-of-way. Other species such as the Townsend's ground squirrel which are attracted to more open or disturbed areas were more abundant on the right-of-way. Aerial surveys and fecal pellet group counts were used to study deer and antelope use of the right-ofway. These species showed no strong positive or negative responses to the right-of-way. Raptors (hawks and eagles) were observed to make extensive use of the d-c transmission line structures for perching and to a lesser extent for nesting (Figure 2).

A study of wheat growing on and off the right-of-way had the greatest potential for isolating possible effects due to the electric field (Figure 3). However, there were no significant effects of the d-c line on mean plant height, productivity, or seed viability. An interesting aspect is that the farmer who owned the wheat field where the study was conducted told us that he had noticed different wheat growth patterns after the line was constructed. He attributed the effects to soil compaction caused by 
construction equipment and indicated the effects were not apparent a few years after construction.

Cattle and horses were often observed under the $d-c$ line. At times this was because some ranchers used the transmission line access road to distribute feed to their livestock. There were a number of feed and water troughs along the right-a-way. In this situation animals were purposely attracted to the right-of-way. Many other times, however, we observed livestock either resting directly under the conductors or grazing. In the sagebrush area, livestock often congregated around towers which provided the only shade available for miles around.

The existence of positive (beneficial) effects of a transmission line such as described for livestock and raptors need to be acknowledged when considering possible adverse effects. Responses of laboratory animals to $d-c$ fields or ions in controlled environments may differ greatly from those of animals exposed to a HVDC line in a complex natural environment.

Systematic interviews of persons who lived or worked near the $d-c$ line were to have been a part of the environmental study. Because of restrictions on the use of "public opinion" surveys by Federal agencies such interviews were not conducted. This was unfortunate because properly designed and conducted studies of this type can provide very useful information.

The value of obtaining information from persons who have first-hand knowledge about living near the $d-c$ line was demonstrated about 1 -year 
after the environmental study was completed. A large group of landowners and others involved in the controversy over the CPA/UPA d-c line in Minnesota visited Oregon and California to talk with persons who lived near the Celilo-Sylmar d-c line.

The results of the 1-year ecological study supplemented by a review of pertinent laboratory research (Biological Studies Task Team, 1978) were to form the data base for responding to comments received on the environmental analysis for a second $d-c$ intertie line. Shortly after the study was completed, construction of the second line was deferred. Consequently the environmental analysis was not issued for public and agency review. When and if the second line is constructed we anticipate questions on biologic effects to be raised. This is based on our experience with a-c lines and on developments surrounding the construction of the $d-c$ transmission line in North Dakota and Minnesota.

\section{CONCLUSIONS}

To provide information most usable by the utility industry, laboratory studies should be conducted under conditions which simulate the electrical environment of an HVDC transmission line. Exposure conditions and test organisms should reflect the need for information on possible effects of HVDC on people as well as on wild and domestic animals and plants. These studies require a strong interdisciplinary approach and must be based on sound scientific principles to yield credible results. 
Environmental studies will continue to be required of both a-c and $d-c$ transmission lines to obtain information on environmental effects due to construction and maintenance activities. These studies can also be designed to detect certain kinds of effects which may be attributable to electric and magnetic fields. In addition, by conducting or sponsoring such research a utility is demonstrating they are actively doing something to respond to public concerns. The position of waiting for someone else to report adverse effects which may have occurred on a utilities rightof-way is proving to be undefensible in the public's view.

The design and conduct of environmental studies involving d-c transmission lines will require even greater emphasis on interdisciplinary aspects then required for a-c lines. It is essential that the complex HVDC environment be considered when interpreting results of environmental studies.

Presently at BPA, we have no immediate plans for sponsoring additional environmental studies of $d-c$ transmission lines. A number of factors could influence the need to conduct such studies. They include, 1) information that would indicate adverse effects are occurring with existing $d-c$ lines, 2) a proposal to construct a new d-c line in areas substantially different from that where our existing d-c line is located, 3) a proposal to construct a d-c line having an operating voltage significantly higher than the existing line, or 4) increased public interest or concern over the possible effects of the exisitng d-c line. At this time I am not aware of any environmental studies planned for $d-c$ transmission lines elsewhere. 
At BPA we believe there is a need to continue work on defining the electrical environment of HVDC lines. There is also a need to begin laboratory research to determine at what levels d-c electric and magnetic fields and ions may produce effects in animals and plants. In the next presentation Mr. John Decker will discuss considerations in designing and conducting laboratory studies involving animals and the HVDC environment. 


\section{REFERENCES}

Ames, S. 1978. Tail of The Dragon. Rain. August/September. pp. 811.

Asanova, T. P. and A. I. Rakov. 1966. The State of Health of Persons Working in Electric Field of $400-\mathrm{kV}$ and $500-\mathrm{kV}$ Switchyards. Hygiene of Labor and Professional Diseases, 5.

Banks, R. S., C. M. Kanniainen, and R. D. Clark. 1977. Public Health and Safety Effects of High-Voltage Overhead Transmission Lines: An Analysis for the Minnesota Environmental Quality Board. Minnesota Department of Health. Minneapolis.

Biological Studies Task Team. 1978. Electrical and Biological Effects of Transmission Lines: A Review. Bonneville Power Administration, Portland, Oregon. 75 pp.

Bridges, J. E. (Principal Investigator) 1975. Final Report to Electric Power Research Institute for RP 381-1. I -- Biological Effects of High Voltage Electric Fields: State-of-the-Art Review and Program Plan. IIT Research Institute. Chicago, Ill.

Goodwin, J. G. Jr. 1975. Big Game Movement Near a 500-kV Transmission Line in Northern Idaho. Western Interstate Commission for Higher Education for Bonneville Power Administration, Portland, Oregon. $56 \mathrm{pp}$. 
Griffith, D. B. 1977. Selected Biological Parameters Associated with a $\pm 400-k V d-c$ Transmission Line in Oregon. Western Interstate Commission for Higher Education for Bonneville Power Administration, Portland, Oregon. $94 \mathrm{pp}$.

Hingorani, N. 1978. The Reemergence of $d-c$ in Modern Power Systems. EPRI Journal. 3:7-13.

Lee, J. M., Jr., and D. B. Griffith. 1978. Transmission Line Audible Noise and Wildlife. Pages 105-168 in J. L. Fletcher, and R. G. Busnel (eds.). Effects of Noise on Wildlife. Academic Press, New York, 305 pp.

Lee, J. M., Jr., L. E. Rogers, and T. D. Bracken,. 1978. Electric and Magnetic Fields as Considerations in Environmental Studies of Transmission Lines. Proceedings of the 18th Annual Hanford Life Sciences Symposium, Richland, WA, October. NTIS, Springfield, VA, January $1980 . \quad$ CONF-781016.

Marino, A. A., R. 0. Becker, and B. Ullrich. 1976. The Effect of Continuous Exposure to Low Frequency Electric Fields on Three Generations of Mice; A Pilot Study. Separatum Experientia 32:565-566. 
Rogers, L. E., R. O. Gilbert, J. M. Lee Jr., and T. D. Bracken. 1979. BPA 1,100-kV Transmission System Development - Environmental Studies. Paper presented at the 1979 IEEE Winter Power Meeting, Feb. 4-9, New York.

Young, I. B. 1973. Power Over People. Oxford University Press, Inc. New York. 216 pp. 


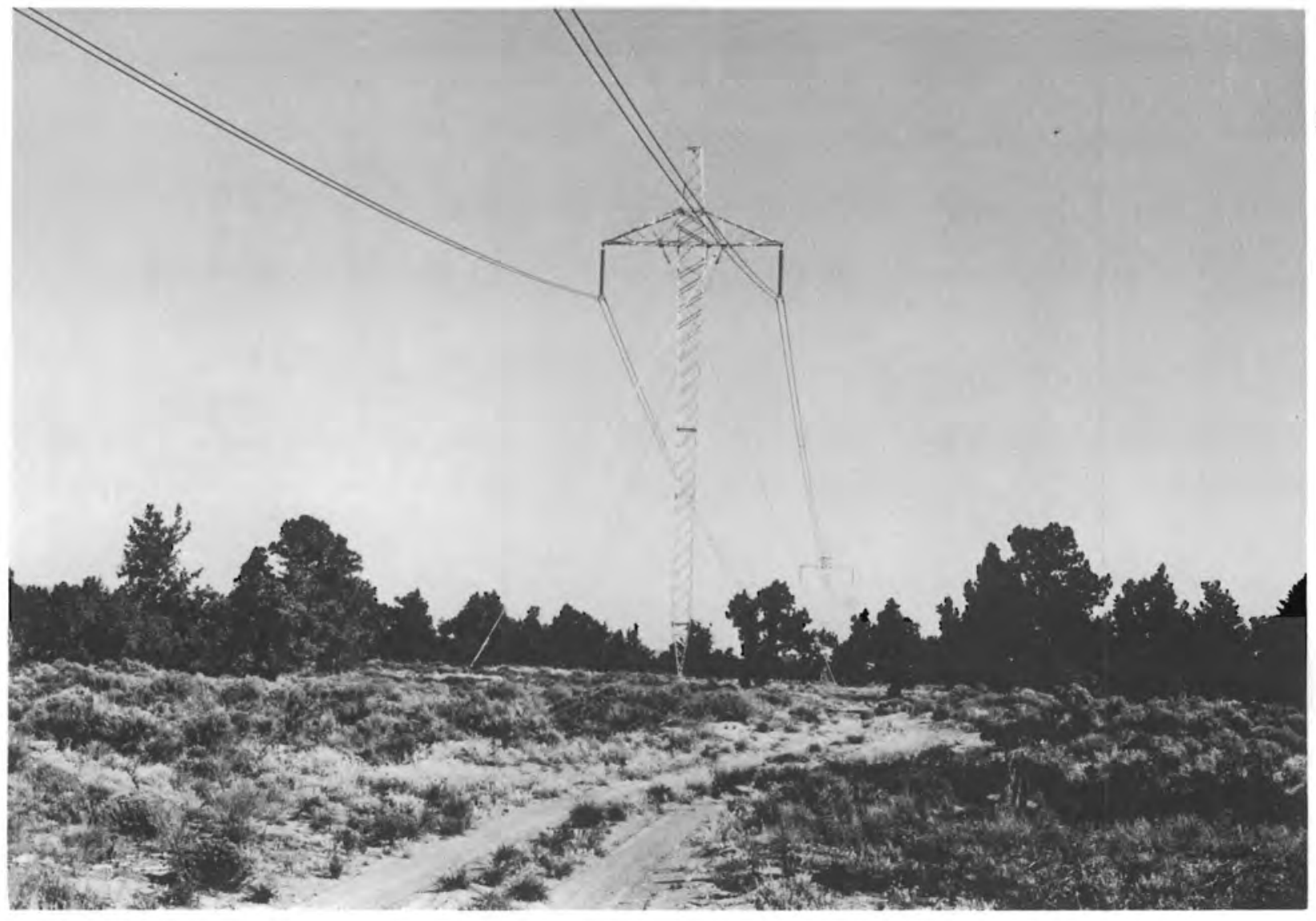

Figure 1. The $\pm 400-\mathrm{kV}$ Celilo-sylmer $\mathrm{D}-\mathrm{C}$ Intertie in the Juniper/Sagebrush Habitat Type in Central Oregon. Effects of Construction Were Still Evident 8 Years After the Line Was Built. 


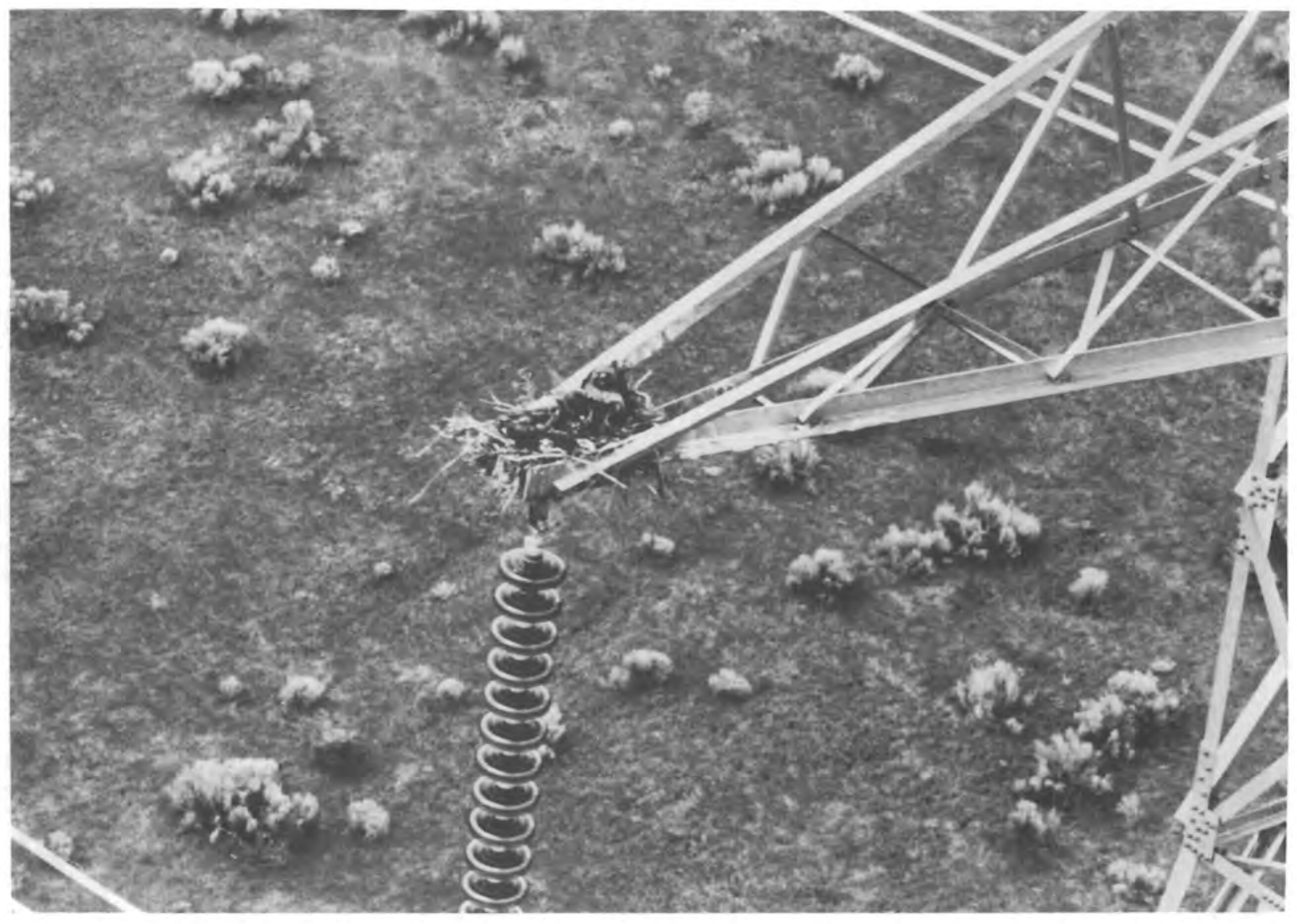

Figure 2. A Red-Tailed Hawk Nest Over the East Insulator String on the $\pm 400 \mathrm{kV} \mathrm{D}-\mathrm{C}$ Intertie. This Was the Most Common Nest Location 


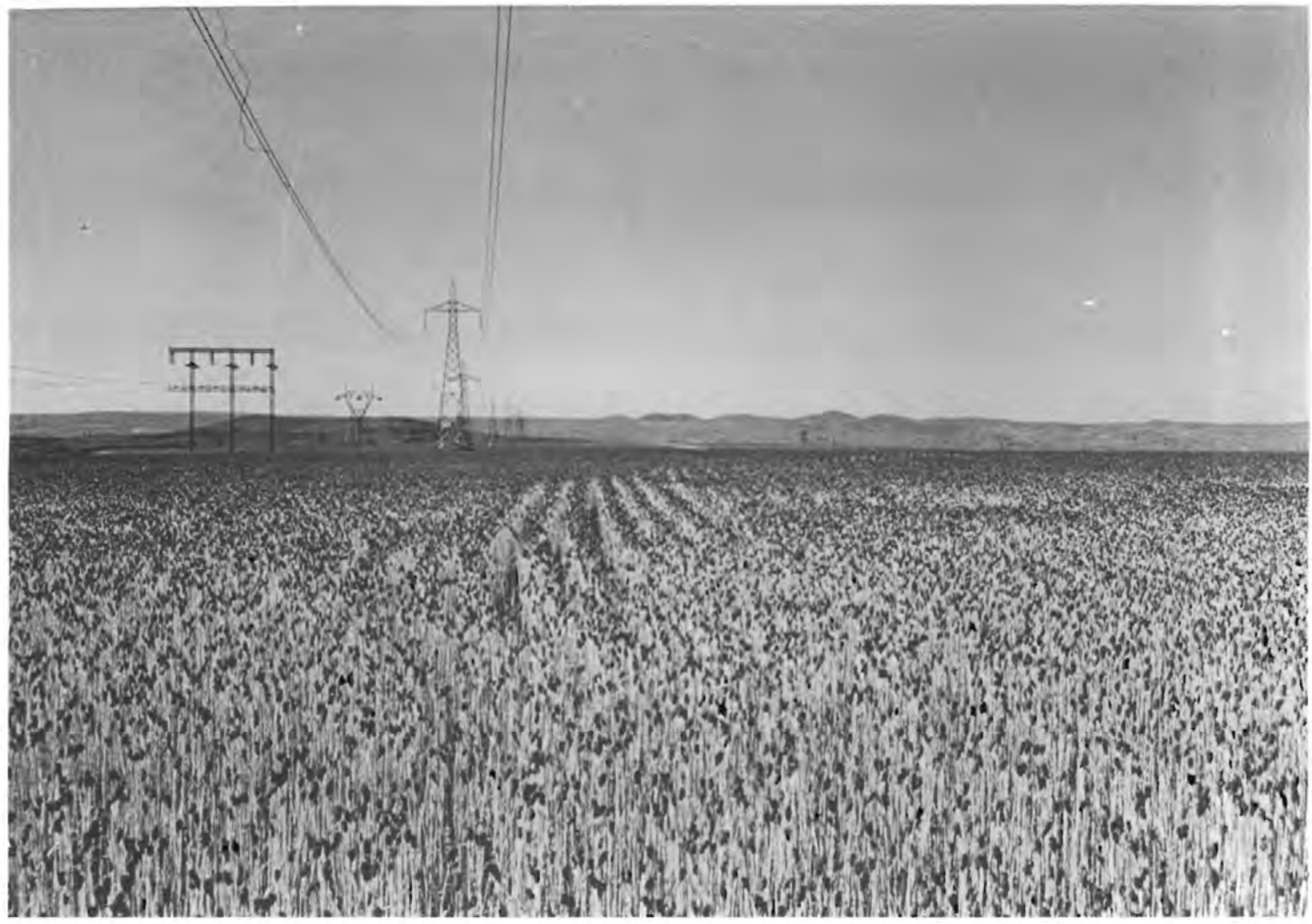

Figure 3. The $\pm 400-\mathrm{kV}$ D-C Intertie Crossing a Wheat Field in North-Central Oregon. A Study Found the Line Had No Effects on Wheat Growth 


\section{DISCUSSION}

A. Frey: You mentioned that the birds seemed to nest on the east side of the towers. Why?

J. Lee: First of a11 there were 8 redtailed hawk nests. Seven of them were on the east conductors, which is predominantly negative. We asked ourselves the same question, why? The prevailing wind at just about al1 the nest sites was from the west. When the birds land on the nests they wi11 be flying into the wind which is what a bird would normally like to do. So we thought that that was probably the major reason. Another aspect is that nests on the east side of the tower receive a greater amount of shading during the summer. Now whether the birds choose it for that reason I don't know, but it does probably increase survival value to the young birds. They do get shading from the tower.

A. Frey: You run the power in the d-c 1ine both directions. How long do you keep the power going in one direction at any particular time? Are we talking minutes, hours, days, weeks?

J. Vithayathil: It depends on the season and the conditions. If we have surplus power in the Northwest then it can go on 24 hours a day for many weeks and months during part of the year. Some other periods of the year there would be power transmission from north to south during the day and from south to north in the night for a few hours.

A. Frey: Could I suggest a sort of a simple-minded thing to do. It shouldn't cost too much to build little shelters up there on the east and west sides for the shading and maybe get some wind measurements. There was a small observation here, maybe it is of some consequence. If there is an inexpensive way to investigate it, it might be worthwhile doing.

J. Lee: One additional thing we have done on a few lines including the d-c line is to install nesting platforms. When the linemen were installing the nesting platform on the d-c line, they noticed the wind shielding effect the high sides of the platform provided. 
J. Vithayathil: We have ac lines in the same region, do you see the same phenomenon there?

J. Lee: We do have some ac lines. I just don't have enough data to say whether we see that kind of phenomenon. The ac intertie consists of two lines one of which has bird guards on it. In that case we are trying to keep the birds off. It's interesting because we found a bird nesting on a bird guard last year. However, I can't really answer that question, because we don't have too many birds nesting on the ac intertie for some reason.

J. de Lorge: Have you done any studies on insects around cattle that are either beneath the line or not beneath the line?

J. Lee: No, we have done no studies of insects around cattle. The only insect study we are doing is the study of honey bees at the $1200 \mathrm{kV}$ site. C. Ehret: Consider that wheat field in which it would appear there was no environmental impact. Consider that wheat doing its best: bushels per acre, height, time to maturity, and germination. How well does that do? We don't want just to know sham against exposed, we want to know how well at best can the same genotype do. In other words, perhaps the plants are already at such a disadvantage, that you couldn't see any worse effects.

J. Lee: That is a good point. As I mentioned that is about the only "good" crop area that we could find, and it was a marginal to medium quality field. It was not a top quality wheat field. Someone mentioned the other day about the effect of organisms in a suboptimal environment, and I assume that is what you are getting at.

C. Ehret: One of your points was the interdisciplinary aspect of the research, but you didn't mention what I think is just as an important part of this aspect, and that is the funding agency and their responsibilities. For an example, an agency with a particular area of responsibility may say any possible effect from that particular technology is no worse than, say, lithium or lead in the metal toxicology field--which is not their responsibility. And if you go into the metal toxicology responsibility area, they might say the effect there is 
no worse than the combined effect of, say, ethanol and caffeine. With this philosophy we will never get around the central question of can we do any better as a human population.

MW Miller: I want to ask what positions you have taken. Apparently you already have a dc line, you have indicated that you have to go through some sort of Federal procedure to get the line; that you are anticipating another line; and that you are in the process of preparing some sort of statements. Can you tell us what positions you have taken, and what steps you are taking? What is your current position, and why?

J. Lee: In 1976, when there was a proposal to construct a second dc intertie, we realized there was a deficiency in the data base for predicting the impact of a dc transmission line. Although the first line had been in operation for 8 years, there had not been any study to see what impact had occurred. One of the problems is that there are few people living near the line and you don't get much feedback even if something were happening. We conducted a literature review of biological effects of dc electric and magnetic fields and ions. We put that in the form of a BPA publication, and made it available to the public. We concluded at that time that as a result of our investigation, we found no evidence that would indicate the electrical parameters from a $\pm 400 \mathrm{kV}$ transmission line posed any hazards to plants or animals. We provided the documentation on which we based that conclusion, and as I say we made that available to the public. We acknowledged that we had not done any field studies, however. Therefore we initiated a study. It was a modest study with one researcher for one year. But he lived near the transmission line during his work and spent thousands of hours driving, working, and living near the transmission line. He collected a fair amount of data in that one time period. By this time we originally thought we would have had feedback as to public and agency concerns about HVDC.

R. Banks: You asked for a few comments on the Minnesota dc line. One way objections to this line were raised perhaps 2 years ago, was by the introduction to the state agencies of Doctors Becker and Marino's testimony before the New York Public Service Commission. At that time they hadn't been crossexamined, and there was only the pre-trial direct testimony available, which 
was not applicable to dc. But again they submitted it as a way to argue that the health and safety effects had not been adequately considered. I mention it as one example to reinforce your point that the public, the scientific community, and the decision makers really haven't distinguished yet between ac and dc. I think that it is crucially important to all of us that we deal with this thing in the public-technology interface. Another example, which would interest some of you here, is that we have on the Minnesota line a $12 \mathrm{kV} / \mathrm{m}$ performance standard for the electric field. Now whether that is to include the ion, or space charge, effects or not, I don't know--I don't think anyone knows. But, the way it was arrived at was simply by application of an $8 \mathrm{kV} / \mathrm{m}$ rms ac standard on a $500 \mathrm{kV}$ line: $12 \mathrm{kV} / \mathrm{m}$ is roughly the crest of an $8 \mathrm{kV} / \mathrm{m}$ ac field, which was extrapolated to $\mathrm{dc}$, without understanding that there is a completely different coupling mechanism involved with a static versus a time varying field. There is a complete blurring that really needs to be straightened out in the minds of a lot of people. I hope some of the discussion here will help.

J. Lee: R. Banks mentioned Dr. Marino's work. We did include in the publication which I talked about, Dr. Marino's study involving dc fields which found glaucoma in developed in the eyes of rats. We did try to be objective and that was certainly a bonafide study. We have gone through over a thousand copies of that publication, and to my knowledge we haven't received any adverse comments for having included that study. On the contrary, we have received some comments saying that the people felt we were objective by including it.

S. Michaelson: Jack Lee gave us a challenge. We laboratory engineers and biologists were given a challenge to get information that the utilities need to assess the effects of building these lines.

I thought I would make a few comments because I perceive certain inconsistencies in what we discussed this morning and this afternoon. On Monday morning I tried to bring out the problem of good science versus bad science, by reading excerpts from an editoral by Cyril Komar. I think it is important to keep this in mind again because bad science would be an impediment to progress in this area. And now we come to some inconsistencies because, as I understand it, or as I heard, there was agreement that the old experiences were inadequate 
for prediction. Yet I heard a whole liturgy given to us of all these beneficial results that have emanated from those old experiments. And then I sat back there and felt quite frustrated because Jim Grissett had asked some very relevant questions and yet we got no answers. The question is: What are we looking for? A comment was made, "We don't know very much about biology." I submit we know a lot about biology, albeit not everything nor as much as we would like to, but why not take advantage of what we do know. The questions that were asked but were never answered were: "How do the ions get to the cells?" We know an awful lot about biology and we should be able to make some predictions and think of some mechanisms. Another question was: "How do the ions get to the alveoli of the lungs?" We heard a lot about these ions getting into the lungs, the question is, "How can they?" Even particulate matter doesn't get down to the alveoli space except for certain sizes: there is tremendous attenuation down to the bronchials. Another question that came up was about caging. Some suggested using wooden cages and we left it at that. I wonder how many people have tried housing rats in wooden cages, and especially trying to maintain certain social interactions, visual interactions. Also, if ions can influence respiratory situations, how are they going to keep these animals free of respiratory diseases? So, all I can think of is: why not worry about mechanisms. I think it is extremely important that we do consider mechanisms; otherwise we just go on a fishing expedition for millions of dollars and not get any answers. 
5. ANIMAL HOUSING DESIGN CONSIDERATIONS IN DC ELECTRIC FIELD BIOEFFECTS RESEARCH

\author{
J. R. Decker \\ W. T. Kaune \\ M. F. Gillis \\ Biology Department \\ Pacific Northwest Laboratory \\ Richland, Washington 99352
}


will fluctuations in relative humidity and air movement in the exposure volume. Requirements, problems and possible solutions to problems associated with four major areas of concern in system design will be discussed: exposure parameters, environmental control, animal containment, ànd animà maintenance.

\section{INTRODUCTION}

There are four basic approaches to the study of possible biological effects resulting from the exposure to power transmission electromagnetic fields: clinical, epidemiological, ecological and experimental animal studies in the laboratory. Of these, the laboratory approach is the preferable method for studying effects of individual, well-controlled parameters. This is due in part to the possibility of controlling the ambient environment in the laboratory and in part to the lower cost of constructing exposure systems. By isolating and carefully controlling a parameter or group of parameters, the laboratory approach provides an excellent means of studying biological mechanisms of effects and suggesting the least expensive methods of reducing those effects. One major disadvantage of the laboratory approach is that it is impossible to fuliy reproduce the environment of the dc transmission line in the laboratory. Thus care must be exercised in the choice of parameters to be modeled and, more important7y, extreme care must be taken not to introduce unknown variables not normally found in the transmission line environment which may produce artifactual effects. 
ANIMAL HOUSING DESIGN CONSIDERATIONS

IN DC ELECTRIC FIELD BIOEFFECTS RESEARCH

J. R. Decker, W. T. Kaune And M. F. Gilli is

\author{
Biology Department \\ Pacific Northwest Laboratory \\ Richland, WA 99352 \\ Operated by \\ Battelle Memorial Institute
}

Complications arise in the design of animal exposure systems for the study of dc electric field effects which are not encountered in analogous studies with ac fields. The situation in the vicinity of de transmission lines is complex and includes not only a static electric field (which varies slowly with weather conditions, particularly wind) but space charge, air ion currents to ground, a small static magnetic field, small alternating fields due to ripples in line voltage following ac-dc conversion, and perhaps corona-produced atmospheric species with potential for biological effects (e.g., oxides of nitrogen, ozone). Simulation of the dc transmission line environment in the laboratory can be accomplished only with considerable compromise. Furthermore, the presence of animal housing (and the animals themselves) will influence to some extent the distribution of space charge and air ion currents, as 
In the small number of dc bioeffects studies previously reported, there is little description of exposure systems and a general disregard for the effects of the system configuration on the results of the experiment. This paper wil. discuss the design considerations of a test system for studying the effects of high-voltage dc electric field expcsure of small animals with emphasis placed in tivo major areas, choice of Exposure parameters and animal housing considerations.

The environment in the vicinity of the high-voltage direct-current (HVdC) transmission line is more complex than the ac line situation. Corona produces potentially biologically hazardcus ozone and oxides of nitrogen along with audible noise which may have psychological effects. Air ions, also a product of corona, migrate in the field creating air ion currents and space charge. The magnitude and distribution of the latter will vary depending on environmental conditions such as wind, humidity, and air contamination. The total electric field is the summation of the field produced by the slowly varying space charge and that induced by the fairly constant line charge. Imposed on the static electric field is a much smaller ac field caused by ripple in the line voltage, a byproduct of the ac-dc conversion process. Static and very small ac magnetic fields are also present.

Even if a complete simulation of all the characterisiics of the transmission line environment were possible (including the physical disruption by the mere presence of the line), the interpretation of the results from such an experiment would be very difficult or impossible; in particular it would be most difficult to identify the specific 
environmental agent responsible for an observed bioeffect. The most important parameters and the quantitative levels which should be in the iaboratory exposure system are discussed in the section "Exposure Parameters".

The animal housing system must provide a way of containing the animal within a given living space while not being stressful to the animal. The system must provide a controlled environment (i.e., temperature, relative humidity, ventilation and lighting) and provide for feeding, watering and clean quarters consistent with good animal care practices. Construction materials must not produce significant biological effects when ingested. All of these factors will be discussed in greater detail in the section "Animal Housing System".

\section{EXPOSURE PARAMETERS}

Bracken (1) has described the complex nature of the environment in the vicinity of HVdC transmission lines. Many of the parameters he introduced will be reiterated here with an emphasis on those parameters which should be simulated in the laboratory exposure system. Most example data given in this discussion are characteristic of the Pacific (Celilo-Sylmar) DC Intertie.

The parameters can be divided into two major categories: 1ineproduced fields similar to those associated with ac transmission lines (i.e., those due to surface charge on the line or current in the line), and those factors unique to the dc line, all related to corona discharge. There are several line-produced fields which must be considered. The 
"nominal" static electric field, due to the surface charge on the conductor (a function of the applied voltage and the conductor geometry), is nearly vertical and relatively uniform at the ground level where exposure of man (except linemen) might be expected to occur. The magnitude of this field, which is dependent on the line voltage, the electrode spacing and the electrode height above ground, was calculated to be about $8 \mathrm{k} ! / m$ for the $\pm 400 \mathrm{kV}$ Pacific Intertie. (2) Since $\pm 1200 \mathrm{kV}$ lines are presently contemplated, the exposure system should generate a field corresponding to the "nominal" field in excess of $8 \mathrm{kV} / \mathrm{m}$ and perhaps as high as $25 \mathrm{kV} / \mathrm{m}$. Associated with the "nominal" field is the static magnetic field generated by line current. This field is comparabie to magnitude to the geomagnetic background (0.5 Gauss) and is probably not biologically significant except in cases of a few animals which possess magnetic field sensing ability.

Superimposed on the nominal dc electric field is an extremely lowfrequency (ELF) field due to residual ac voltage resulting from ac-dc conversion deficiencies. The estimation of the level of ELF field to which humans might be exposed under the line varies widely, depending on the line configuration and the degree of filtering. For one $\pm 750 \mathrm{kV}$ configuration, USSR engineers calculate a $4 \mathrm{kV} / \mathrm{m}$ field at the height of the head (3), while the ac field under the Pacific Intertie, assuming a $1 \%$ rms distortion, is calculated to be about $0.8 \mathrm{kV} / \mathrm{m}$. At $360 \mathrm{~Hz}$, the predominant harmonic, $0.8 \mathrm{kV} / \mathrm{m}$ is sufficient to induce an ac current of about $80 \mu \mathrm{A}$ in the body of a man or neariy 16 times the expected dc body current due to interception of air ion current. The exposure system 
design should permit including this ac field to study the possible synergistic effect of the ac-dc fields. The ELF magnetic field associated with this ac field is very small and can be excluded at this time.

The second category of exposure parameters to be discussed incluces corona products. Air ion production by corona will be the most dificicult parameter to simulate in the exposure system. The ions produced at both the positive and negative conductors introduce two important parameters to the exposure system: a space charge and a dc ion current. The electric field produced by the space charge can contribute as much or more to the total field as the "nominal" field. Thus the total dc field (space charge field plus "nominal" field) at ground level beneath a 1200-kV transmission line could exceed $50 \mathrm{kV} / \mathrm{m}$, the minimum level for which the exposure system should be designed. If data from the animal exposures is to be extrapolated to humans the exposure field should be even greater as the field enhancement factor for man, which affects the nominal and ion fields as well as the ion current, is considerably greater than that of a rat. The space charge distribution is very dependent on air movement, making it mandatory to control air flow in the exposure system. The mobility of the air ions within the field create a de current density of which has been calculated to be as much as $1 \mu \mathrm{A} / \mathrm{m}^{2}$. (4) This density could induce a dc body current of up to $5 \mu$ in man.

The ions beneath the transmission line have not been well characterized, however some characteristics can be derived from the literature. The ions produced are originally smal1, 0.001 to $0.003 \mu \mathrm{m}$, and quite 
mobile, 1 to $2 \times 10^{-4} \mathrm{~m}^{2} / \mathrm{V}-\mathrm{s} .(5,6)$ As the ions are propelled through space by the field, they grow by attaching to water molecules and condensation nuclei. It is believed that only the small ions are biologically active (biehner, 1969). The size and composition of the ions to which the body is exposed is dependent on the humidity and particulate contamination of the atmosphere, both which should be controlled in the exposure system, and upon the time for the ion to traverse from the conductor to ground, a few seconds for the typical transmission line case. If the exposure system is designed so that the transition time from the ion generator to the test animal is kept small, the ion size should closely approximate that under the transmission line since the natural half-life of a small air ion is estimated to lie between 20 and 50 seconds. However, more research is necessary to define other characteristics of the ions under the transmission line, such as ion species.

Oxidants, such as ozone and oxides of nitrogen, are also a product of corona. Ground level concentrations (above ambient) of these products are very smal1 $(8)$ and should probably be excluded from the system. This is an important point, as possible air ion generation schemes may introduce significant amounts of these products into the exposure area and create artifactual exposure conditions.

Also associated with corona are radio-frequency electromagnetic fields on the order of 1 to $3 \mathrm{mV} / \mathrm{m}^{(9)}$ at ground level under the Pacific Intertie. This is on the same order of magnitude as radio transinission fields near transmitting stations and consequently need not be of concern. The audible noise from corona is of concern primarily because of its 
possible psychological effects on humans. The effects of this parameter would be difficult to study in animals primarily because of their exiremely different hearing frecuency ränge and behavioral respcrses to novel sounds.

\section{ANIMAL HOUSING SYSTEM}

The functions of the animal housing system can be divided into three categories: environmental control, animal containment and animal maintenance. It is important to stress that, with respect to all three of these categories, the exposed animals and the control animals should be treated identically. Control animals should be sham-exposed in an identical system lacking only the exposure parameters of interest. To eliminate human bias it is also advisable that the study be done blind so that neither the animal handlers nor the investigators know which animals were exposed until all data are collected.

The major environmental factors which must be controlled are air, lighting, and noise and vibrations. Air humidity, contamination and flow have already been mentioned with respect to air ion characteristics and distribution. These parameters, as well as temperature must be maintained within reasonable limits to assure good animal care practices. For example the ambient temperature for rats, to minimize stress and the possibility of disease from airborne micro-organisms, should be controlled between 24 and 28 degrees centigrade while relative humidity should not vary beyond 45 to $65 \%$. (10) Good animal care practice also requires a 
minimum of 10 volumetric air changes per hour. The air flow necessary to accomplish this must be uniform for all animals in order to maintain a consistent air ion distribution. It must not sweep oxidants, possible byproducts of the air ion generator, into the animal space. Likewise, it must not sweep animal waste decay products, such as ammonia, into the ànimal space.

A day-night cycle lighting system should be designed to provide equal light for all animals in both exposed and sham-exposed groups. Noise and vibration should be minimized to avoid stressing the animals. Careful measurements should be made to assure that no noise or vibration (from such equipment as transformers, rectifiers or switch gear) are present in the exposure system that are not also present in the sham system. Vibration may also be induced in the exposure system by forces exerted by the ac field on insulated animal caging components which acquire a dc charge by collection of air ions.

Construction of an animal containment system which does not significantly interfere with the desired exposure parameters and is at the same time biologically and psychologically compatable with the animal is, without a doubt, the most vexing problem in designing a system to expose small animals to a simulated de transmission line environment.

All materials used in construction of the system which the animals might chew on must be nontoxic. Also, since the effects of stress on the animal may mask or confuse effects caused by exposure to the dc test parameters, the housing system must be minimaliy stressful. 
The exposure system must be constructed in such a manner as to not significantly interfere with the exposure parameters, thus allowing quantitative measurement or estimation of the fields and currents to which the animals are exposed.

Typical animals caging configurations cannot be used due to their interference with the exposure parameters. "Etal cages will greatly attenuate the field within the cage. Roofed cages constructed of insulating material will charge up by collection of ions, thus diverting the ion current and perturbing the field. Removing the roof helps little as high walls are then needed to contain the animals. The field and ion current will be substantially affected near the walls where the animals spend much of their time. Walls constructed of nontoxic semiconducting material with conductivity and dielectric constant close to that of air with a given space charge density would perturb the field very little. However, this system would be quite limiting since it would not permit exposures at different space charge densities. Also, contamination of these walls by animal oils or waste will alter the field characteristics.

Ideally animals should be exposed on a ground plane with nothing except the animal protruding above ground. This may be possible if suitable nonprotruding barriers can be identified. Possibilities include electric shock strips, water moats or trap doors between living areas, or limiting animals to a given territory by leash or behavioral training. Several of these ideas, such as shock strips and leashes, may be unsuitable due to their stressful nature. 
Knowledge of the field configuration prior to the introduction of the animals is not sufficient for accurate dosimetry because the animal's body perturbs the local field, ion current and space charge distribution. The degree of perturbation is dependent on body shape. For example, the Field at the nose of a rat oriented with its major axis parallei to the field may be more than five times that of a rat whose orientation is perpendicular to the field. Many small animals are naturally exploratory and tend to rear on their hind legs, changing their orientation in the field and making dosimetry difficult. The ideai exposure system should minimize this problem by maintaining a single orientation of the animal in the field.

The coupling of the animal to the field can be greatly altered by the proximity of other animals, again making dosimetry difficult. In the case of animals which tend to huddle while sleeping, the animais at the bottom of the huddle may be completely shielded. For these reasons the animals should be singly caged.

Animal maintenance, including feeding, watering and necessary housekeeping is an integral part of the animal containment system and must be considered in the design of the system. If water and food are to be provided while the animals are being exposed, the food and water dispensing apparatus must not perturb the field uniformity. More importantly, the apparatus must not be a source of electrical shock to the animals when they feed or drink. These goals can be accomplished by placing food and water dispensers below the cage floor and enclosing 
them in a zero-field region. Small, dry food pellets could be placed directly on the floor with little effect on the field, simplifying the feeding system.

Urine and feces should be collected in a zero-field region to avoid the possible problem of field-induced outgassing of excreta, which may affect the animal. A ficor constructed of two layers, an upper layer of screen and a solid lower layer, would allow biological waste and other debris to be collected on the lower, field-free level. A removable catch-pan would aid in periodic cleaning.

General maintenance of the exposure system must be considered both from the standpoint of economy and of quality control of the exposure. The system should be easy to clean, preferably constructed of modules small enough and sufficiently durable to be removed and placed in an automatic cage washer. A final but important consideration: the animal containment system must allow quick and easy access to all animals without exposing the animal technicians or investigators to unsafe conditions.

\section{SUMMARY}

Arguments have been presented to define the exposure parameters and animal housing requirements necessary in designing a system to expose small animals to a controlied simulation of the situation in the vicinity of dc transmission lines. This summarization will clarify the chosen parameters and requirements. 
The study of the effects which may be the result of perturbation of the environment by the physical presence of the transmission line were of necessity excluded from the laboratory exposure system. The exposure system should provide a minimum electric field of $50 \mathrm{kV} / \mathrm{m}$ which is vertical and uniform. If the animal data is to be extrapolated to man this field may need to be raised by a factor of 5 . A method of superimposing a $360-$ or $720-\mathrm{Hz}$ ac electric field of up to $4 \mathrm{kV} / \mathrm{m}$ onto the dc field should be incorporated into the system. The rf electric fields resulting from corona as well as the magnetic fields associated with the dc and ac line currents are small enough to be excluded from the system.

Al though more characterization of the air ion size and species at transmission line sites is necessary, some preliminary decisions concerning air ions in the exposure system can be made. The air ions at the exposure site should be small $(\sim 0.002 \mu \mathrm{m})$ and of sufficient number to produce an unperturbed current density on the order of $1 \mu \mathrm{A} / \mathrm{m}^{2}$. The animal should be in electrical contact with ground and exposed to ions generated from either the positive'or the negative electrode.

Corona-produced oxidants such as ozone and nitrogen oxides should be excluded from the exposure area, as should corona-produced audible noise.

The animals should be individually housed on a ground plane, ideally with no containment structure protruding above the ground plane. The containment structure should not stress the animals, and all structural 
parts on which the animal may chew must be nontoxic. Food and water distribution systems and animal waste collection should be contained in a zero-field region below the ground plane.

The environment must be closely controlled. Air temperature should be maintained with $\pm 2^{\circ} \mathrm{C}$. Relative humidity should not vary more than $-5,+15 \%$. Air should be filtered to renove particulate contaminants. Air flow must be uniform, provide 10 to 15 air changes per hour and not sweep corona produced oxidants or animal waste decay gasses into the exposure àrea.

Diurnal cycled, uniform lighting must be provided for all animals. Externally and internally generated noise must be minimized or eliminated.

Introduction of food and water into the system, removal of animal waste, routine cleaning and repair of the system and access to the animals must be quick, simple and inexpensive.

Finally the exposed and control animals must be housed in identical systems, except for the exposure parameters. Ideally animal handlers and investigative personnel should not be aware of which group of animals is being exposed until all data has been collected. 


\section{REFERENCES}

1. Bracken, T. D. 1978. HVDC Electrical Environment. BPA/DOE Workshop on Electrical and Biological Effects Related to HVDC Transmission, Richland, Wáshington, October, 1978. PNL-3121.

2. Bracken, T. D., A. S. Capon, and D. V. Montgomery. 1978. Ground level electric fields and ion currents on the Celilo-Sylmar $\$ 400 \mathrm{kVdc}$ Intertie during fair weather. IEEE Trans, on Power Apparatus and Systems, PAS-97: $370-378$.

3. Gertsik, K. A. et al. 1973. Protection from electric fields and aerial ions on very high voltage dc transmission lines. In: Filippov, V. I. and Morozov, Y. A. (eds.): Protection from the Action of Electromagnetic Fields and Electric Currents in Industry. DOE-TR-20. All Union Control Scientific Res. Inst. on Work Safety, Moscow.

4. Morozov, Y. A., and B. G. Yakobson. 1973. Calculation of electric fieid intensity, concentration of aerial ions and ion current density on overhead de power lines. In: Problem of Electrical Safety in the National Economy (DOE-TR-21). A11 Union Control Scientific Research Institute on Fork Säiety, Moscow.

5. Chalmers, J. A. 1567. Atmospheric Electricity, Pergamon Press, 0xiord. 
6. Israel, H. 1971. Atmospheric Electricity, Vol. 1. TT-67-51394/1. NTIS, Springfield, VA.

7. Wehner, A. P. 1969. Special Review: Electro-aerosols, air ions and physical medicine, Am. J. Phys. Med. 48:119-149.

8. Droppo, J. G. Ozone field study adjacent to a high voltage dc transmission test line. Proceedings of the 18th Annual Hanford Life Sciences Symposium, Richland, WA, October. NTIS, Springfield, VA, January 1980. CONF-781016.

9. Hiłl, H. L., A. S. Capon, O. Ratz, P. E. Renner, W. D. Schmidt, et al. 1976. Transmission Line Reference Book HVdc to $\pm 600 \mathrm{kV}$. Prepared under sponsorship of the Bonneville Fower Administration and the Electric Power Research Institute (EPRI). EPRI, 3412 Hillview Avenue, Palo Alto, CA 94304.

10. Weihe, W. H. 1971. The significance of the physical environment for the health and state of adaptation of laboratory animals. Proceedings of the Fourth International Conference on Laboratory Animals, 1969. pp. 353-375. National Academy of Science, Washington, DC. 


\section{DISCUSSION}

J. Decker: I would like to hear some comments from Dick Finger on the problems and solutions that he has had with animal containment.

R. Finger: A comment on the ammonia is worthwhile. You showed 10 air changes per hour as being necessary. We work with a laminar flow system running at a higher rate which eliminates a lot of the waste problem, and provides for the uniform distribution of ions and the maintenance of a uniform field. That system is specifically related to individual animal exposure, as opposed to group exposure. I don't know why anybody would want to, in this work, deal with groups--especially in the initial stages. We are going to bring to publication soon a paper which we co-authored with an eastern university on "Inhalation Chambers for Air Ion Research." Now it would probably be out of order to discuss this work because the placement of the article is being done by them. This was a study of brain levels of serotonin in rats, specifically related to concentrations in various lobes.

Wood and issues concerning wood or all metal cages and the distribution of fields and ions, we have studied pretty thoroughly. It really comes down to the particular experimental design of the people who are working with it. Tom Michel would be better suited to discuss the analysis of wood. Primarily it entails construction of the chamber so that gnawing is almost impossible. We learned the hard way, having worked on a project with Miami Heart Institute at one time. You can control the ion level, and you can control the distribution of ion concentration through devices such as ones which we have made available in our projects. But dust and animals chewing food are considerations that you must have, too. You also have the atmospheric background level of ionization, and you have to have the air quality ascertained both going into and out of the chamber. Urine is a big problem for consideration. Feeding may well lend itself towards handling techniques that you might not have worked with before because no one has worked with air ion concentrations in this manner before. So there are a number of variables. 
There are about 13 variables of which you have hit 3 or 4 here specifically. If you keep these variables within control or have knowledge of any one of them then you can always ascertain what your air ion concentration is at any one particular time in a study chamber without disturbing the atmosphere to get in there and take your readings and do your measurements. One of the things you might want to think about in that regard is that it appears from the literature, that there is a "threshold level therapeutic dose range" that you are going to be dealing with and not a specific level. Thus you may find that you are going to be dealing with ion concentrations that are $10^{4}-10^{5}$ ions $/ \mathrm{cm}^{3}$. As a result, in doing your measurement work you will restrict yourself to a range of levels, say, 50,000 to 500,000 ions $/ \mathrm{cm}^{3}$. Your animal can $\mathrm{climb}$ up on his haunches because the density of ions in the 4 or 5 inches, that he may reach, will not change outside those limits if you control it properly. So it might be possible to minimize some of the problems you have raised in that regard.

J. Decker: That would be true of the air ions, but not true of the enhancement due to the static field. Bill Kaune of Battelle has made some of these measurements. Bill, can you recall what the difference between enhancement of the animal in the vertical versus horizontal aspect are?

W. Kaune: I'm not really sure: Somewhere from a factor of two to a factor of five.

T. Michel: I need to clarify a statement I made earlier. When I said build cages out of wood I was not advocating a chamber that was built as a wood cube that you merely threw the animals in. Wood is an elegant material because it has very controllable electrostatic characteristics that can be shifted a little by various sealers. You can use boiled sterilized linseed oil or something else to give the wood a little water repellency; or you can go to a hardwood like teak, which is essentially water repellent because of its own internal oils. When you build a wooden study chamber you build it in a fairly large cylinder and put only 2 or 3 animals in it. You use an electrically conducting stainless steel screen to support the animals, and make the screen the same extended body height as the animal. It is important to keep the 
aspect ratio of the holes of the screen sufficiently large so its effect on the electric field and on the ion current flow is minimized. The screen also serves as a good grounding plane for the animals themselves. By making the screen essentially in a cup-structure, you can put the animals inside of it and they can crawl up. If you space the wooden walls a centimeter or so away it is very difficult for the animals to get to the wooden surface to chew. You also have the advantage of the good electrostatic characteristics of the wood. The chamber ought to be fairly long so you can direct your air flow and introduce your ions at the top and exhaust your waste gases out the bottom. This also takes care of the problem of out-gasing of feces and nitrate components from urine. So, perhaps when I said make the study chamber out of wood that was not specific enough. I hope this clears up some of the conceptual problems the people might have with the execution of it. It is a very simple mechanical engineering problem, and it isn't such that it will destroy the experiments. It is pretty easy to do, we have done it many times.

One of the study chambers at Miami Heart Institute is 2 meters high. We used another 1 meter high. If we made them rectangular, the animals would all clump in the corner. The obvious alternative was to get rid of the corners, so we made them round. It worked well: the animals tended not to clump together, there were only 2 or 3 in a chamber. If you make a round wooden chamber, you can put access doors any place. On the sides there are stand-off insulators for the stainless steel screen that uses 18 or 16 gauge wire on $1 / 4$ inch spacing. The mesh may be smaller depending on how large your rats are: you don't want the spacing so large that their feet fall through the holes. You want the spacing small enough so that their toes and feet can stay in 2 or 3 grids.

You bring the stainless screen up the sides. If the extended length of the rat or mouse is 6 or $7 \mathrm{~cm}$, bring the screen up another centimeter, or 2 centimeters. The animals do not have the tendency to climb up on the screens to chew the walls because it is physically uncomfortable for them. Thus, the wooden chamber has a concentric screen on the inside for support. This allows for controlled velocity ventilation and a laminar flow situation is set up. 
The animal droppings go down in the bottom, and the effluent gas exits there also. You don't get any outgassing contamination from the urine and feces because of the airstream of the exhaust gas. This allows you to control your ionization and ionization products up at the top of the chamber where you may want humidification units, a constant temperature device, an air conditioner, or heater depending upon the external environmental factors that you are dealing with. If you are conducting studies up in the Northeast or the Northwest in the winter time, you have a humidity problem to deal with. In Florida we don't have that problem. So the specific objectives of chamber design will relate to where you are running the tests.

J. Decker: The problem that I see with this type of an arrangement, and we have spent a considerable number of hours discussing problems with these types of chambers is the region right in the bottom corner of the cage. If you use a conductive wall such as stainless steel mesh, perhaps the air ion situation is not affected too much, but the field is affected quite a bit because the conductor, of course, is a constant potential line. Rats or mice love to sleep right in the corner and they spend, say, more than 50 percent, and probably 70 percent, of their time inactive. Thus the region where they are going to spend most of their time is shielded by the fact that the field lines do not terminate in the corner. You are going to have a decrease in the field in the corner compared to the nice uniform field in the center of the cage. That presents a problem for the electric field exposure portion of your experiment. Perhaps the cylindrical type of system could be used if you just eliminate the walls. The ideal situation is to just have the animals standing on a grounded platform with another plate above it. With the animal in the center, you have the ideal situation. Then, if you add the wooden walls out away from the platform (or, for that matter, any kind of wall that is not going to put too much perturbation on the electric field), the animal can't huddle in a nofield region or in a low-field region, but he can fall off the edge, and indeed does. We tried this with rats. Instead of just using a platform ( $I$ know that they will crawl off a platform), we used a trap door type of mechanism. In other words, if we had something which they could put their foot on, but which wouldn't support them, perhaps they wouldn't walk out on it and 
fall through. This does not work 100 percent of the time. On the average a rat falls through about once every 24 hours. If you have 100 rats, there is a lot of work trying to pick them up. But I think something like this may be a solution to the housing problem.

B. Scott-Walton: If animals like to huddle in a corner, why not try a type of funnel. Then when the animals spend 70 percent of the time sleeping they are sleeping at the bottom of the funnel where the maximum field occurs?

J. Decker: The problem with that configuration would be the difficulty of defining the field or coming up with a field that would be uniform and equivalent to that at ground level under the transmission line. Bill Kaune thought of a system that was rather elegant, but expensive: it was a spherical exposure system. The animal would be placed in a sphere with an electrode at the center. The animal could roam around only on the bottom which is quite limiting but adequate if the sphere is big enough. In this case the field is nice and uniform, but introducing air ions into the situation was difficult. If you were singly housing the animals to eliminate shielding problems, then this type of an exposure system becomes economically unfeasible.

W. Kaune: Also the voltage required on the center electrode becomes quite 1arge.

J. de Lorge: One of the things that seems to have been overlooked in terms of simulating the natural environment is the lighting system. It ought to be something that mimics the natural spectrum, and very few studies do this. There has been quite a bit of research showing that if you use unnatural lighting systems or systems that have too much red or not enough blue, you do effect animals such as mice and rats.

J. Decker: Is this going to overshadow effects, if the control animals are similarly exposed?

J. de Lorge: You could very well have a synergistic effect, which could overshadow effects, you just don't know. It is a matter of attempting to simulate the natural environment which is what, I thought, we were trying to do. 
T. Michel: Most of the rats, at least the ones we have worked with, spend their entire life in an artificial lighting environment. They have never been exposed to sunlight cycles.

J. de Lorge: Most colonies which raise rats use Vita lights, which are very close to the natural spectrum.

C. Ehret: Could you comment on an al1-glass exposure system? The design of the one we had, for example, was very much like the wooden one that has been described, except it was entirely made of glass. In the ac case, it worked out beautifully. In that case, we had the ground plane through the middle of the cage. I wonder if the charge effects will be the same.

J. Decker: Essentially the glass is going to pose the same problem: the charge won't leak off glass much better than off plastic.

R. Finger: We had experience with glass in plant study work; we found glass absolutely no better than plastic. We had charge accumulation take place very quickly.

J. Decker: We have had the experience of exposing animals to aerosols in different types of apparatus. These are particles that are considerably larger than the particles that we are talking about here, but the same type of problems exist. If you get a charge on the particles, you end up essentially attracting these particles to the sides of the walls of the chamber. We found glass to be no different than plastic in this regard.

M. Gillis: You mentioned that you thought we would ignore ozone and audible noise at least in the first-cut systems, and I would word it a little stronger: we would actually want to eliminate them. The air ion generator will probably produce noise and maybe corona. How are you going to eliminate both noise and ozone?

J. Decker: This pertains to the air flow system. You have to pay a lot of attention to which direction the air is flowing so that you don't sweep some unwanted substance generated by the air ion generator into the exposure system. 
This also brings up another problem related to what you build the system out of. If you use plastic or some material on which charge accumulates and then you include the ac component. The forces that are exerted on this large charge are going to make the wall vibrate. So the vibration induced into the system by an ac component in a dc field is something else you have to consider.

M. Preach: Have you worked on problems with bedding for use in reproduction studies in an electric field?

R. Phillips: We ran into this problem in our ac study. In fact, it was a nightmare: we spent about 6 months trying every kind of material we could think of. We finally found a synthetic carpet material in raw form which we obtained from one of the manufacturers. It works beautifully. I think we had the same problem, that John mentioned, with the plastic accumulating charge. This material is a synthetic material which has small carbon conductive pathways inside of it. It worked fine. Basically, we were trying to eliminate shocks in our system.

D. Poznaniak: Would it be possible to train the animals to restrict their activity and keep them within a certain area? In other words, could you set up photocells at the edge of a region and anytime that the animal broke the beam he would be subjected to some unpleasant experience: a loud noise or something like that. So that he would eventually confine himself within a region.

J. Decker: That thought had also entered our minds. The problem of training is that the rat or the mouse probably would have to be trained with something noxious or some punishment. If you use a shock, a bright light, or loud noise, then one wonders what effect the shock, bright light or noise is having on the rat. Also, he doesn't maintain this learning forever. For example, in the system that we tried, we placed a garbage can filled full of ice water below the trap door. The rat really did not want to fall into the ice water but he remembered falling into the ice water for less than a 24-hour period. He would still go over and fall through the trap door into the ice water, so his learning, in this case, went away every 24 hours. 
Don Deno: I think this question of the walls is probably a very important and very difficult problem. As an electrical engineer I certainly would be suspicious of any of these experiments actually solving this problem. I thought I would throw out another idea. The sides of the wall could be made out of some wires with gradation to assure the correct voltage boundary condition. The wall could contain some small thin wires with a voltage for shock, in the same way that we contain cows regularly with an electric fence. It seems to be very successful and they learn and relearn without any problem. I am interested in what the biologists think of this type of containment because it would assure the correct electric field distribution.

R. Phillips: My experience has been, that if you train a rat to avoid an adverse stimulus, you have to reinforce this periodically. This, of course, requires time and manpower, and in most studies you try to at least keep this in bounds. If you had to go through this procedure it would become very expensive to do studies with very many animals, you would be working with small populations. A1so, you need to be concerned about those cases where some of your animals didn't learn too well. In this case you are also superimposing the response to an adverse stimulus on what you are trying to look at.

A. Frey: Essentially what Dick Phillips has said sums up behavior pretty we11. The animals are dumb, they forget pretty fast. As soon as you take away the thing that is aversive, they forget all about it more or less, and they extinguish their aversive behavior and they begin doing all the wrong things. If you start hitting them with shocks, it will vary how many shocks are required among different animals. You also have the problem of working with the dc electric fields and hitting them with electric shock at the same time. I am not sure I would particularly like to use electric shocks as aversive stimulus when we are worried about working with people living in dc fields. So, in general I think we ought to avoid using aversive techniques to try and keep animals contained. 
D. Deno: I thought I would make one more comment on the training of aversion to shock. We leave the electric voltage on electric fences for cows all the time. This is selected for minimum effort, minimum maintenance. I don't really appreciate how such a system would be a significant additional effort. Farmers find this to be the very easiest kind of containment. The cows are reminded regularly and they don't seem to be bothered by it. There might be some difference with a rat.

M. Gillis: It is time for your friendly veterinarian. I frankly don't know which animal is more stupid--a rat or a cow. If I had to guess I would probably guess the rat is considerably more stupid. One difference between the rat and the cow is that the rat is an exploratory animal, highly exploratory, whereas the cow is a foraging animal. So the cow is not all that anxious to get into the next pasture unless she is running out of food. That is one big difference between them.

J. Decker: I think that the idea of using wires instead of walls is probably a good one. Instead of using a solid wall you use wire, like a boxing ring, but you have to be careful how you do this. If you use insulated wire the total charge accumulation on the wire is going to be considerably less than it would be on a solid insulated wall and the wires would probably effect the field considerably less than a solid wall. I would suggest using insulated wires. If you use conducting wire and some sort of a resistance divider to make each of the wires at the same levels as the unperturbed field, then the grounded animal could get a shock when he puts his nose on the wire. I think we really want to eliminate this shock, because it has come out as being a problem in previous research. So, another thing that you could add to this would be the trap door. You are doing two things now: you are trying to prevent the rat from spending most of his time up against the wires and you are using the wires to produce less of a perturbation than you would have with a solid wall. Essentially the trap door would be small enough so they can't fall through, but large enough so sleeping is uncomfortable next to the wall. Another concern is that the rat can't chew through the wire. 
D. Poznaniak: Up to now I guess we have restricted our attention just to mice and rats which are exploratory animals. As a suggestion, why do we have to use either rats or mice? Why couldn't we use an animal that is less exploratory? Or why couldn't we use an animal that somehow cues on the existence of an edge and wouldn't venture beyond the edge? Do such animals exist?

R. Phillips: There are other animals we could use, I don't know why we are locked into rats and mice except that we have a lot of background information on these animals. There are other options. One possibility, although some people don't like to use this animal, is the guinea pig. He is stupid. He is not good for behavioral studies, on edges and so forth he tends to fall off and land head first. But he also isn't a very exploratory animal, he just tends to sit.

B. Scott-Walton: I would like to make one comment and that has to do with boundary conditions. In the case of the ac field underneath ac transmission lines it would seem that the environments that could be created in a laboratory might be very similar to one an animal might experience in the field. However, it is obvious there are a number of major difficulties in creating an environment which is at all similar to what an animal might experience in the dc field. And, it seems it might be very, very difficult to create in the laboratory, experiences that would compare to those of an animal in the dc field and ion environment. Could anyone comment on that?

R. Phillips: I think we have to ask the question why are we using laboratory animals. We are not using them to mimic animals in the field, we are just using them as a tool to understand what is going on.

W. Kaune: I would like to ask Dr. Deno a question. This is something that has puzzled me for a long time and it has to do with the guard ring electrode scheme. You use guard electrodes to essentially compel the potential to be the unperturbed potential. But the animal in the field perturbs the potential so that when he moves over close to the wall the potential should change, but the wires prevent it from changing. (It depends on what the resistances are, of course.) It seems to me that by putting these guard electrodes in and allowing your animal to get close to them you are changing the way the animal is being exposed to the field. There may be ways to minimize this. 
D. Deno: My previous question really was presented about the idea of the electric fence. The idea of what can and cannot be done on grading boundary conditions in a cage was something I really didn't get into. If we take some metal surfaces which are conductors we can have networks of resistors which would give correct impedances for matching the metal surfaces to the air impedance. Or you could try and actually match the air impedances to those of the metal surfaces. The metal surfaces would not collect charge. Now, you wouldn't have a perfect match, but you could avoid the sparks. There would be very negligible currents from touching any single surface. There are some details I didn't bother to mention, but I think there is a lot that can be done in this direction.

A. Valentino: I don't know what detailed problems we will get into, but it is my thought that we can use some resistive material, perhaps resistive wire or string, in conjunction with the regular plastic boxes that people now use to house rats and mice. In other words, these strings placed on or imbedded in the plastic can help you match the boundary condition electrically. It won't be perfect, but it is an approach, a concept.

J. Decker: The only problem, that I can think of, with matching the boundary condition is that the exposure system must be flexible, i.e., if you want to change the ion current, you also have to be able to adjust the boundary conditions to match the change in the conductivity of the air. To have it flexible, you may not want to put the wires in the plastic.

D. Janes: Caging is a very interesting problem and I thought I would throw something else out to think about: How fast would you have to rotate a cylinder to keep the rat away from it? The other thing I wanted to address has to do with the simulation of the electrical environment under the line. I would encourage you to use fields that would enable you to develop dose-response. Finally, you want to make sure that you are simulating in the animal system those kinds of fields and induced currents that you are interested in looking at in the human. 
$\bullet$

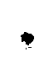


6. ONGOING RESEARCH RELATED TO HVDC TRANSMISSION LINES AND EFFECTS 


\section{ONGOING RESEARCH RELATED TO HVDC TRANSMISSION LINES AND EFFECTS}

D. Bracken, BPA: I would like to call on a few people to give a brief summary of what they are doing in the area of dc bioeffects. First, Dick Finger, could you describe your work. You said you didn't see any problem in duplicating the electric field and ion environment. Have you worked with an electric field present as well as with ions present?

R. Finger, Santek: Yes, we have worked with the field present because the instrumentation which we make also creates a field. You can use the field independent of ion generation as well as control the volume flow. Essentially, you can control current levels as well as control the E field. There hasn't been that kind of a problem present in the work that we have done. You can independently handle ions and fields: if you need more ion concentration you can increase the number of discharge points.

We are instrumentation people. We manufacture instruments primarily for industrial use. These instruments are used in detecting ultra low current leakage in high voltage systems and distributed leakage current in printed circuit

boards. We manufacture a 1 ine of electrometers that can resolve $1 \times 10^{-17}$ amps with 2 percent accuracy, so you can see their usefulness when you get into the low level measurements here. We also produce air ion generators for industrial purposes which are certified to produce not more than 0.008 parts per million of ozone, which eliminates another problem. Thus, you can use corona discharge devices in this type of project. We use them primarily for industrial applications, and we don't sell generators to people who want to feel good. We also manufacture a line of volumetric counter devices for study chamber purposes as well as atmospheric use. Our experience with study chambers has been direct, because we have been collaborators in a number of study projects. Some of the work is proprietary, that is, we are doing it for our own interests. However, the bulk of our work is industrial and in the electronics business for current leak detection. 
Tom's experiences and mine have been reflected here somewhat today and we offer ourselves to help people with the problems that they encounter whether it be with cage design or with instrumentation. If anybody has any particular question feel free to call on either one of us.

Our work in the area of ultra low current measurement, air ion generation, and study chambers has been going on since 1973 and I would agree with the statement that it is "presumed" biological effects and nothing more than that can be said.

R. Humphreys, General Electric: Just about a year ago the Department of Energy gave Project UHV a contract to develop a high voltage dc test line. This past summer--during July we energized it at $\pm 600 \mathrm{kV} \mathrm{dc}$. The power supply is in two sections and we can series up the two sections to get up to $1500 \mathrm{kV}$ dc one polarity. Last summer, at a seminar sponsored by EPRI, we had the opportunity of conducting about a 100 people under the dc line and performing various tests. You would raise your hand and see if you felt anything, and stand on an insulated rubber mat and touch the ground and note the field at which you got a shock. We had test stations all underneath the line, and you would hold up an umbrella and put your thumb to it. As you got close to the line you could get quite a zap. We had people record these kinds of perceptions, and we will come out with a report on the perception levels for these effects. We noticed a flock of birds landing on the lines just before we were about to energize the line. They were sitting on the negative pole of the line near the insulating end, the dead end. When we turned on the field, we expected to see a flock of birds flying up. Well, the results were very disappointing, the birds sat there for about a minute and gradually one by one flew away as if they were vaguely disturbed by something. They were not really as upset over the dc field as we thought they might be.

We have also observed a relative humidity effect on our dc lines which nobody seems to have observed before. On several successive days we had a fixed absolute humidity. The quantity of water vapor present was fixed, but as the day warmed up the relative humidity went down from about 75 percent to 50 percent. As the relative humidity went down so did the ion current by about a factor of 
2 on both the negative and positive poles. Most investigators up to now just worried about how much absolute humidity was in the air and they never considered the relative humidity. But it seems to be a factor which you ought to include. Apparently, when the relative humidity gets high, more ions are being generated near the line, and maybe the character of the ions changes. We have a setup that is pretty similar to BPA. We have test stations underneath the line; we are automatically monitoring ion currents at various points. We are having problems with our electric field measurement devices because they get rained upon quite heavily and they don't seem to last too long outdoors. If any of you know where we can get a waterproof electric field measuring device, we are very interested in knowing about it.

S. Maruvada, IREQ: At IREQ, we just completed one phase of an EPRI project on dc. We studied three different conductor bundles in the voltage range \pm 600 to $\pm 1200 \mathrm{kV}$. The final report should be available sometime before the end of 1978 . We measured a number of things: audible noise, corona loss, RI, and also ion current. Since we were measuring so many things we couldn't pay attention to each individual thing in very much detail. Still I think we have some very interesting data on the ion currents and electric field. Now, we are in the second stage of this study where we are concentrating more on the various aspects. We are studying the performance of one conductor bundle: a 6 -conductor bundle good for $\pm 900 \mathrm{kV}$. This configuration will be energized for the whole year. We started energization at the end of August. Under this line we have nine current probes to obtain instantaneous profiles, continuously. In addition to the current probes, we also have one probe directly under the positive pole, which continuously monitors the field. This particular field probe is not a commercial one. It is a rotating field mill type. It would be quite difficult to develop 8 or 9 of them. We have gotten good results with this instrument in the past. In addition to these measurements, we are also going to do some special studies of currents and voltages induced on objects. These will be done over the year and statistical data obtained.

C. Chowaniec, Westinghouse: We are doing a project for EPRI developing instrumentation. Many of the individual instruments are pretty much the same 
same as Ralph Kotter mentioned earlier today. The big thing is that it is an integrated package approach which tries to measure everything at the same time. It is microprocessor controlled. We hope that it will be an all-weather and unattended operation type of instrument, which is "portable." The problem is that it isn't exactly the kind of thing you put into your back pocket. We have a sensor package which included four field mills, which allow you to measure all three components of the electric field, plus detect charge buildup on the sensor package. There are also two ion counters, one for each polarity, and two conductivity chambers. We have also included a Faraday cage which is about a cubic meter in volume. If there are high concentrations of ions of both polarity and you are taking a difference of the two, you are going to have a very inaccurate measurement of the net space charge. In these circumstances the Faraday cage offers a better measurement of net space charge. We also have a Wilson plate which is being modified to take care of charge transfer associated with splashing water droplets. What we have done is essentially make a screen across the top of the plate and put brass wool inside of it. There is a minimal amount of splashing and we think we are going to get rid of a lot a the problems that way. It also has a guard ring. There is a cup anenometer and wind vane that go on a separate pole as does the Faraday cage. All of these things are successively sampled by the microprocessor system. The sensor package itself is sitting on an insulating pole. To aspirate the chambers we use a hollow support pole with a fan in the base. Air is drawn through the whole sensor package and down the tube and out to the ambient. In order to provide communication from the microprocessor up to the sensor package we use a pair of fiber optic links. There is a zero charge maintenance system, as we call it, which measures the self field of the sensor with a pair of field mills and thus detects a charge. The present plan is to use corona discharge points to spit the excess charge down the hollow tube that we are using for aspiration. There are some problems and we may have to go to a different approach before we are done.

The parameters we measure are: the three components of the electric field, positive and negative ion density, the net space charge density, positive and negative conductivity, ground current density with modified Wilson plate, wind 
speed, and direction. From these we can get, in addition to the electric field magnitude, the direction so we have the complete vector electric field. By using the electric field measurement, the conductivity, and wind, it is possible to determine what the conduction and convection currents in the air are above the ground plane. You can also determine the positive and negative average mobilities. Thus, we have instrumentation, which can take a lot of data, process it, store it on a cassette, if you wish, and display it to the user through a CRT display.

Right now we are starting to build the overall instrument package. To this point in time we have redesigned the atmospheric physicist's approach to measuring these parameters. This enables us to go from the atmospheric levels a11 the way up to the levels that you have underneath a line. We have verified that the individual instruments perform over the full range that we expect to operate in. What still has to be done is to assemble them all into one package and make sure that they work together. We don't see any real problems. After we have shown that, then you can buy one.

A. Valentino, IITRI: About 5 months ago the Department of Energy issued an RFP to do work of this type: that is to study the problems and develop a prototype chamber for work with small animals. Perhaps, it is appropriate to read directly from the RFP. It says that "the objectives are a) to complete preliminary experimental design for determining biological effects of typical overhead $\mathrm{ac} / \mathrm{dc}$ systems on animals: for this program small laboratory animals are to be used--that is mice, rats, hamsters; and b) to design, fabricate, and test an enclosure for housing small laboratory animals during exposure to dc." There are some other specifics about anticipating lines to $\pm 1200 \mathrm{kV}$. We responded to that RFP, as did some of you here. We got the job and now we have all the problems that we have been talking about today. So, I listened with quite a bit of interest, as you might expect, to some of the ideas. The project is a 16-month project starting about now. About 5 months from the beginning of the project, we have planned to have a workshop, and present what our concept would be at that time. We hope that those of you who have been working on problems like this for years, could give us some constructive criticism early in the program. That is still part of the plan and this was an excellent start for this project. 


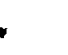

, 
7. GENERAL DISCUSSION 


\section{GENERAL DISCUSSION}

John Vithayathil: I would like to make a couple of comments. One is in regard to questions that $\mathrm{Dr}$. Miller raised in the morning about comparing ac and dc corona induced audible noise. In addition, Dr. Kaune asked what is our position regarding building dc lines. Questions of that type cannot be answered without reference to the specific design. We can design an ac line or a dc line to almost any specifications. Our policy as far as dc is concerned is no different from that of ac: if you can design it properly, both are acceptable. The thing we are seeking, in promoting so much research in this area is guidelines on what are acceptable levels. We can then optimize the design.

Also, I will briefly comment on the prospect of dc in this country and the world. The line design for the highest voltage in the world is one in South Africa which is designed for $\pm 533 \mathrm{kV}$. It is probably worse from the electric field point of view because it is two monopolar lines: the two poles are separated by one kilometer. So I would expect fairly high gradients. One of the biggest dc projects in the world is just getting starting in Brazil. That transmission line is likely to be close to $600 \mathrm{kV}$, in the range of 500 to $600 \mathrm{kV}$.

In this country the prospects for dc will depend very much on how the power system plans develop and also on some basic decisions regarding energy utilization. It requires a crystal ball. I can think of two conditions where there might be a great demand for high voltage dc, probably what you call UHDC, in the range of $\pm 1000 \mathrm{kV}$. One is, how all that coal in the Montana-WyomingUtah region is used. If you decide that this coal is going to be converted to electric power at site, which is an assumption not necessarily acceptable to everybody, then you have a problem of transmission because the big population centers in the west are on the coast. Depending on the assumptions regarding the load growth in the early part of the next century, we will be talking about additional transmission capacity of the order of 100,000 or 150,000 megawatts. The problem is complicated by the fact that there are three major mountain ranges you have to cross which limit the rights-of-way you have for 
transmission lines. You have only 8 mountain passes all the way from north to south, from the Puget Sound area down to Los Angeles. Therefore, you would have to build a very high density power transmission line, because you can build only so many lines there. The distances, in this case, are in the range where dc lines would definitely be more economical. Thus, if you talk about transmitting that order of power for those kinds of distances, you probably would be thinking in terms of $\pm 1000 \mathrm{kV}$ or that order of dc 1 ines. That, of course, is based on assumptions of how you are going to use that power. The second possibility for a large increase in dc transmission is a national grid. There is a study going on at present in the Federal government by an agency of the Department of Energy on the pros and cons of a national grid. I don't know what the conclusion is going to be. Perhaps the study will show that we can make more use of the existing generation facilities in the country by taking advantage of the diversity in load between the areas, either because of the time-zone differences or because of the climatic differences. (Incidentally, a second dc line which BPA was planning on building along with the people in the south, was primarily justified on diversity of load: There is a summer peak in the south and a winter peak in the north.) So if you have a transmission line between them, you can eliminate a lot of new generation facilities. So, if it is found in the national grid study that there is a need for a large transmission capability between the different parts of the country, I think it is likely that dc, both for economic and technical regions, will be the solution.

D. Bracken: I would like to ask if it is necessary to expose animals to all the variables of the dc line at once. That is, is it really necessary to simulate the field and ion environment completely or for the first work would it be sufficient to do them separately? I am just curious what other people think about this, given the difficulty of providing simultaneous field and ion exposures.

B. Scott-Walton: We have been debating the various characteristics of the electrical circuitry, I wonder how easy it really is to eliminate the ion currents in the case where you want just the pure field. 
R. Humphreys: It is easy. Juse use nice round edges for everything and big electrodes to make sure there is no corona. Then the ion currents will be way down compared to the nanoamps per square meter that we are talking about. You might still have to worry about picoamps.

B. Scott-Walton: It is important that you really make a very careful measurement of these ion currents. It is not safe just to go out and build yourself an apparatus with a field in it. You really have to be careful to measure the ion currents as well.

c. Chowaniec: Along those lines, we were trying to verify performance of our field mills. We had two large screens and were putting a field mill at one side of this parallel plate capacitor and putting a voltage on the other. We noticed there was space charge buildup inside of that chamber, which we were not trying to get. I don't know what the long-term equilibrium value would be but you should recognize the fact that there is going to be a space charge buildup over a period of time inside a chamber. This is due to separation of naturally ionized charges in the field.

R. Phillips: Can we deliver air ions to an animal that is sitting there getting charged up with a fur coat?

A. Frey: This is one of the reasons why you just ignore 98 percent of the air ion literature. Because this is one of those controls that are essential and this is why to all intents and purposes there really is no air ion literature in the terms of the biological phenomenon.

M. Gillis: I would like to hear more about it. The rat is covered mostly with hair. Can it accumulate enough space charge so that the electric field transported ions will actually be diverted around the animal and there will be no steady-state currents in the animal except for those lines which touch the tip of the nose and the relatively hairless tail and the thin film of fluid on the eyeballs where there is no hair? Perhaps these animals have no body current at all. It is something that somebody maybe has measured, certainly something we will all have to measure sometime. 
A. Frey: I have done some measurements in terms of the currents through the rat and such, but I don't think I can remember the details and the numbers just off the top of my head.

J. Grissett: As I understand it, it really isn't the negative or positive ion effect that you are trying to investigate; but that it is the ion current under the transmission line which really constitutes a whole body current from the line to ground that you are trying to simulate. If that is the case, then of course, I think probably it would be a good idea to simulate both the field and ions at the same time; let the air ions work their way in the cage; and let the animal build up a static charge and discharge it. I would not be concerned about the biological effect of inhaling the air ions, but I would be concerned about the ions as a body current component.

A. Sheppard: When I had to approach that aspect, I took the other tack and said that the ion current is a much smaller body current than we had to consider in the case of ac displacement currents. Therefore, let us shove the current question out of view and realiy face up to the issue: Is it realiy possible that air ions have an effect? From the phenomenonology that is claimed, you saw what I was forced to present. I agree with you that, if you ask the question about mechanisms that was posed previously, then how can you explain an ion effect. Who can even come up with a far out physical mechanism for it that could hold our attention for a moment? None of us has. But somebody, collective somebody, has to decide: whether your approach is right, that because the mechanism is so improbable that it really isn't an air ion question but simply a matter of cleaning up some bad experiments that involve body current or this or that; or that we should really approach the question of possible air ion effects.

A. Frey: Let me add something, so maybe we don't fall in the trap that has happened so many times in the history of science. I will use one example that is familiar to many of the people here. Back in the late 1950s and very early 1960s in the microwave research area, some people said that there could not be any possible mechanisms for low intensity microwaves to do anything and that area was largely ignored. Earlier than that, there were some 
people who said: "I heard some things when I was in a microwave field." A couple of engineers from AIL went to an expert on hearing, and explained that they had run these tests, and that they had heard things in a microwave field. The expert said, "Oh, there couldn't possibly be any mechanisms for that, you are obviously hearing some fence post vibrating or something." They asked him to come out and listen because they felt they had controlled for those things. The expert said it was obviously ridiculous, that there can't be a possible way for someone to hear an electromagnetic field, and he did not come out. At that point the engineers dropped the matter. This particular case was around 1945. It was quite a few years later, in about 1961, when I started 1ooking into reports that people hear electromagnetic fields. A technician happened to mention to me that he heard things when he was out measuring microwave fields. I went out there and heard things too, and I studied and reported on it. Since then, a great deal of research has been done. This is a real pheomenon, and some people have proposed mechanisms for it. So, very often, if you decide first there is not a possible mechanism for it and you don't look at it, you will end up missing some things. Similarly, there is a wide variety of low intensity microwave effects that have been observed by many labs even though it was assumed that there couldn't be a mechanism. Let us be careful that we don't fall into the same kind of position on air ions. Just because I don't happen to see a mechanism within the context of my present biological knowledge let's not say that such phenomena cannot exist, they could. If we looked, we might find something and then maybe we could conceive of some mechanisms which may not be very exotic after all.

R. Phillips: I would just like to agree with Allen on this. It is very dangerous, we have found out over the years, to argue from first principles. Too many times we have been wrong. We found out that we don't know all the first principles, at least, in biological systems. It is a very complex system. So I think it would be dangerous, as Allen stated, to make any assumptions at this stage.

Don Deno: I am addressing this question to the biologists. The dc electric fields that are being complicated with the space charge are quite strong, they are equivalent to the ac electric fields at $60 \mathrm{~Hz}$, to which I have been exposed. 
A phenomenon which hasn't been discussed and which I am interested in, is the dehydration or evaporation which is enhanced by a strong electric field. Are there any comments on this? Would there be any difference in running experiments at low humidities as well as the differences at high humidities? Would this have any influence on an animal? It is noticeable, I think, in hairs in high fields: they become dehydrated and tend to pick up charge, and their characteristics change significantly.

M. Gillis: I just learned something: I didn't know that electric fields accelerated evaporation. We have done a hair vibration study. We simply put a dead pig's ear between electrodes. We were going to watch the hairs vibrate and confirm once and for all that they do vibrate at $120 \mathrm{~Hz}$. This is what we all expect, since it is polarization vibration. Of course, as probably most of you know, when we looked at it with a strobe outfit and a spotting scope they vibrated at $60 \mathrm{~Hz}$ and $120 \mathrm{~Hz}$ vibration was quite rare. The only possible explanation was that the hairs were picking up free charge from somewhere. We tried to determine the sign of the charge on the hair with a photo transistor, stroboscope, and oscilloscope. To eliminate an enormous phase lag between the motion of the hair and the field which was due to the viscosity of air, we put the hair into a vessel and evacuated it. When we turned on the pump and evacuated the vessel, all the hairs stopped vibrating. It proves to my satisfaction that the charge does collect on the hair from the atmosphere which I suppose everybody knew to begin with. My original question a few minutes ago was how much influence does this have on ion current on the animal. I know this will depend on the conductivity of the hair, whether it is large or small compared to that of the air. However, I have no idea what the conductivity of the hair is.

R. Phillips: Did you also do some experiments where you actually changed the water content of the air?

M. Gillis: Bill Kaune and I disagree on our observations there. As I recall, we wanted to raise the humidity. So we simply poured a little water in the vessel that we had the ear in and put the lid back on. This should obtain a 100 percent humidity in not too long a time. It was my observation that the 
number of hairs vibrating and the amplitude of vibration of the hairs decreased as it got more humid. Bill disagrees. We have not repeated it. That is all we have done with humidity, but I would like to do it again. It could have two effects: raising the humidity could somehow effect the character of the ions or it could also increase the conductivity of the hair which would decrease the vibration because the charge would leak off faster.

S. Michaelson: I would like to make a qualification. No one here suggested that we not do research just because we don't understand mechanisms or we don't know a mechanism. My point has always been that we have to do the research. The mechanisms will come along. My only plea is that the research be done well, it should be good research. We have to find out what we are doing with the experimental animal and the conditions under which he is studied, and then we can get something. Otherwise it just becomes a fishing expedition that has no productivity, that was the point that I made earlier.

A. Sheppard: I would like to say that I heard the other part of Dr. Deno's question, and it really is an interesting question, but $I$ don't know what to make of it. The interfacial phenomena on a film of water certainly are charge dependent. Were you saying that you know for sure that in the fields we are talking about there is going to be a differential evaporation from the surface; that this is a possible mechanism for dehydrating tissue; and perhaps that is what is happening in some of these experiments?

D. Deno: I have never approached the subject with any great rigor, but where we have strong fields we will have some local corona on the human bodies as well as animals. At those levels, I have seen fluids start to tear apart. I know fuels, hydrocarbons, burn much faster in fields, they evaporate. We have been doing some experiments in which this type of phenomena was really very much of a side issue. But, I have always presumed that you get significant increase in evaporation.

R. Humphreys: The Industrial Application Society of the IEEE, which met in Toronto a few weeks ago, had several papers along this line: the influence of the electrostatic and ac fields on such things as surface tension, evaporation, 
and rate of combustion. There are definite effects; particularly, the surface tension might be influenced by an electrostatic field, and that might relate to what goes on between cells.

D. Deno: My discussions concerning this evaporation were with Guy McKee on his observation of damage to leaf tips. It was just one of a number of mechanisms that we were discussing. But in additional experiments, which I have been conducting in the last week with hydrocarbons, this is a very obvious phenomenon.

J. Grissett: I guess I am going to begin to sound like a sponsor, which I am not, of course, but I agree with Allen and Dick that the history of science is replete with cases where we made bad mistakes and where we thought that no effects would occur or there was no mechanism and we later found there were. If we had unlimited resources, then, of course, we ought to pursue any and everything that we can possibly dream of and some things we can't. But the fact of the matter is that we don't. There is just no way that we are going to avoid decisions about what is the better payoff for a given number of dollars. If I were a sponsor I would, no doubt, consider whether or not there was any plausible mechanism for what I was being asked to sponsor.

J. Lee: This is related to what we have been talking about: the mechanisms, the parameters of the HVDC environment which may cause an effect. We still have to keep in mind the test organism or the organism of interest. In other words, will a study designed to answer the question of whether the HVDC environment will effect man, will that study automatically answer the question the farmer will have about effects to his cow? If you shampoo the rat for the man study, you may not want to do it if you are trying to answer the question about the cow. Right at the outset you need to define whether this is looking at the human case or whether it is looking at a typical farm animal or something else. If I am writing a proposal or reviewing one from a utility standpoint I would want to know which questions a study is going to answer.

D. Janes: The total impact of the transmission line environment may be greater than the sum of its parts. But, with as many confounding issues as there are between electric field effects and air ion effects, I think probably the most 
efficient way to proceed is to at least separate those things before you put them together. Even doing that I see some very fundamental problems. The first comes out of instrumentation. Independent of whether you separate the field and ions or not you are going to have to characterize them. I don't think I heard a good description today of instrumentation that you can take into the laboratory and characterize the environment that you are going to use. Even if you are not investigating air ions, you are going to have to know what they are in order to make the experiment interpretable. There are some basic questions like Murt Gillis raised if you are going to look at air ions. We don't even know whether fur-bearing animals are the animals to look at for interpretation for humans. It seems to me there is some very basic underlying groundwork that needs to be done before we start designing experiments for the total impact of the field.

R. Kotter: I whole-heartedly agree with that. The emphasis I placed was on instrumentation for measurements out under the lines. Much of that instrumentation is not directly applicable to the laboratory situation, and there is a need for development of suitable instrumentation.

W. Kaune: My point of view, if I were a sponsor, is that based on the literature you would just have to investigate the air ions first, because that is where the literature shows effects exist. Maybe there is no mechanism that we can conceive of and, as Allen Frey said maybe 98 percent of it is bad, but I don't see how you can ignore it.

R. Dunham: We are an instrumentation manufacturer in upstate New York. We find it very hard to get input from users as to what accuracies, levels and resolution are required. Data such as this is very essential to a manufacturer. We are relatively smal1. Our emphasis is on noncontact voltage measurement, which lends itself very well by way of a gradient adapter to field measurements. We are also making inroads into environmental type probes. But things such as accuracy, resolution, and levels are pertinent information for the people that are developing and building this kind of instrumentation. So those are the kinds of inputs we need. 
A. Sheppard: I think that before we start talking about experiments we have to have a good go-around at just how long we think it is appropriate we expose the animals; whether we think we should have continuous exposure or 8-hour per day exposures; or what is it we are trying to model; and whether the experiments should be designed initially to just find an effect, or should they be sweeping through a broad enough range to be determining thresholds. There are numerous other questions that are related to the whole field that anybody who is going to design an experiment will face.

M. Gillis: In the absence of any conclusions in the literature that we think are really certain, and in the absence of any conceiveable mechanisms by which static fields can produce effects, I don't see that we have any alternative other than to screen across a rather broad array of clinical parameters: a fishing expedition, in other words. Otherwise, what is the alternative?

S. Michaelson: If you don't have the instrumentation to measure, how do you know what you are fishing for? What is the sense of doing a biological experiment if you don't have the equipment to measure what the animals are exposed to? The results you get could very well be meaningless unless you can characterize the exposure system. There is no sense in spending $\$ 100,000$ or $\$ 1,000,000$ doing biological experiments if you can't characterize the animal's environment.

A. Frey: I have done quite a bit of experimentation on instrumentation and controls at least with respect to the air ions. The instrumention that is suitable for outside work is not particularly good in the laboratory, at least in the air ion area. It tends to jump all over the place. There is instrumentation that has been developed which is very good for use in the laboratory; you can take a look at the spectrum of the air ions in addition.

R. Phillips: I think we are getting unnecessarily concerned about something which is down the road a number of years. The issues first, of course, are instrumentation, and characterizing what you want to put in the laboratory. Then, of course, you have the problem of building this thing. It could be that your biological design may be limited by what you can do in the laboraory. So it could be just a little bit premature to worry about the biological end points at this stage. 
A. Valentino: The people at DOE, who formulated this RFP that we responded to, apparently had this all in mind because that is basically how our project is structured. The purpose of the project that we are starting is: to attack these problems, not to do the biological experiment, but to attack all the problems that we have been talking about. Then we decide whether more groundwork is needed or whether we are ready to tool up and do the biological experiment.

D. Bracken: In closing I would like to thank all of you for helping us meet the objectives which we set out. It is evident from the presentations and discussions that we are all going away with something to do. For the engineers there are obviously more measurements to be made under HVDC transmission lines. The electrical environment requires additional definition and investigation. For the biologists, there are questions about the existence of effects and if there are effects what are the mechanisms. For the bioengineers there are the challenging problems in exposure design: containment of the animals, duplication of the transmission line environment and dosimetry. Identification and discussion of the problem areas has given us an appreciation for the difficulties inherent in all aspects of this work. No discipline is immune from the uncertainties of the ions and interdisciplinary effort will be required to attack most of these problems. The presentations and discussions have brought out many answers and caveats as well as questions. Hopefully, these answers and an increased awareness can serve as the basis for successful research in the area of HVDC transmission line effects. 
APPENDIX A

PROGRAM 
APPENDIX A

PROGRAM

"ELECTRICAL AND BIOLOGICAL EFFECTS RELATED TO HVDC TRANSMISSION"

Thursday, October 19, 1978 - Holiday Inn, Richland, Washington

8:00 a.m. Introduction, T. Dan Bracken, BPA, Vancouver, WA

8:15 "HVDC Electrical Environment" - T. Dan Bracken, BPA, Vancouver, WA

9:15 "Instrumentation and Measurement Techniques" - F. Ralph Kotter, NBS, Washington, DC

10:15 Coffee Break

10:30 "Biological Effects" - Asher R. Sheppard, VA Hospital, Loma Linda, CA

11:30 Lunch - No Host Buffet in Holidome Area

12:30 p.m. "Methodology for Biological Studies" - Jack M. Lee, BPA, Portland, OR John R. Decker, PNL, Richland, WA

2:00 Working Sessions

4:00 Summary

5:00 Adjourn - No Host Cocktail Bar

Friday, October 20, 1978 - Trip to BPA HVDC Test Site

8:30 a.m. Depart Holiday Inn, Richland, by bus to The Dalles, OR

11:30 No Host Luncheon - Portage Inn, The Dalles, OR

12:30 Tour of BPA HVDC Test Site and Celilo Converter Station. The dc test line operates at voltages up to $\pm 600 \mathrm{kV}$. A measurement system for electric fields and ion currents under the test line will be demonstrated. The tour will offer participants an opportunity to experience the dc field strength environment and to familiarize themselves with HVDC transmission systems. Celilo is the northern terminus of the Pacific Northwest - Pacific Southwest DC Intertie.

3:00 Depart The Dalles for Portland

5:00 Arrive Portland Airport 
APPENDIX B

WORKSHOP PARTICIPANTS AND INSTITUTIONAL AFFILIATIONS 
Rod Baishiki

Pacific Gas and Electric

San Francisco, CA 94106

Dr. Robert S. Banks

Research Fellow

School of Public Health

University of Minnesota

Minneapolis, MN 65455

Dr. T. D. Bracken

Bonneville Power Administration

P.0. Box 491 - ERJH

Vancouver, WA 98660

C. R. Chowaniec

Westinghouse Electric Corp.

700 Braddock Avenue

East Pittsburgh, PA 15112

Roger E. Clayton

Power Technologies Inc.

P.0. Box 1058

Schenectady, NY 12301

John Decker

Battelle, Pacific Northwest Laboratories

Richland, WA 99352

Dr. John de Lorge

L33JD

Naval Aerospace Medical Research Lab.

Pensacola, FL 32508

Dr. D. W. Deno

General Electric Company

Project UHV

100 Woodlawn

Pittsburgh, MA 01201

Roger E. Dunham

Trek, Inc.

1674 Quaker Rd.

Barker, NY 14012
Dr. C. R. Ehret

Argonne National Laboratory

9700 S. Cass Ave.

Argonne, IL 60439

R. H. Finger

Santek INC.

4095 N. 28 Way

Hollywood, FL 33021

A. H. Frey

Randoml ine Inc.

County Line and Mann Rds.

Huntingdon Valley, PA 19006

Dr. M. F. Gillis

Battelle, Pacific Northwest Laboratories

Richland, WA 99352

Dr. J. D. Grissett

Biomedical Division

Naval Aerospace Medical Research Lab.

Pensacola, FL 32508

Larry D. Gust

Minn. Dept. of Health

717 SE Delaware

Minneapolis, MN 55440

Dr. D. R. Humphreys

General Electric Company, Project UHV

100 Woodlawn Ave.

Pittsfield, MA 01201

David Janes

Environmental Protection Agency

9100 Brookside Rd.

Silver Springs, MD 20910

Sue Kaiser

Electric Power Research Institute

3412 Hillview

Palo Alto, CA 94303 
Dr. William Kaune

Battelle, Pacific Northwest Laboratories

Richland, WA 99352

Dr. F. Ralph Kotter

National Bureau of Standards

B 344 Metrology

Washington, DC 20234

Dr. Harry Kornberg

Electric Power Research Institute

3412 Hillview Ave.

Palo Alto, CA 94303

J. M. Lee, Jr.

Bonneville Power Administration

P.0. Box 3621 ETMC

Portland, OR 97208

L. Y. Lee

Bonneville Power Administration

P.0. Box 3621 - EI

Portland, OR 97208

Carl B. Lindh

Generaly Electric Co.

One River Road, 2-202

Schenectady, NY 12345

Dr. P. S. Maruvada

Hydro Quebec Institute of Research

1800 Montee Ste Julie

Varennes, P.Q.

Canada, JOL 2PO

Dan D. McConnon

Manager

Environmental \& Lands Division

United Power Association

Elk River, MN 55330

Dr. S. M. Michaelson

Department of Radiation Biology and Biophysics

University of Rochester

School of Medicine and Dentistry

Rochester, NY 14642
Tom Michel

Santek, Inc.

4095 N. 28 Way

Hollywood, FL 33021

M. C. Miller

Battelle, Pacific Northwest Laboratories

Richland, WA 99352

Dr. M. W. Miller

Dept. of Radiation Biology

and Biophysics

University of Rochester

School of Medicine and Dentistry

Rochester, NY 14642

Dr. C. L. Mitchell

NIEHS

P.0. Box 12233

Research Triangle Park, NC 27709

W. T. Norris

Central Electric Research Laboratory

Leatherhead, England

Dr. Richard Phillips

Battelle, Pacific Northwest Laboratories

Richland, WA 99352

Dr. Elliot Postow

EMR Project Officer

Naval Medical Research

and Development Command

National Naval Medical Center

Bldg. 142

Bethesda, MD 20014

Dennis T. Poznaniak

Westinghouse Electric Corporation

B1dg. 7L33

East Pittsburgh, PA 15112

Dr. Maureen Preache

I ITR I

10 West 35th Street

Chicago, IL 60616 
Dr. D. Robertson

University of Rochester

School of Medicine and Dentistry

Rochester, NY 14642

Dr. Leonard Sagan

Electric Power Research Institute $3412 \mathrm{Hi} 11$ view

Palo Alto, CA 94303

Dr. A. R. Sheppard

Research Service (151)

J. L. Pettis V. A. Hospital

Loma Linda, CA 92357

Barry Scott-Walton

Stanford Research Institute

Men 1o Park, CA 94-25
Dr. A. Valentino

IITR I

10 West 35th St reet

Chicago, IL 60616

Dr. John Vithayathil

Bonneville Power Administration

P.0. Box 3621 EOG

Portland, OR 97208

Dr. W. G. Wisecup

Aerospace Corporation

20030 Century Blvd.

Germantown, MD 20767 
PNL-3121

$U C-97 a$

\section{DISTRIBUTION}

No. of

Copies

Offsite

John N. Adams, Jr.

Senior Substation Staff

Florida Power \& Light Co.

P. 0. Box 013100

Miami, FL 33101

Ross Adey

Veterans Administration Hospital

Loma Linda, CA 92354

Stig A. Annestrand

Bonneville Power Administration

P. 0. Box 3621

Portland, OR 97208

Michael P. Bahrman

DC Control Engineer

Minnesota Power \& Light Co.

30 West Superior Street

Duluth, MN 55802

Rod Baishiki

Pacific Gas and Electric

77 Beale Street

San Francisco, CA 94106

R. S. Banks

Research Fellow

School of Public Health

University of Minnesota

Minneapolis, MN 55455

Dietrich E. Beischer

1917 Front Street

Durham, NC 27705

William Blair

Electric Power Research Inst.

P. 0. Box 10412

Palo Alto, CA 94303
No. of

Copies

Offsite (continued)

50 T. Dan Bracken

Bonneville Power Administration

P. 0. Box 491 (ERJH)

Vancouver, WA 98660

Jack Bridges

IITRI

10 West 35th Street

Chicago, IL 60616

A. Bulawka

Electrical Energy Systems Division

Department of Energy

Washington, D.C. 20545

C. Calabrese

Consolidated Edison Co. of NY., Inc.

4 Irving Place

New York, NY 10003

Vince Caleca, Liaison with DC Subcommittee

Chas. T. Ma in, Inc.

Southeast Tower

Prudential Center

Boston, MA 02199

A. Stanley Capon

Bonneville Power Administration

P. 0. Box 491 (ER)

Vancouver, WA 98660

C. R. Chowaniac

Westinghouse Electric Corp.

700 Braddock Avenue

East Pittsburgh, PA 15112 


\section{DISTRIBUTION}

No. of

Copies

Offsite (continued)

Charles F. Clark

Bonneville Power Administration

P. 0. Box 3621

Portland, OR 97208

Roger E. Clayton

Power Technologies Inc.

P. 0. Box 1058

Schenectady, NY 12301

Michael J. Comber

General Electric Co.

Project UHV

100 Woodlawn Avenue

Pittsfield, MA 01201

Louis Delaplace

IEEE Working Group on AC Fields, Chairman

Boston Edison Company

800 Boylston Street

Boston, MA 02199

C. C. Diemond

4840 S. W. Fairhaven Lane

Portland, OR 97221

John de Lorge

L33JD

Naval Aerospace Medical Research Laboratory

Pensacola, FL 32508

D. W. Deno

General Electric Company

Project UHV

100 Woodlawn

Pittsburgh, MA 01201

R. E. Dunham

Trek, Inc.

1674 Quaker Road

Barker, NY 14012
No. of

Copies

Offsite (continued)

C. R. Ehret

Argonne National Laboratory

9700 S. Cass Avenue

Argonne, IL 60439

William Feero

Electrical Energy Systems Division

Department of Energy

10 Massachusetts Avenue

Washington, D.C. 20545

R. H. Finger

Santek, Inc.

3601 N. 47 th Avenue

P. 0. Box 6036

Hollywood, FL 33021

Robert W. Flugum

Assistant Director

Transmission Division of

Electric Energy Systems

Department of Energy

MS: $2221 \mathrm{C}$

20 Massachusetts Avenue, NW Washington, D.C. 20545

Allan H. Frey

Randoml ine, Inc.

County Line and Mann Road

Huntington Valley, PA 19006

Stuart G. Gathman

Naval Research Laboratory

Washington, D.C. 20390

E. H. Gehrig

Bonneville Power Administration

P. 0. Box 3621

Portland, OR 97208 


\section{DISTRIBUTION}

No. of

Copies

Offsite (continued)

Ralph S. Gens

Bonneville Power Administration

P. 0. Box 3621

Portland, OR 97208

Om Ghandi

Electrical Engineering Dept.

University of Utah

Salt Lake City, UT 84112

H. B. Graves

Dept. of Poultry Sciences

Pennsylvania State University

University Park, PA 16802

Jerry Griffin

Assistant Professor of Medicine

Director, Stanford Pacemaker

Clinic

Stanford University Medical

Center

Stanford, CA 94305

D. B. Griffith

U.S. Forest Service

c/o 327 N.W. 16th

Corvalitis, OR 97330

J. D. Grissett

Biomedical Division

Naval Aerospace Medical Research Laboratory

Pensacola, FL 32508

Larry D. Gust

Minnesota Dept. of Health

717 SE Delaware

Minneapolis, MN 55440

R. E. Harrison, Liaison with DC Subcommittee

Teshmont Consultants

1146 Waverly Street

Winnipeg, Manitoba, Canada

R3T OP4
No. of

Copies

Offsite (continued)

William A. Hoppel

Naval Research Laboratory

Washington, D.C. 20390

D. R. Humphreys

General Electric Company, Project UHV

100 Woodlawn Avenue

Pittsfield, MA 01201

W. Janischewskyj

University of Toronto

Department of Electrical

Engineering

Toronto, Canada M5S IA4

David Janes

Environmental Protection Agency

9100 Brookside Road

Silver Springs, MD 20910

Sue Kaiser

Electric Power Research Inst.

3412 Hillview

Palo Alto, CA 94303

5 Robert Kavet

Electric Power Research Inst. 3412 Hillview

Palo Alto, CA 94303

Richard Kennon

Electric Power Research Inst.

3412 Hillview

Palo Alto, CA 94303

Lance Kiler

Westinghouse Electric Corp.

700 Braddock Avenue

East Pittsburgh, PA 15112 


\section{DISTRIBUTION}

No. of

Copies

\section{Offsite (continued)}

Harry Kornberg

Electric Power Research Inst.

3412 Hillview

Palo Alto, CA 94303

F. Ralph Kotter

National Bureau of Standards

B 344 Metrology

Washington, D.C. 20234

Jack M. Lee

Bonneville Power Administration

P. 0. Box 3621 (ETMC)

Portland, OR 97208

L. Y. Lee

Bonneville Power Administration

P. 0. Box 3621 (EI)

Portland, OR 97208

C. B. Lindh

General Electric Company

One River Road, 2-202

Schenectady, NY 12345

Andrew A. Marino

Veterans Administration Hospital

Irving Avenue \& University Place

Syracuse, NY 13210

Sarma Maruvada

Hydro Quebec Institute of Research

1800 Monte Ste Julie

Varennes, Quebec, Canada

JOL $2 \mathrm{PO}$

Dan D. McConnon

Manager

Environmental \& Lands Division

United Power Association

Elk River, MN 55330
No. of

Copies

Offsite (continued)

Donald I. McRee

National Institute of

Environmental Health

Sciences

P. 0. Box 12233

Research Triangle Park, NC 27709

W. Harrison Mehn

Medical Director

Commonwealth Edicon

P. 0. Box 767

Chicago, IL 60690

Sol Michaelson

Dept. of Radiation Biology

and Biophysics

University of Rochester

School of Medicine and

Dentistry

Rochester, NY 14642

Tom Michel

Santek, Inc.

4095 N. 28 Way

Hollywood, FL 33021

Morton Miller

Dept. of Radiation Biology

and Biophysics

University of Rochester

School of Medicine and

Dentistry

Rochester, NY 14642

Martin Minthorn, Jr.

Acting Director

Health Effects Research Div.

Office of Health and

Environmental Research

Department of Energy

Washington, D.C. 20545 


\section{DISTRIBUTION}

No. of

Copies

Offsite (continued)

Martin Misakian

National Bureau of Standards

B 344 Metrology

Washington, D.C. 20234

C. L. Mitche11

National Institue of

Environmental Health Sciences

P. 0. Box 12233

Research Triangle Park, NC 27709

R. M. Morris

National Research Council

Division of Electrical

Engineering

Power Engineering Section

Ottawa, Canada K1A OR6

W. T. Norris

C. E. R. L.

Kelvin Avenue

Leatherhead, Surrey

KT22 7SE

England

Henry Nowak

Niagara-Mohawk Power Corp.

300 Erie Boulevard, West

Syracuse, NY 13202

Fox Perry

Electrical Energy Systems Div.

Department of Energy

Washington, D.C. 20545

E. Postow

Naval Medical R\&D Command

National Naval Medical Center

Bethesda, MD 20014

Dennis T. Poznaniak

Westinghouse Electric Corp.

700 Braddock Avenue

East Pittsburgh, PA 15112
No. of

Copies

Offsite (continued)

Maureen Preache

I ITRI

10 West 35th Street

Chicago, IL 60616

V. L. Pruett

City of Los Angeles

Department of Water and Power

Sylmar Converter Station

13201 Sepulveda Boulevard

Sylmar, CA 91342

D. Robertson

Department of Radiation

Biology and Biophysics

University of Rochester

School of Medicine and

Dentistry

Rochester, NY 14642

Thomas C. Rozzel

Office of Naval Research

800 N. Quincy Avenue

Arlington, VA 22217

J. Sabath, Chairman

Southern California Edison Company

P. 0. Box 800

Rosemead, CA 91770

Leonard Sagan

Electric Power Research Inst.

3412 Hillview

Palo Alto, CA 94303

Barry Scott-Walton

SRI International

333 Ravenswood Avenue

Men 10 Park, CA 94025 


\section{DISTRIBUTION}

No. of

Copies

Offsite (continued)

Steven A. Sebo

Ohio State University

Dept. of Electrical

Engineering

2015 Neil Avenue

Columbus, $\mathrm{OH} 43210$

Asher Sheppard RS 151

J. L. Pettis Memorial Veterans

Administration Hospital

Loma Linda, CA 92357

R. J. Spiegel

Southwest Research Institute 6220 Clebra Road

Post Office Drawer 28510

San Antonio, TX 78284

J. R. Stewart

Power Technology, Inc.

P. 0. Box 1058

Schenectady, NY 12345

Harold Tukey

Department of Floriculture

\& Ornamental Horticulture

Corne11 University

Ithaca, NY 14853

A. Valentino

I ITRI

10 West 35th Street

Chicago, IL 60616

John J. Vithayathil

Branch of System Engineering

Bonneville Power Administration

P. 0. Box 3621

Portland, OR 97208

R. E. Vosteen

Monroe Electronics, Inc.

100 Housel Avenue

Lyndonville, NY 14098
No. of

Copies

Offsite (continued)

Richard Wade

Minnesota Department of Health

717 S.E. Delaware Street

Minneapolis, MN 55440

Brendon J. Ware

American Electric Power

Service Corp.

2 Broadway

New York, NY 10004

Raymond W. White, Esq.

Safety, Health \& Claims Department

Pacific Gas \& Electric Co.

245 Market Street

San Francisco, CA 94106

Will iam Wisecup

Civil Defense Preparedness Office

1300 Wilson Blvd.

Arlington, VA 22209

A. A. Churm, Director

Patent Division

DOE - Chicago Operations Office

9800 South Cass Avenue

Argonne, IL 60439

27 DOE Technical Information

Center

Onsite

110 Pacific Northwest Laboratory

J. R. Decker

M. F. Gillis (12)

W. T. Kaune (25)

M. C. Miller

R. D. Phillips (15)

R. L. Richardson

Biology Department Library (1)

Technical Information Center (50)

Technical Publications (4) 
No. of

Copies

Onsite (continued)

Department of Energy - RL

Mary White 
